\title{
Selective Photodimerization in a Cyclodextrin Metal-Organic Framework
}

Xiao-Yang Chen, ${ }^{1}$ Haoyuan Chen, ${ }^{4}$ Luka Đorđević, ${ }^{1,3}$ Qing-Hui Guo, ${ }^{1}$ Huang Wu, ${ }^{1}$ Yu Wang, ${ }^{1}$ Long Zhang, ${ }^{1}$ Yang Jiao, ${ }^{1}$ Kang Cai, ${ }^{1}$ Hongliang Chen, ${ }^{1}$ Charlotte L. Stern, ${ }^{1}$ Samuel I. Stupp, ${ }^{1,3,8,9,10,11}$ Randall Q. Snurr, ${ }^{4}$ Dengke Shen*,2 and J. Fraser Stoddart*,1,5,6,7

${ }^{1}$ Department of Chemistry, Northwestern University, 2145 Sheridan Road, Evanston, Illinois 60208, USA

${ }^{2}$ Institutes of Physical Science and Information Technology, Anhui University, Hefei 230601, China

${ }^{3}$ Center for Bio-inspired Energy Science, Northwestern University, 2145 Sheridan Road, Evanston, IL 60208, USA

${ }^{4}$ Department of Chemical \& Biological Engineering, Northwestern University, 2145 Sheridan Road, Evanston, Illinois 60208, USA

${ }^{5}$ School of Chemistry, University of New South Wales, Sydney, NSW 2052, Australia

${ }^{6}$ Stoddart Institute of Molecular Science, Department of Chemistry, Zhejiang University, Hangzhou 310027, China ${ }^{7}$ ZJU-Hangzhou Global Scientific and Technological Innovation Center, Hangzhou 311215, China

${ }^{8}$ Department of Materials Science and Engineering, Northwestern University, 2220 Campus Drive, Evanston, IL 60208, USA

${ }^{9}$ Department of Biomedical Engineering, Northwestern University, 2145 Sheridan Road, Evanston, IL 60208, USA

${ }^{10}$ Department of Medicine, Northwestern University, 676 N St. Clair Street, Chicago, IL 60611, USA

${ }^{11}$ Simpson Querrey Institute, Northwestern University, Chicago, IL 60611, USA

*Correspondence: shendk@ahu.edu.cn; stoddart@,northwestern.edu

\section{Supporting Information}

\section{Table of Contents}

General Information

Synthetic Procedures

Additional Data

NMR Spectroscopy

Binding Studies by NMR Titration

High-Performance Liquid Chromatography

Optical Microscope Images

X-Ray Crystallography

Powder X-Ray Diffraction

DFT and GFN2-xTB Calculations

References

\section{Pages}

S2

S3-S5

S6

S7-S20

S21-S22

S23-S25

S26

S27-S32

S33

S34-S37

S38-S39 


\section{General Information}

Commercially available reagents and solvents were purchased from Alfa Aesar, Fisher Scientific, Sigma Aldrich, and TCI America, and were used directly without further purification. Water was deionized and micro-filtered using Milli-Q water filtration station. Cryo-cooled photoreactions were performed using a Kessil PR160L-370nm LED photoredox lamp (set to maximum intensity) and a Julabo FT902 Immersion cooler. The distance between the sample and the lamp was $3 \mathrm{~cm}$. Reactions were monitored by thin layer chromatography (TLC) carried out on $250 \mu \mathrm{m}$ Merck silica gel plates (60 F254). Preparative thin layer chromatography was undertaken using Analtech Uniplate silica gel chromatography plates $(20 \times 20 \mathrm{~cm}, 1000$ micron). Visualization of the developed TLC plate was performed by irradiation with UV light $(365 \mathrm{~nm})$. Organic solvents were concentrated under reduced pressure on a Büchi rotary evaporator using a water bath $\left(20^{\circ} \mathrm{C}\right)$.

NMR Spectra were recorded on a Bruker Avance III 500 with a working frequency of $500 \mathrm{MHz}$. Chemical shifts are reported in ppm relative to the signals corresponding to the residual nondeuterated solvents $\left(\mathrm{D}_{2} \mathrm{O}: \delta 4.79 \mathrm{ppm}\right.$ for ${ }^{1} \mathrm{H} N \mathrm{NM} ; \mathrm{CD}_{3} \mathrm{OD}: \delta 3.31 \mathrm{ppm}$ for ${ }^{1} \mathrm{H} N \mathrm{NR}$, and $49.00 \mathrm{ppm}$ for ${ }^{13} \mathrm{C}$ NMR). Data for ${ }^{1} \mathrm{H}$ NMR spectra are reported as follows: chemical shift ( $\left.\delta \mathrm{ppm}\right)$, multiplicity ( $\mathrm{s}=$ singlet, $\mathrm{d}=$ doublet, $\mathrm{t}=$ triplet, $\mathrm{q}=$ quartet, $\mathrm{m}=$ multiplet $)$, integration, coupling constant $(\mathrm{Hz})$ and assignment. Data for ${ }^{13} \mathrm{C}$ NMR spectra are reported in terms of chemical shift and multiplicity where appropriate. High-resolution mass spectra (HRMS) were measured on an Agilent 6210 Time of Flight LC-MS, using an ESI source, coupled with Agilent 1100 HPLC stack, using direct infusion $(0.6 \mathrm{~mL} / \mathrm{min})$.

Optical Microscope Images were recorded using an Olympus DP25 Optical Microscope. Powder Xray diffraction (PXRD) patterns were collected at room temperature on a STOE-STADI MP powder diffractometer equipped with an asymmetric curved Germanium monochromator ( $\mathrm{CuK} \alpha 1$ radiation, $\lambda=1.54056 \AA$ ) and one-dimensional silicon strip detector (MYTHEN2 1K from DECTRIS). The line focused $\mathrm{Cu}$ X-ray tube was operated at $40 \mathrm{kV}$ and $40 \mathrm{~mA}$. The activated powder was sandwiched between two Kapton foils and measured in transmission geometry in a rotating holder. Intensity data from 2 to 30 degrees two theta were collected over a period of 18 minutes. The instrument was calibrated against a NIST Silicon standard (640d) prior to the measurement. X-Ray crystallographic data was obtained on a XtaLAB Synergy diffractometer equipped with a micro-focus sealed X-ray tube PhotonJet $(\mathrm{Cu}) \mathrm{X}$-ray source or micro-focus rotating anode X-ray tube Rigaku $(\mathrm{Cu}) \mathrm{X}$-ray source and a Hybrid Pixel Array Detector (HyPix) detector. Temperature of the crystal was controlled with an Oxford Cryosystems low-temperature device. Data reduction was performed with the CrysAlisPro software using an (empirical | numerical) absorption correction. 


\section{Synthetic Procedures}

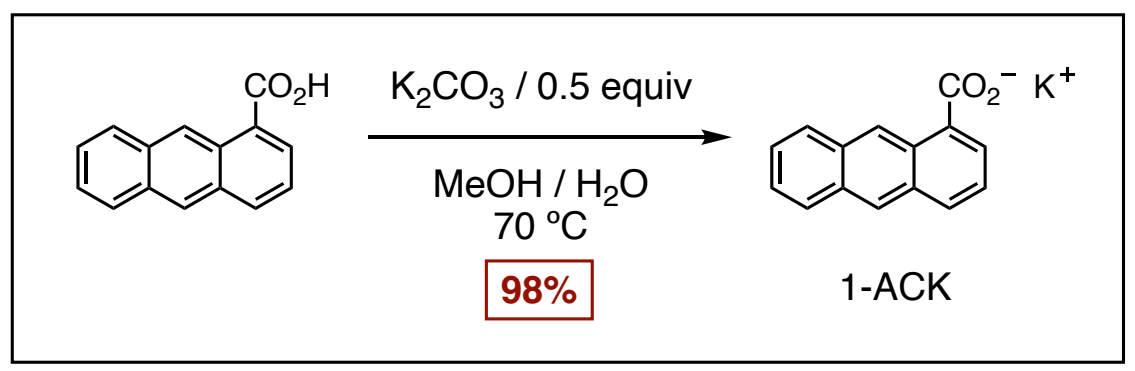

Scheme S1. Synthesis of 1-ACK

1-ACK: A $250 \mathrm{~mL}$ round-bottomed flask, equipped with a magnetic stirrer, was charged with 1anthracenecarboxylic acid (667 mg, $3.0 \mathrm{mmol}), \mathrm{K}_{2} \mathrm{CO}_{3}(208 \mathrm{mg}, 1.5 \mathrm{mmol}), \mathrm{MeOH}(30 \mathrm{~mL})$ and $\mathrm{H}_{2} \mathrm{O}(30 \mathrm{~mL})$. The suspension was heated at $70^{\circ} \mathrm{C}$ with stirring until all the solids had dissolved. The solvents were concentrated in vacuo and the precipitate was re-dissolved in a minimal amount of $\mathrm{MeOH}(10 \mathrm{~mL})$. The crude mixture was centrifuged, and the supernatant was separated and concentrated in vacuo, yielding 1-anthracenecarboxylate potassium salt (1-ACK) as a dark yellow solid (762 mg, 98\%). ${ }^{1} \mathrm{H}$ NMR (500 MHz, $\left.\mathrm{D}_{2} \mathrm{O}\right) \delta 8.79(\mathrm{~s}, 1 \mathrm{H}), 8.35$ (s, 1H), $8.05-7.95$ (m, 2H), $7.94-7.89(\mathrm{~m}, 1 \mathrm{H}), 7.64(\mathrm{dt}, J=6.7,1.1 \mathrm{~Hz}, 1 \mathrm{H}), 7.51-7.44(\mathrm{~m}, 3 \mathrm{H}) .{ }^{13} \mathrm{C} \mathrm{NMR}\left(126 \mathrm{MHz}, \mathrm{D}_{2} \mathrm{O}\right)$ $\delta 178.1,137.4,131.6,131.6,131.2,129.5,128.5,127.9,127.7,126.6,126.0,126.0,124.8,124.7$, 124.3.

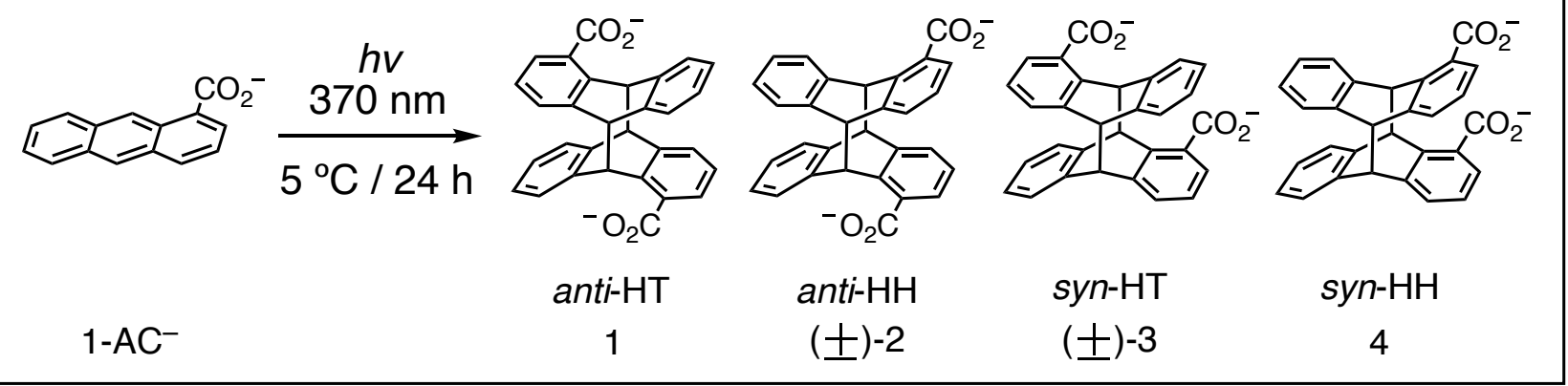

Scheme S2. Photodimerization of $1-\mathrm{AC}^{-}$in solution

A 1-mL borosilicate glass culture tube was charged with 1-ACK (5.2 mg, $20 \mu \mathrm{mol})$ along with one of the reaction solvents $(0.8 \mathrm{~mL})$ listed in Table 1. The tube was capped and placed in a circulating water bath (1 cm deep) maintained at $5{ }^{\circ} \mathrm{C}$ and irradiated with UV light $(370 \mathrm{~nm})$ for $24 \mathrm{~h}$. The resulting mixture was diluted with $\mathrm{H}_{2} \mathrm{O}(20 \mathrm{~mL})$ and acidified with a few drops of $6 \mathrm{M} \mathrm{HCl}$. The aqueous solution was extracted with EtOAc $(3 \times 15 \mathrm{~mL})$ and the combined organic fractions were 
dried $\left(\mathrm{Na}_{2} \mathrm{SO}_{4}\right)$ and concentrated in vacuum before 1,1,2,2-tetrachloroethane $(2.1 \mu \mathrm{L}, 20 \mu \mathrm{mol})$ was added. The yields of the four possible regioisomeric photodimerization products were obtained by integration of selected probes (Figure S19) in the ${ }^{1} \mathrm{H}$ NMR spectra, recorded in $\mathrm{CD}_{3} \mathrm{OD}$ solutions of the crude products and using 1,1,2,2-tetrachloroethane as an internal standard. For characterization purposes, purification was performed by preparative thin layer chromatography using $\mathrm{CH}_{2} \mathrm{Cl}_{2} / \mathrm{MeOH}$ (10:1) as the developing solvent. 1 (anti-HT): ${ }^{1} \mathrm{H}$ NMR $\left(500 \mathrm{MHz}, \mathrm{CD}_{3} \mathrm{OD}\right) \delta 7.23-7.06$ (m, 4H), $6.93-6.81(\mathrm{~m}, 4 \mathrm{H}), 6.73-6.66(\mathrm{~m}, 6 \mathrm{H}), 5.58(\mathrm{~d}, J=11.1 \mathrm{~Hz}, 2 \mathrm{H}), 4.66(\mathrm{~d}, J=11.1 \mathrm{~Hz}, 2 \mathrm{H}) .{ }^{13} \mathrm{C}$ NMR (126 MHz, CD 3 OD) $\delta 146.2,145.5,145.4,143.9,128.8,128.2,127.9,126.6,126.1,126.0$, 125.5, 55.0, 51.3. HRMS-ESI $m / z 443.130$ ([M- H] $]^{-}, \mathrm{C}_{30} \mathrm{H}_{19} \mathrm{O}_{4}$, calc. 443.129). 2 (anti-HH): ${ }^{1} \mathrm{H}$ NMR (500 MHz, CD 3 OD) $\delta 7.21-7.07(\mathrm{~m}, 5 \mathrm{H}), 6.91-6.81(\mathrm{~m}, 4 \mathrm{H}), 6.76-6.65(\mathrm{~m}, 6 \mathrm{H}), 5.59(\mathrm{~d}$, $J=10.9 \mathrm{~Hz}, 2 \mathrm{H}), 4.69(\mathrm{~d}, J=10.9 \mathrm{~Hz}, 2 \mathrm{H}) .{ }^{13} \mathrm{C} \mathrm{NMR}\left(126 \mathrm{MHz}, \mathrm{CD}_{3} \mathrm{OD}\right) \delta 145.9,145.8,145.8$, 129.7, 128.7, 127.4, 126.7, 126.2, 126.0, 125.4, 55.0, 51.5. HRMS-ESI $m / z 443.127\left([M-\mathrm{H}]^{-}\right.$, $\mathrm{C}_{30} \mathrm{H}_{19} \mathrm{O}_{4}$, calc. 443.129). 3 (syn-HT): ${ }^{1} \mathrm{H}$ NMR (500 MHz, CD $\left.{ }_{3} \mathrm{OD}\right) \delta 7.20-7.07$ (m, 4H), $6.88(\mathrm{t}$, $J=6.3 \mathrm{~Hz}, 4 \mathrm{H}), 6.76-6.61(\mathrm{~m}, 6 \mathrm{H}), 5.69(\mathrm{~s}, 2 \mathrm{H}), 4.55(\mathrm{~s}, 2 \mathrm{H}) .{ }^{13} \mathrm{C} \mathrm{NMR}\left(126 \mathrm{MHz}, \mathrm{CD}_{3} \mathrm{OD}\right) \delta$ 146.0, 145.6, 145.3, 129.2, 126.9, 126.1, 125.4, 55.4, 51.0. HRMS-ESI $m / z 443.127\left([M-\mathrm{H}]^{-}\right.$, $\mathrm{C}_{30} \mathrm{H}_{19} \mathrm{O}_{4}$, calc. 443.128). 4 (syn-HH): ${ }^{1} \mathrm{H}$ NMR (500 MHz, CD $\mathrm{CD}_{3} \mathrm{O} 7.21(\mathrm{~d}, J=7.8 \mathrm{~Hz}, 2 \mathrm{H}), 6.98$ $(\mathrm{d}, J=7.3 \mathrm{~Hz}, 2 \mathrm{H}), 6.92-6.87(\mathrm{~m}, 4 \mathrm{H}), 6.78-6.71(\mathrm{~m}, 6 \mathrm{H}), 5.98(\mathrm{~s}, 2 \mathrm{H}), 4.60(\mathrm{~s}, 2 \mathrm{H}) .{ }^{13} \mathrm{C}$ NMR (126 MHz, $\left.\mathrm{CD}_{3} \mathrm{OD}\right) \delta 146.3,145.8,145.4,144.3,129.4,128.6,127.8,127.5,126.2,126.2,125.6$, 55.3, 50.1. HRMS-ESI $m / z 443.127$ ([M- H $]^{-}, \mathrm{C}_{30} \mathrm{H}_{19} \mathrm{O}_{4}$, calc. 443.130).

CD-MOF-1: Following a previously reported procedure ${ }^{1}$ with slight modifications, a stock solution of $\gamma$-CD $(0.025 \mathrm{M})$ and $\mathrm{KOH}(0.2 \mathrm{M})$ was prepared by dissolving $\gamma$-CD $(324 \mathrm{mg}, 0.25 \mathrm{mmol})$ and $\mathrm{KOH}(112 \mathrm{mg}, 2 \mathrm{mmol})$ in $\mathrm{H}_{2} \mathrm{O}(10 \mathrm{~mL})$. The solution was filtered through a $0.45-\mu \mathrm{m}$ syringe filter and transferred $(0.25 \mathrm{~mL})$ into separate $1 \mathrm{~mL}$ borosilicate glass culture tubes using a micropipette. $\mathrm{MeOH}(5 \mathrm{~mL})$ was allowed to diffuse slowly into the solution over a period of one week, yielding colorless, cubic crystals in an average yield of $80 \%$. The mother liquid was decanted, and the crystalline sample was directly taken to the next step.

Note: The CD-MOF-1 crystals in each tube contain approximately $5.0 \mu \mathrm{mol}$ of $\gamma$-CD, which was used to calculate the yields of photodimerization in 1-AC ${ }^{-} \subset$ CD-MOF-1.

1-AC ${ }^{-} \subset$ CD-MOF-1: The as-synthesized CD-MOF-1 was immersed in 1-ACK solutions $(0.8 \mathrm{~mL})$ of different concentrations (20.8 mg, $0.08 \mathrm{mmol} / 41.7 \mathrm{mg}, 0.16 \mathrm{mmol} / 83.3 \mathrm{mg}, 0.32 \mathrm{mmol})$ at both 
RT and $-20{ }^{\circ} \mathrm{C}$. After allowing the solution to age for $14 \mathrm{~d}$, the mother liquid was transferred into small vials, acidified with $6 \mathrm{M} \mathrm{HCl}$, and the precipitate washed several times with $\mathrm{H}_{2} \mathrm{O}$ to give the recovered 1-anthracenecarboxylic acid (88\%). Dry crystals, suitable for the recording of ${ }^{1} \mathrm{H}$ NMR spectra and X-ray diffraction patterns, were obtained by evaporating the residual solvent in a fumehood for $6 \mathrm{~h}$.

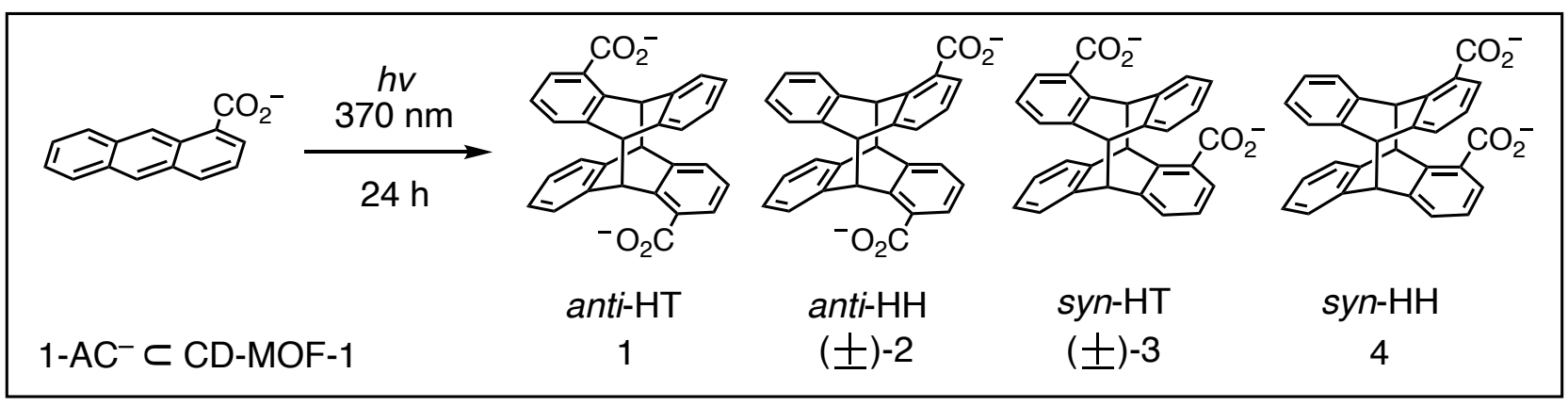

Scheme S3. Photodimerization of 1-AC ${ }^{-} \subset \mathrm{CD}-\mathrm{MOF}-1$

The as-synthesized 1-AC ${ }^{-} \subset$ CD-MOF-1 crystals were wrapped in Paratone oil and laid on a thin microscope slide in a quartz fluorometer cell under a $\mathrm{N}_{2}$ atmosphere. The cell was capped and submerged in $i \mathrm{PrOH}(2 \mathrm{~cm}$ deep) in a Dewar that was already connected to a cryocooler. The sample was cooled to the temperature of choice before it was irradiated with UV light $(370 \mathrm{~nm})$ for $24 \mathrm{~h}$. The oil was removed by washing the sample with hexanes, and the crystals were dissolved in $\mathrm{H}_{2} \mathrm{O}$ $(10 \mathrm{~mL})$, followed by the addition of a few drops of $6 \mathrm{M} \mathrm{HCl}$. The aqueous solution was extracted with EtOAc $(3 \times 10 \mathrm{~mL})$ and the combined organic fractions were dried $\left(\mathrm{Na}_{2} \mathrm{SO}_{4}\right)$ and concentrated in vacuo before 1,1,2,2-tetrachloroethane $(0.5 \mu \mathrm{L}, 5.0 \mu \mathrm{mol})$ was added. The yields of the four possible regioisomeric photodimerization products were obtained by integration of selected probes (Figure S22) in the ${ }^{1} \mathrm{H}$ NMR spectra, recorded in $\mathrm{CD}_{3} \mathrm{OD}$ solutions of the crude products containing the internal standard.

1-AC ${ }^{-} \subset$ CD-HF: $\gamma$-CD $\left(6.5 \mathrm{mg}, 5 \mu \mathrm{mol}\right.$, ) and 1-ACK $(20.8 \mathrm{mg}, 80 \mu \mathrm{mol})$ were dissolved in $\mathrm{H}_{2} \mathrm{O}$ $(0.2 \mathrm{~mL})$. The solution was centrifuged, and the supernatant was transferred into a $1-\mathrm{mL}$ borosilicate glass culture tube. $\mathrm{Me}_{2} \mathrm{CO}$ was allowed to diffuse slowly into the solution over a period of $5 \mathrm{~d}$, yielding orange, cubic crystals. Dry crystals, suitable for the recording of ${ }^{1} \mathrm{H}$ NMR spectra and Xray diffraction patterns, were obtained by evaporating the residual solvent in a fume-hood for $6 \mathrm{~h}$. 


\section{Additional Data}

Table S1. Anion-Exchange of 1-AC ${ }^{-}$with CD-MOF-1 Table S2. Anion-Exchange of 1-AC ${ }^{-}$with CD-MOF-2

\begin{tabular}{|c|c|c|c|c|c|c|c|c|c|}
\hline \multirow{2}{*}{ Entry } & \multicolumn{3}{|c|}{ Anion Exchange with CD-MOF-1 ${ }^{a}$} & \multirow{2}{*}{$\begin{array}{c}1-A C^{-} / \\
Y^{-C D} \\
\text { Ratio }^{b}\end{array}$} & \multirow{2}{*}{ Entry } & \multicolumn{3}{|c|}{ Anion Exchange with CD-MOF-2 ${ }^{c}$} & \multirow{2}{*}{$\begin{array}{l}1-A C^{-} \\
\text {Y-CD } \\
\text { Ratio }\end{array}$} \\
\hline & $\begin{array}{c}\mathrm{MeOH} / \mathrm{H}_{2} \mathrm{O} \\
\text { Ratio }\end{array}$ & $\begin{array}{c}\text { Conc of } \\
1-A C^{-} / M\end{array}$ & $\begin{array}{l}\text { Temp } \\
/^{\circ} \mathrm{C}\end{array}$ & & & $\begin{array}{c}\mathrm{MeOH} / \mathrm{H}_{2} \mathrm{O} \\
\text { Ratio }\end{array}$ & $\begin{array}{c}\text { Conc of } \\
1-A C^{-} / \mathrm{M}\end{array}$ & $\begin{array}{l}\text { Temp } \\
/{ }^{\circ} \mathrm{C}\end{array}$ & \\
\hline 1 & $3: 1$ & 0.4 & -20 & $0.84: 1$ & 1 & Pure $\mathrm{MeOH}$ & 0.2 & 25 & $0.81: 1$ \\
\hline \multirow[t]{2}{*}{2} & $2: 1$ & 0.4 & -20 & $0.70: 1$ & 2 & $3: 1$ & 0.2 & 25 & $0.65: 1$ \\
\hline & & & & & 3 & $2: 1$ & 0.2 & 25 & $0.63: 1$ \\
\hline
\end{tabular}

(a) Freshly grown CD-MOF-1 (5 $\mu \mathrm{mol})$ were submerged in a solution of 1-ACK for $50 \mathrm{~d}$. (b) The 1 -AC $-1 \gamma$-CD ratios were determined by integration, employing appropriate probe protons, from the ${ }^{1} \mathrm{H}$ NMR spectra, recorded in $\mathrm{D}_{2} \mathrm{O}$ solutions of 1-AC $\mathrm{C}^{-} \subset \mathrm{CD}-\mathrm{MOF}$ following anion exchange. (c) Freshly grown CD-MOF-2 (5 $\left.\mu \mathrm{mol}\right)$ were submerged in a solution of $1-\mathrm{ACRb}$ for $14 \mathrm{~d}$.

Table S3. Photodimerization of $1-\mathrm{AC}^{-} \subset \mathrm{CD}-\mathrm{MOF}-2$

\begin{tabular}{|c|c|c|c|c|c|c|c|c|}
\hline \multirow{2}{*}{ Entry } & \multicolumn{2}{|c|}{ Anion Exchange with CD-MOF-2a } & \multirow{2}{*}{$\begin{array}{c}\text { Reaction } \\
\text { Temp } \\
/^{\circ} \mathrm{C}^{\mathrm{b}}\end{array}$} & \multicolumn{4}{|c|}{ Product Yields $\mathrm{c} / \%$} & \multirow{2}{*}{$\frac{\% e^{d}}{(-)-2}$} \\
\hline & $\mathrm{MeOH} / \mathrm{H}_{2} \mathrm{O}$ Ratio & Temp $/{ }^{\circ} \mathrm{C}$ & & 1 & $( \pm)-2$ & $( \pm)-3$ & 4 & \\
\hline 1 & Pure $\mathrm{MeOH}$ & 25 & 5 & 26 & 63 & 5 & 3 & 7 \\
\hline 2 & $3: 1$ & 25 & 5 & 21 & 70 & 4 & 5 & 25 \\
\hline 3 & $2: 1$ & 25 & 5 & 18 & 67 & 3 & 4 & 33 \\
\hline
\end{tabular}

(a) A $0.2 \mathrm{M}$ solution of 1-ACRb was used for the anion exchange. (b) The reaction was performed with 1-AC $\subset$ CDMOF-2 (5 $\mu \mathrm{mol})$ wrapped in Paratone oil under a $\mathrm{N}_{2}$ atmosphere and UV irradiation $(370 \mathrm{~nm})$ for $24 \mathrm{~h}$. (c) Yields were obtained by integration of selected probes in the ${ }^{1} \mathrm{H}$ NMR spectra, recorded in $\mathrm{CD}_{3} \mathrm{OD}$ solutions of the crude products with 1,1,2,2-tetrachloroethane ( $5 \mu \mathrm{mol})$ as an internal standard and were based on the percentages of 1-AC ${ }^{-}$incorporated in CD-MOF-2 under the anion-exchange conditions employed. (d) Enantiomeric excesses were obtained by integration of the peaks present in the reverse-phase chiral high-performance liquid chromatograms of the crude products.

Table S4. Photodimerization of $1-\mathrm{AC}^{-} \subset \mathrm{CD}-\mathrm{HF}$

\begin{tabular}{c|cccc}
\hline $\begin{array}{c}\text { Reaction } \\
\text { Temp } \\
/{ }^{\circ} \mathrm{C}^{\mathrm{a}}\end{array}$ & \multicolumn{4}{|c}{ Product Yields $\mathrm{b} / \%$} \\
\cline { 2 - 5 } & 1 & 2 & 3 & 4 \\
\hline 5 & 4 & 7 & 7 & trace
\end{tabular}

(a) The reaction was performed with 1-AC $\mathrm{AC}^{-} \subset \mathrm{CD}-\mathrm{HF}$ ( $5 \mu \mathrm{mol}$ ) wrapped in Paratone oil under a $\mathrm{N}_{2}$ atmosphere and UV irradiation $\left(370 \mathrm{~nm}\right.$ ) at $5{ }^{\circ} \mathrm{C}$ for $24 \mathrm{~h}$. (b) Yields were obtained by integration of selected probes in the ${ }^{1} \mathrm{H}$ NMR spectra, recorded in $\mathrm{CD}_{3} \mathrm{OD}$ solutions of the crude products with 1,1,2,2-tetrachloroethane (5 $\left.\mu \mathrm{mol}\right)$ as an internal standard. 


\section{NMR Spectroscopy}

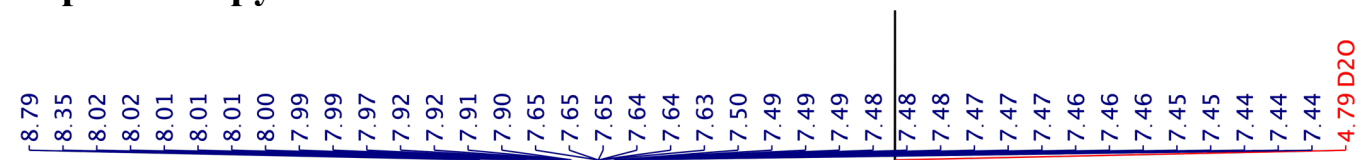

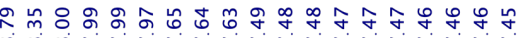

on

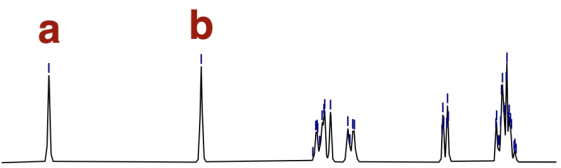

$\begin{array}{llllllllll}8.8 & 8.6 & 8.4 & 8.2 & 8.0 & 7.8 & 7.6 & 7.4\end{array}$

$\delta / \mathrm{ppm}$<smiles>[3H][Na]</smiles>

b $\mathrm{H}$

$1-A C K$

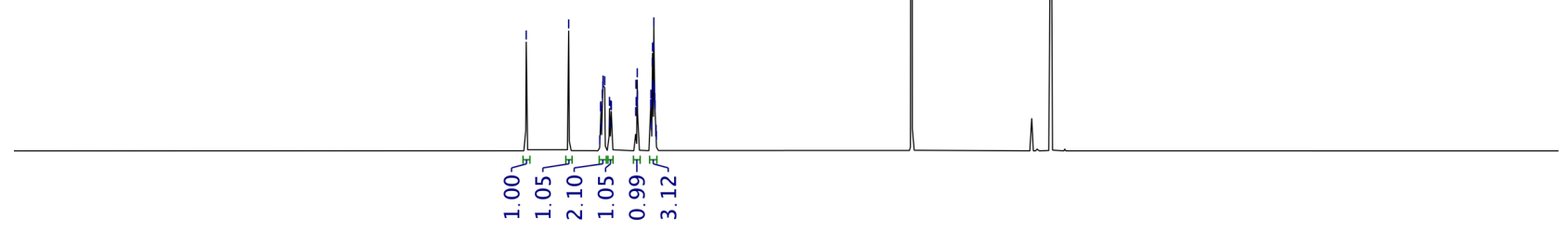

\begin{tabular}{llllllllllllllll}
\hline 4 & 13 & 12 & 11 & 10 & 9 & 8 & 7 & $\begin{array}{c}6 \\
\delta / \mathrm{ppm}\end{array}$ & 5 & 4 & 3 & 2 & 1 & 0 & -1
\end{tabular}

Figure S1. ${ }^{1} \mathrm{H}$ NMR Spectrum $\left(500 \mathrm{MHz}, \mathrm{D}_{2} \mathrm{O}, 298 \mathrm{~K}\right)$ of 1-ACK

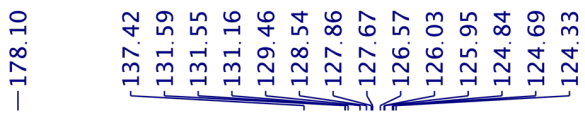

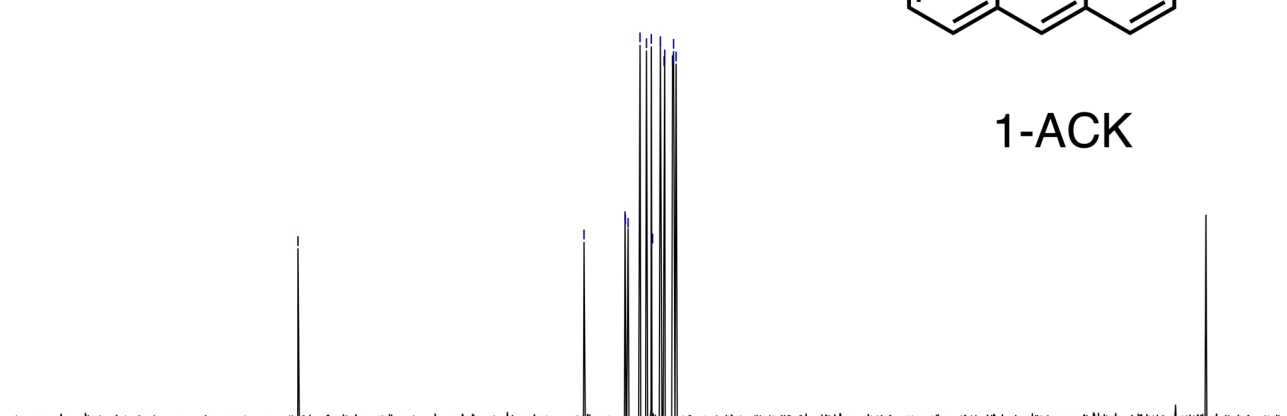<smiles>[3H][Na]</smiles>

$\begin{array}{llllllllllll}210 & 190 & 170 & 150 & 130 & \begin{array}{c}110 \\ \delta / \mathrm{ppm}\end{array} & 90 & 70 & 50 & 30 & 10 & -10\end{array}$

Figure S2. ${ }^{13} \mathrm{C}$ NMR Spectrum $\left(126 \mathrm{MHz}, \mathrm{D}_{2} \mathrm{O}, 298 \mathrm{~K}\right)$ of 1-ACK 


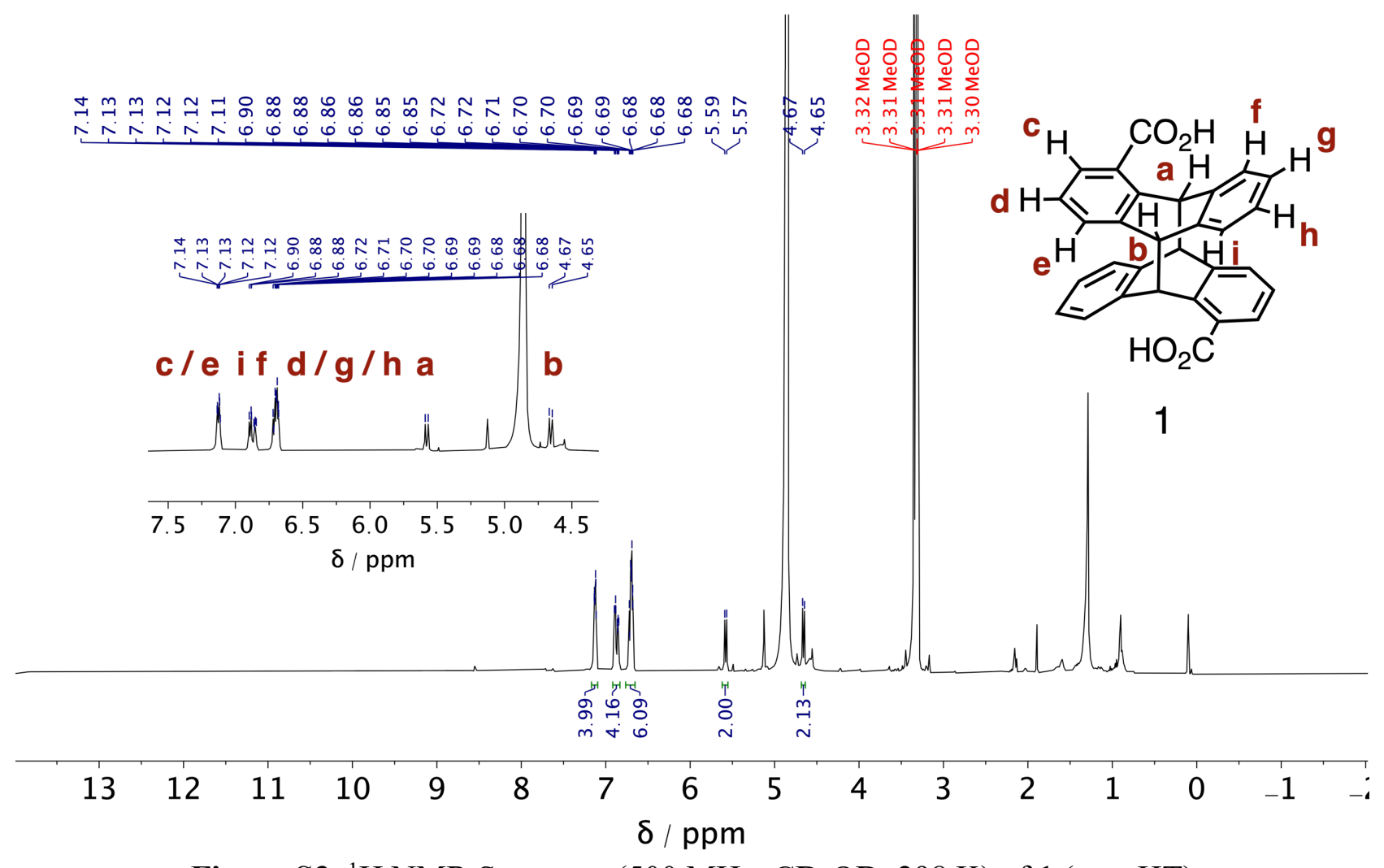

Figure S3. ${ }^{1} \mathrm{H}$ NMR Spectrum $\left(500 \mathrm{MHz}, \mathrm{CD}_{3} \mathrm{OD}, 298 \mathrm{~K}\right)$ of 1 (anti-HT)

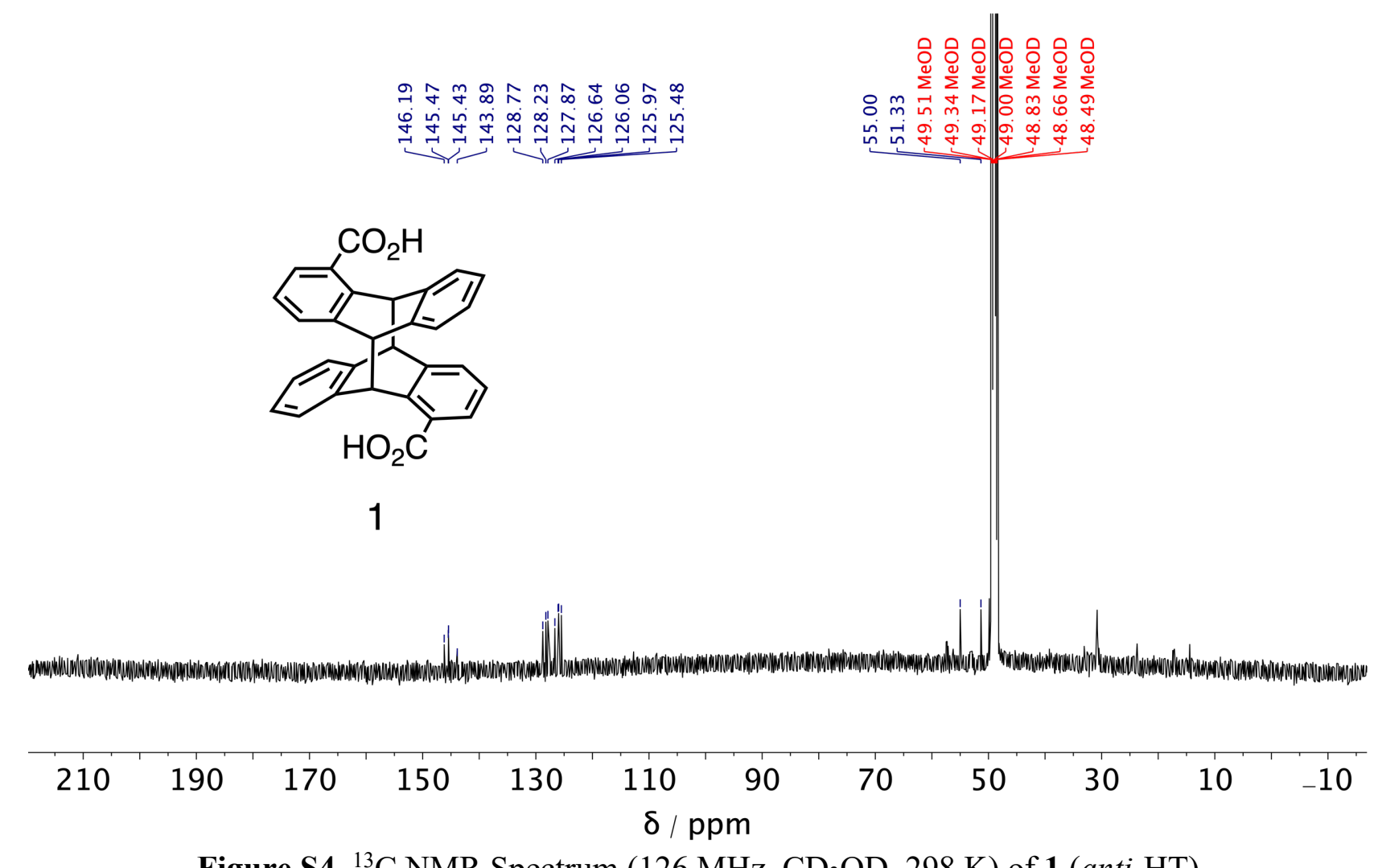

Figure S4. ${ }^{13} \mathrm{C}$ NMR Spectrum (126 MHz, CD $\left.{ }_{3} \mathrm{OD}, 298 \mathrm{~K}\right)$ of $\mathbf{1}$ (anti-HT) 


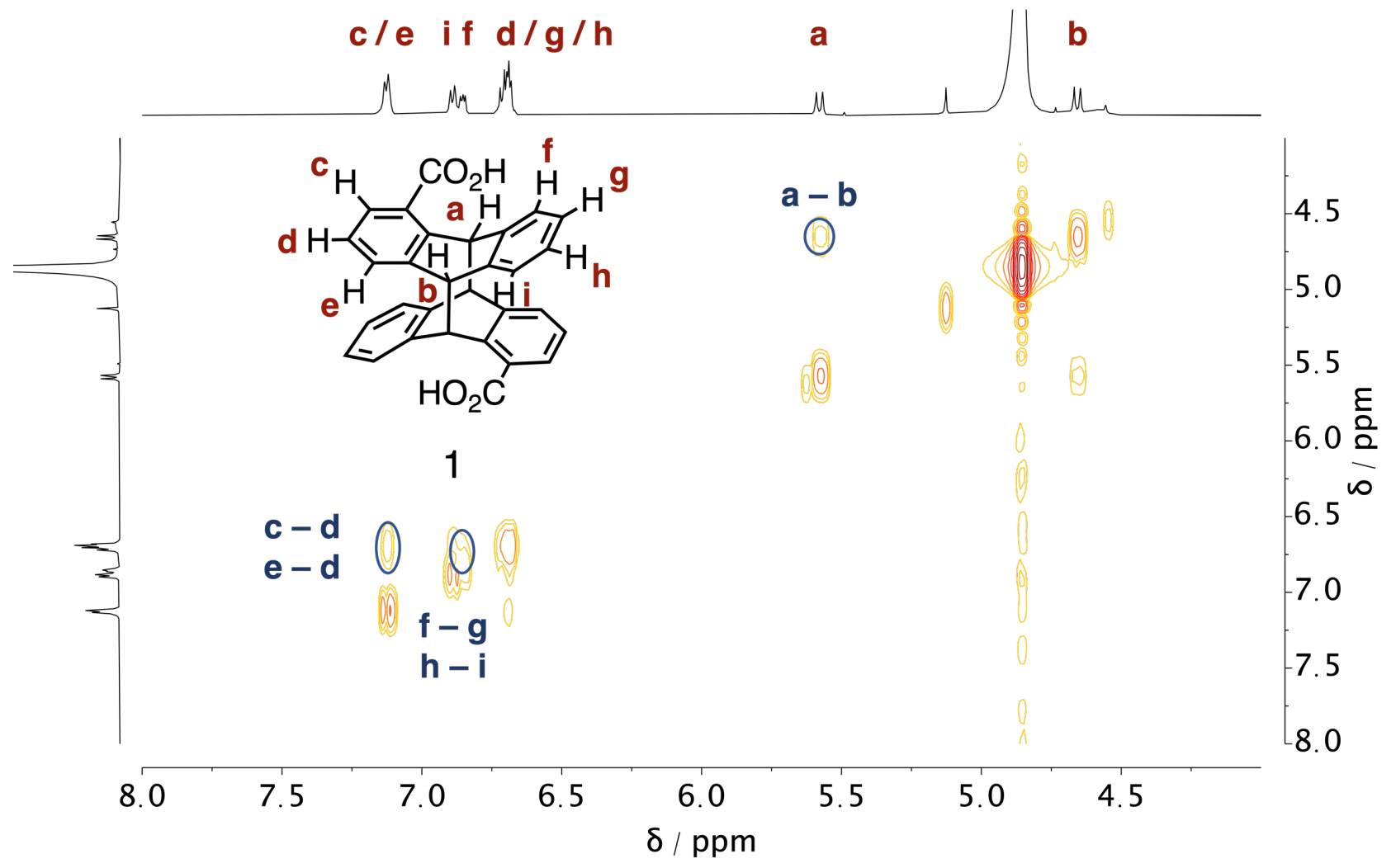

Figure S5. ${ }^{1} \mathrm{H}-{ }^{1} \mathrm{H}$ COSY NMR Spectrum $\left(500 \mathrm{MHz}, \mathrm{CD}_{3} \mathrm{OD}, 298 \mathrm{~K}\right)$ of 1 (anti-HT)

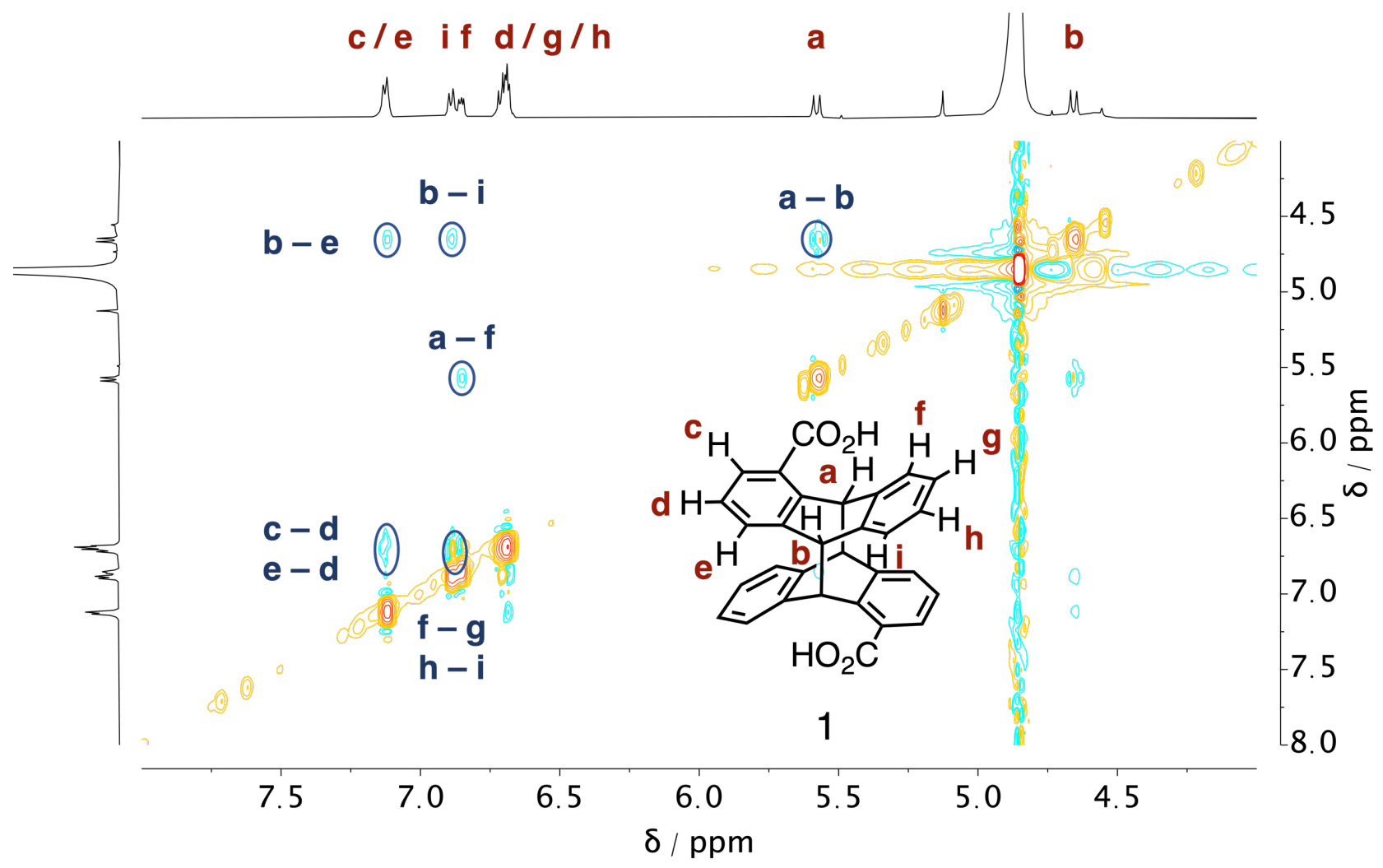

Figure S6. ${ }^{1} \mathrm{H}-{ }^{1} \mathrm{H}$ NOESY NMR Spectrum (500 MHz, CD $3 \mathrm{OD}, 298 \mathrm{~K}$ ) of $\mathbf{1}$ (anti-HT) 


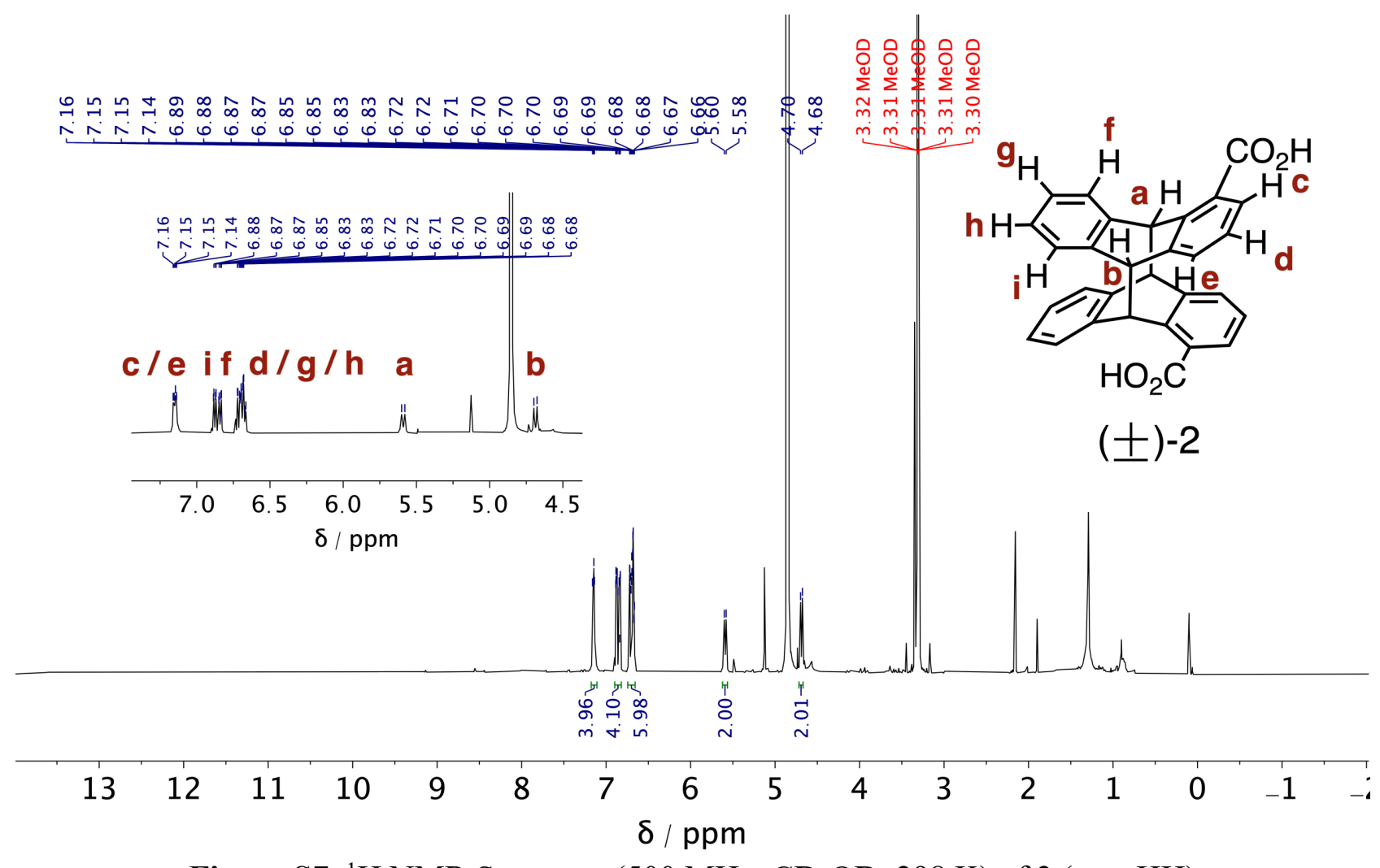

Figure S7. ${ }^{1} \mathrm{H}$ NMR Spectrum $\left(500 \mathrm{MHz}, \mathrm{CD}_{3} \mathrm{OD}, 298 \mathrm{~K}\right)$ of 2 (anti-HH)

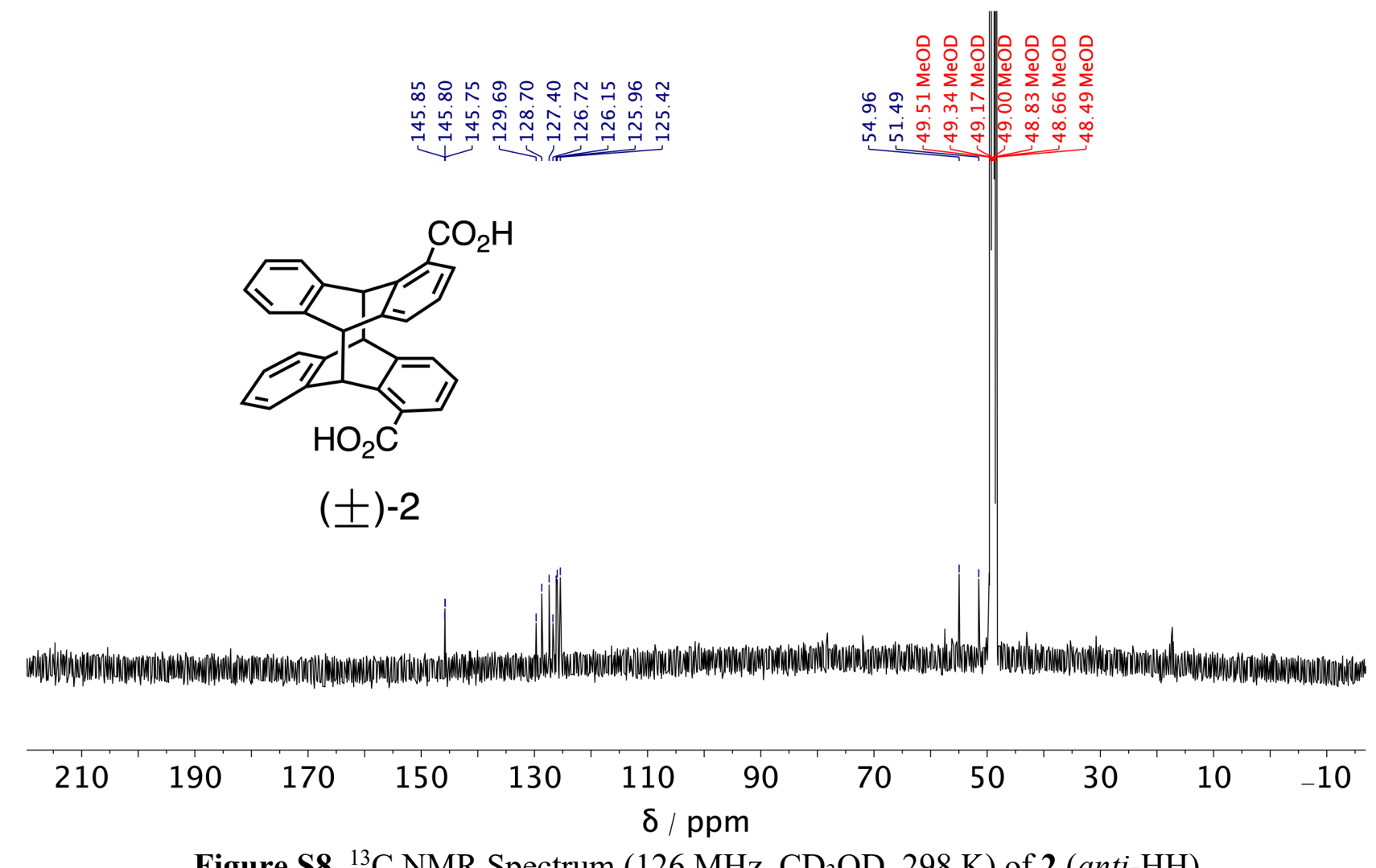

Figure S8. ${ }^{13} \mathrm{C}$ NMR Spectrum (126 MHz, CD $\left.\mathrm{CD}_{3}, 298 \mathrm{~K}\right)$ of 2 (anti-HH) 


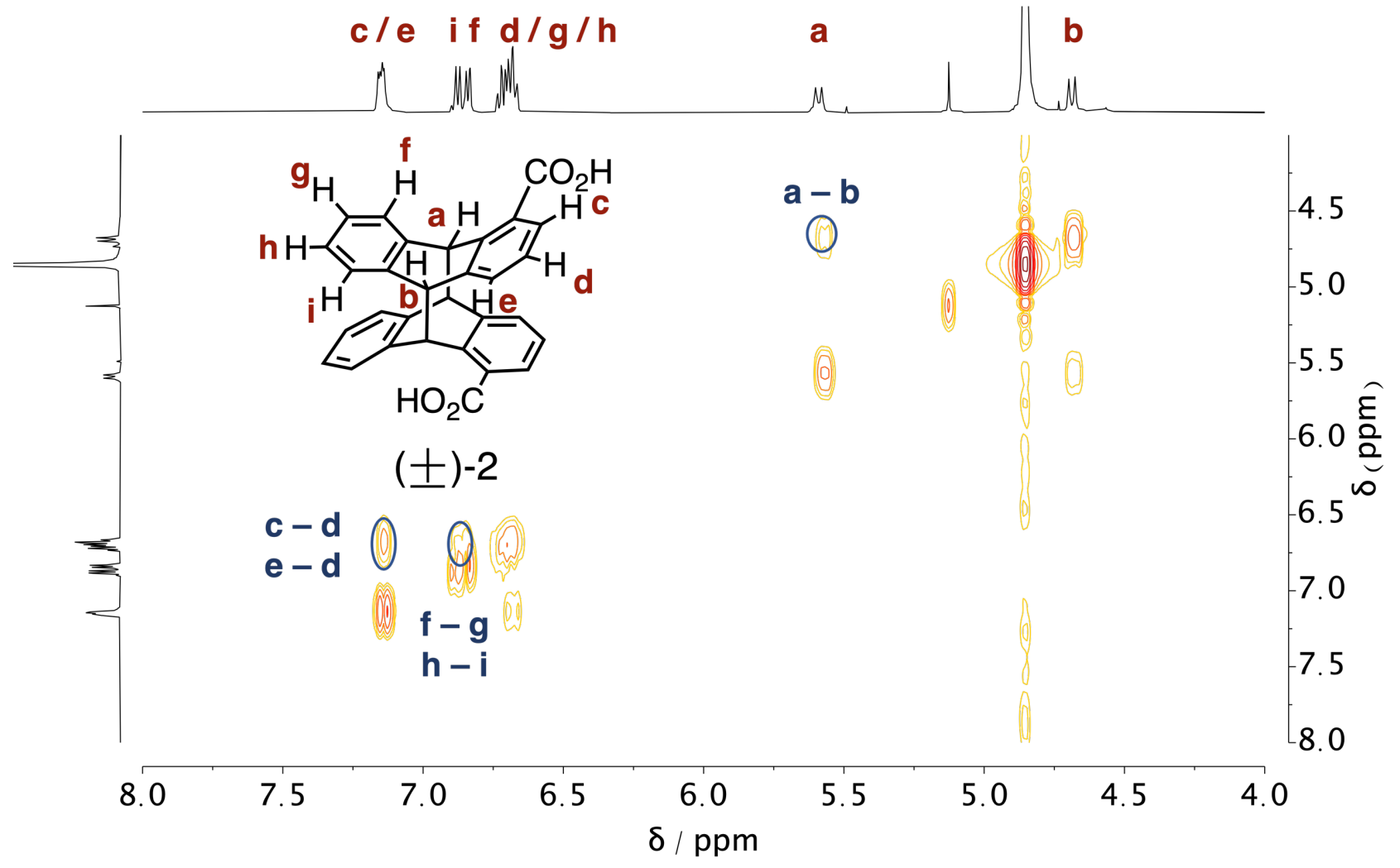

Figure S9. ${ }^{1} \mathrm{H}-{ }^{1} \mathrm{H}$ COSY NMR Spectrum $\left(500 \mathrm{MHz}, \mathrm{CD}_{3} \mathrm{OD}, 298 \mathrm{~K}\right)$ of 2 (anti-HH)

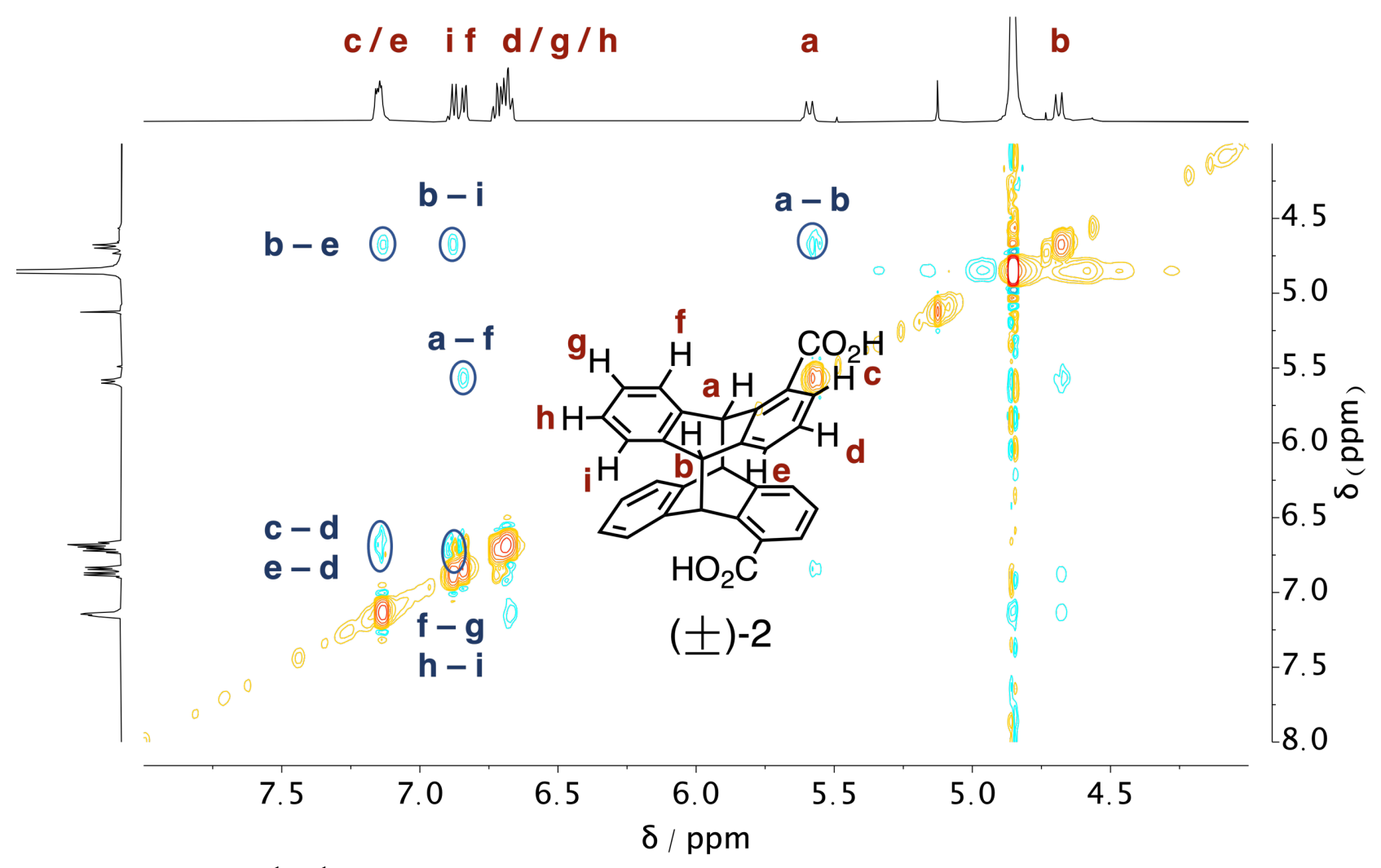

Figure S10. ${ }^{1} \mathrm{H}-{ }^{1} \mathrm{H}$ NOESY NMR Spectrum $\left(500 \mathrm{MHz}, \mathrm{CD}_{3} \mathrm{OD}, 298 \mathrm{~K}\right)$ of 2 (anti-HH) 


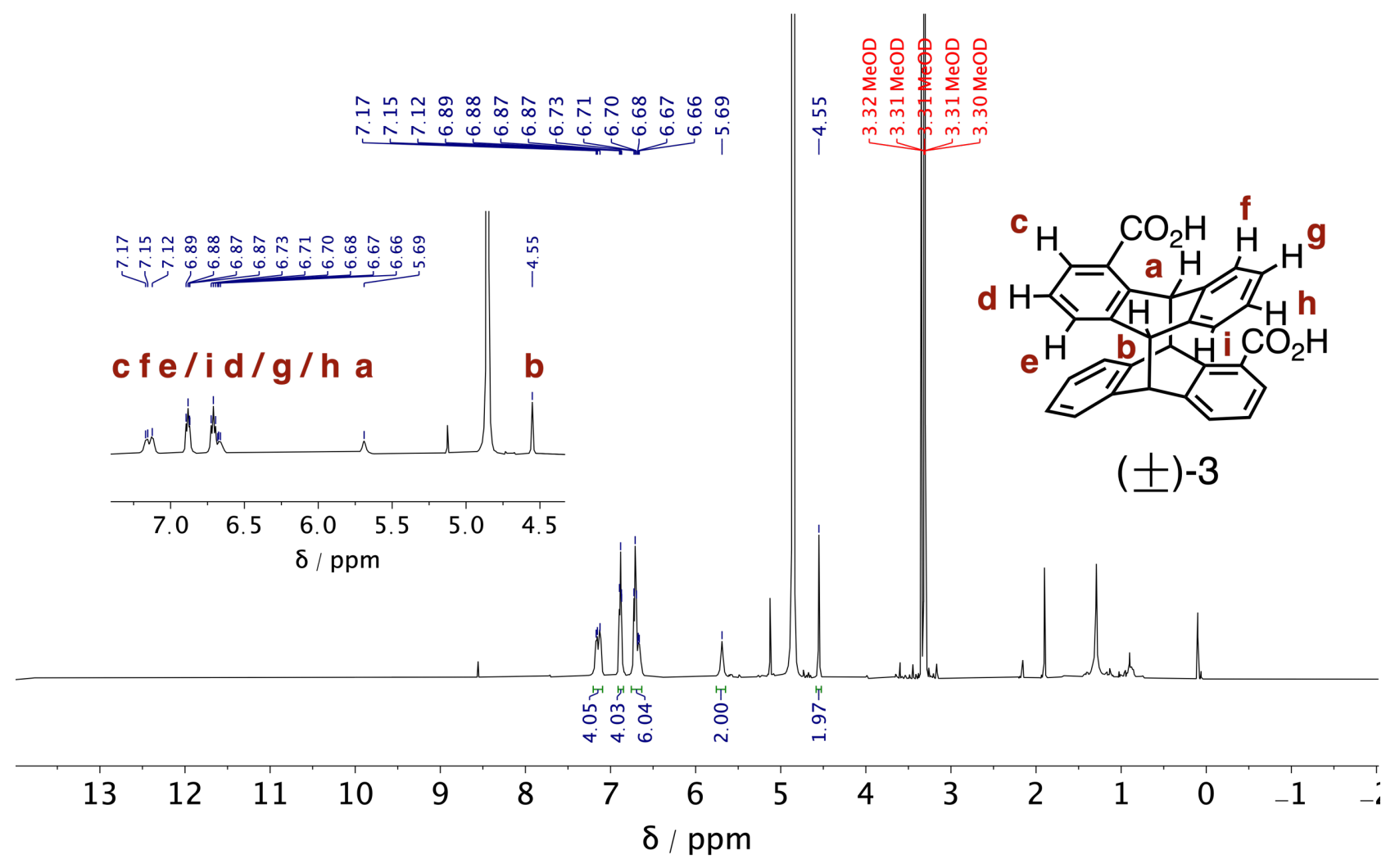

Figure S11. ${ }^{1} \mathrm{H}$ NMR Spectrum $\left(500 \mathrm{MHz}, \mathrm{CD}_{3} \mathrm{OD}, 298 \mathrm{~K}\right)$ of $\mathbf{3}$ (syn-HT)

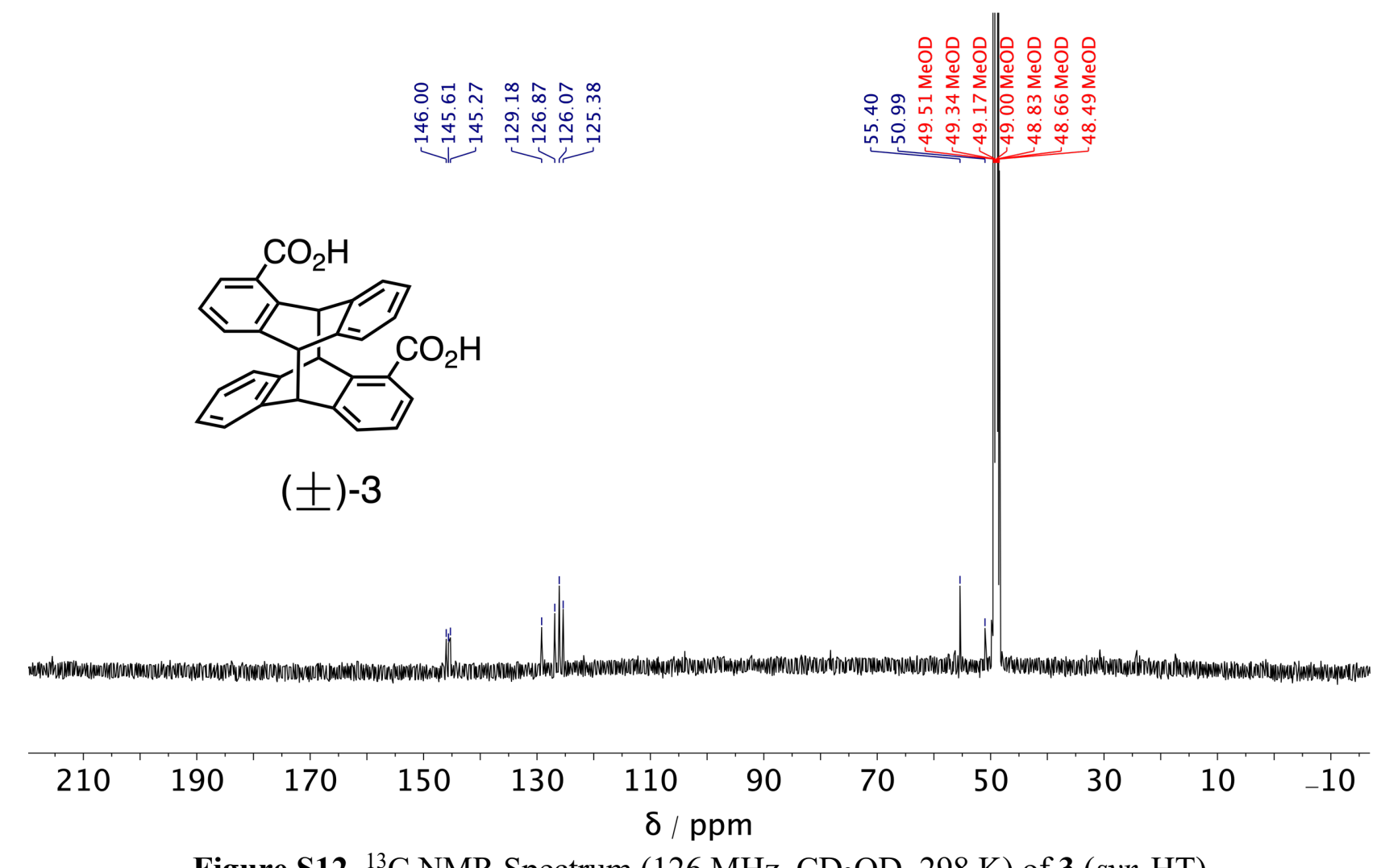

Figure S12. ${ }^{13} \mathrm{C}$ NMR Spectrum (126 MHz, CD 3 OD, $\left.298 \mathrm{~K}\right)$ of 3 (syn-HT) 


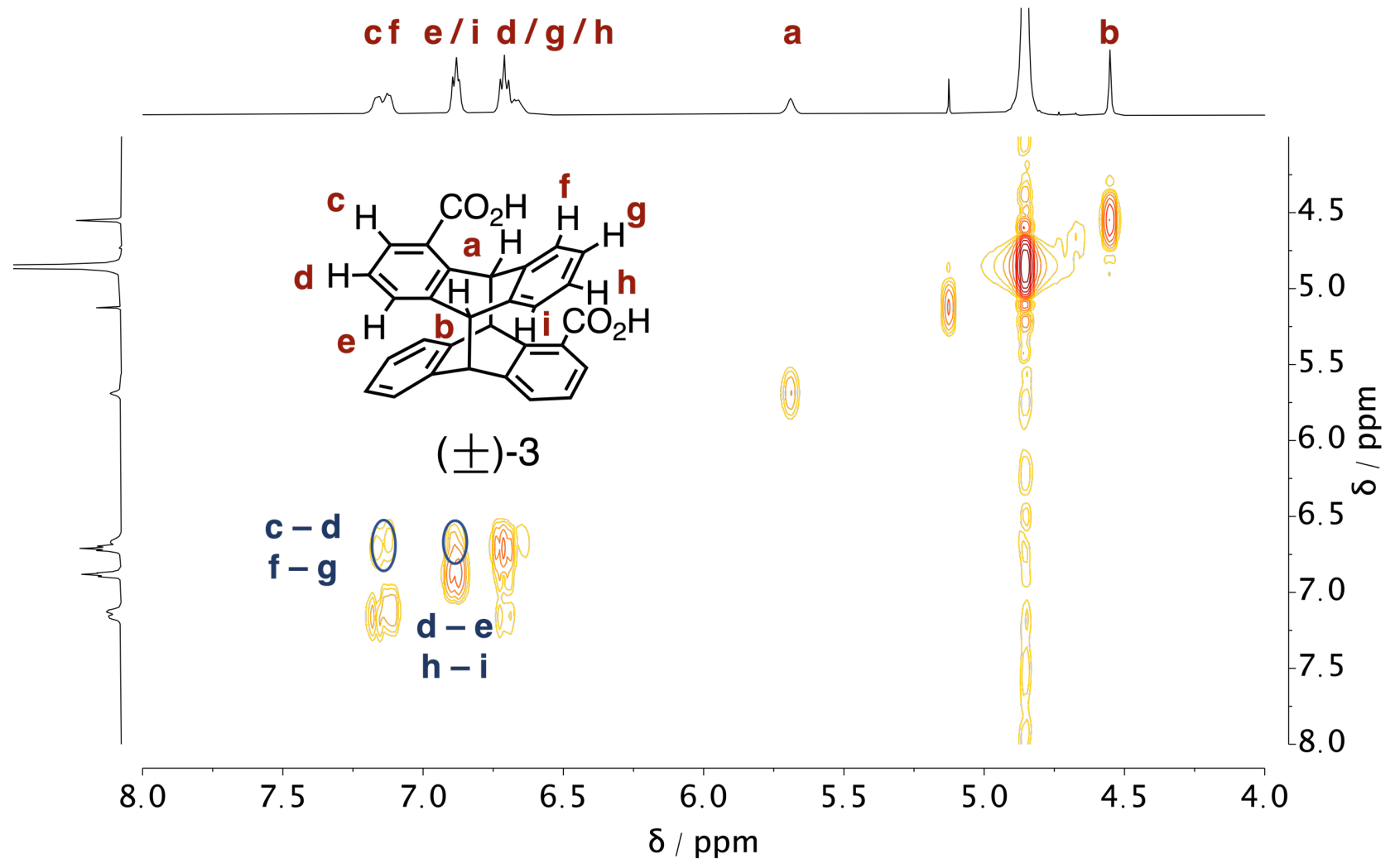

Figure S13. ${ }^{1} \mathrm{H}-{ }^{1} \mathrm{H}$ COSY NMR Spectrum (500 MHz, CD ${ }_{3} \mathrm{OD}, 298 \mathrm{~K}$ ) of $\mathbf{3}$ (syn-HT)

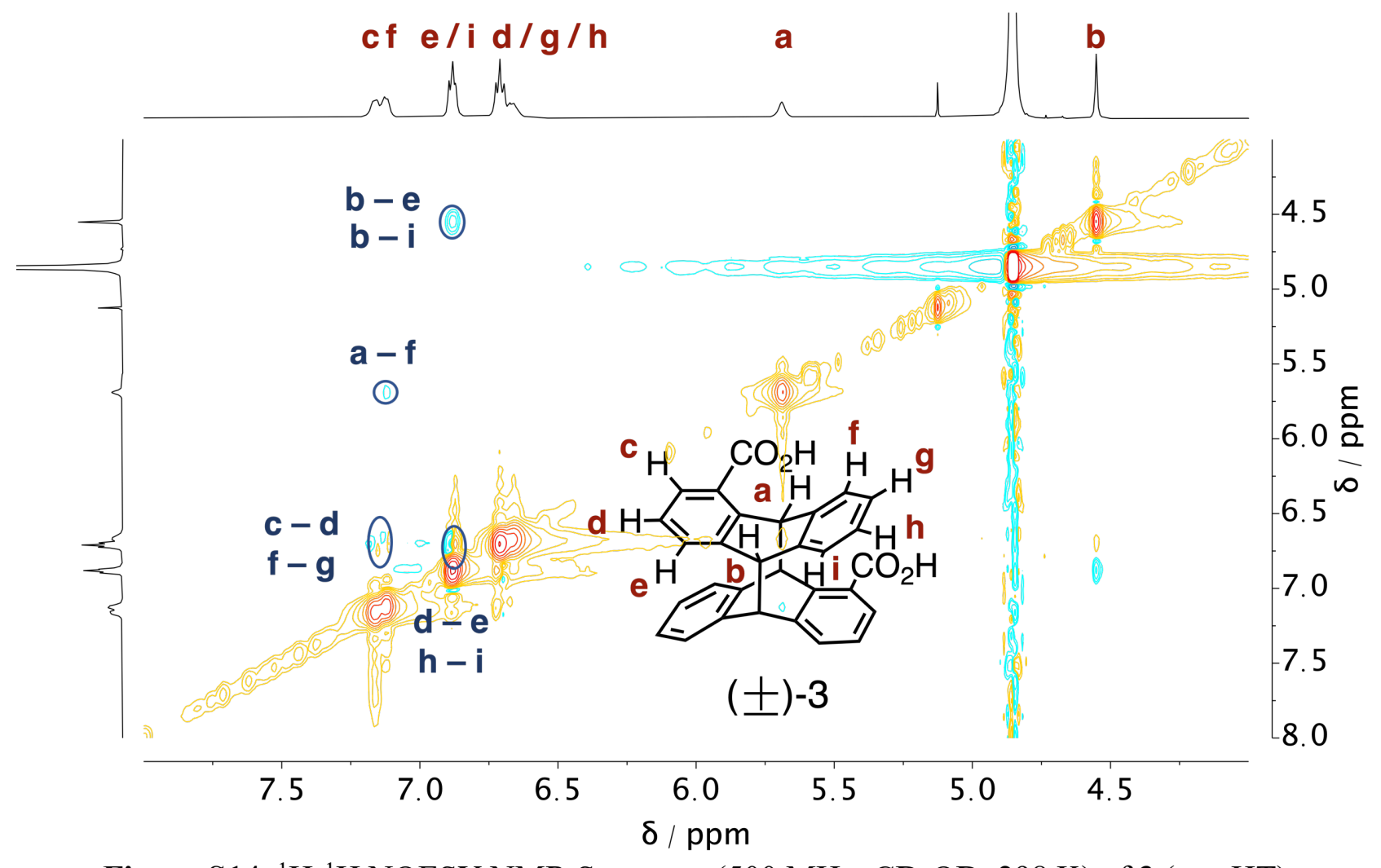

Figure S14. ${ }^{1} \mathrm{H}-{ }^{1} \mathrm{H}$ NOESY NMR Spectrum $\left(500 \mathrm{MHz}, \mathrm{CD}_{3} \mathrm{OD}, 298 \mathrm{~K}\right)$ of 3 (syn-HT) 


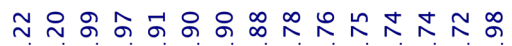

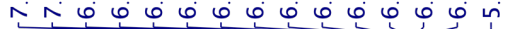

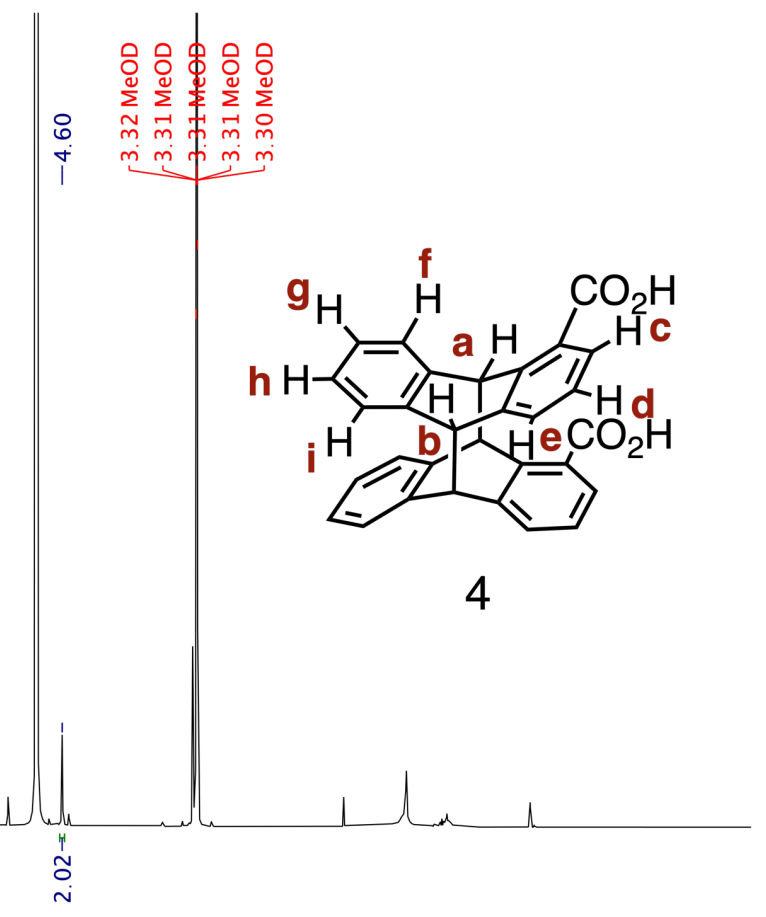

\section{$\begin{array}{llllllllllllllll}13 & 12 & 11 & 10 & 9 & 8 & 7 & 6 & 5 & 4 & 3 & 2 & 1 & 0 & -1 & - \text { : }\end{array}$ $\delta / \mathrm{ppm}$}

Figure S15. ${ }^{1} \mathrm{H}$ NMR Spectrum $\left(500 \mathrm{MHz}, \mathrm{CD}_{3} \mathrm{OD}, 298 \mathrm{~K}\right)$ of 4 (syn-HH)

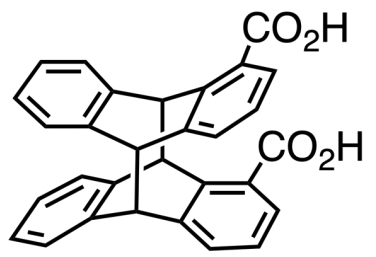

4

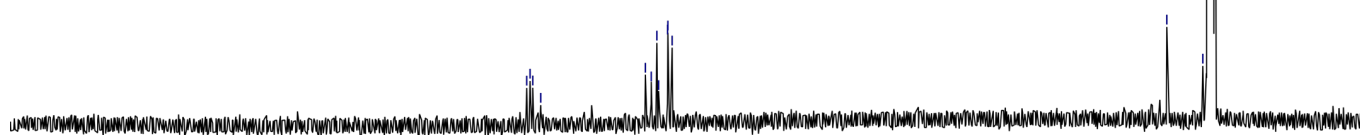

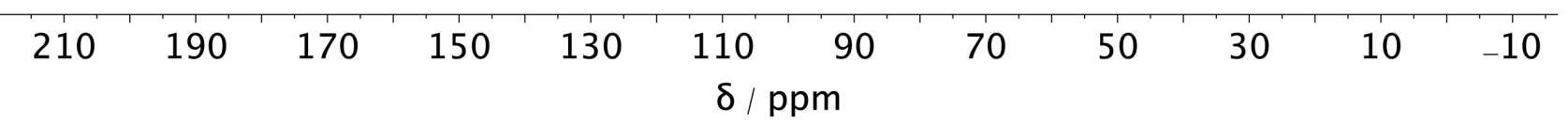

Figure S16. ${ }^{13} \mathrm{C}$ NMR Spectrum (126 MHz, CD 30 OD, $\left.298 \mathrm{~K}\right)$ of 4 (syn-HH) 


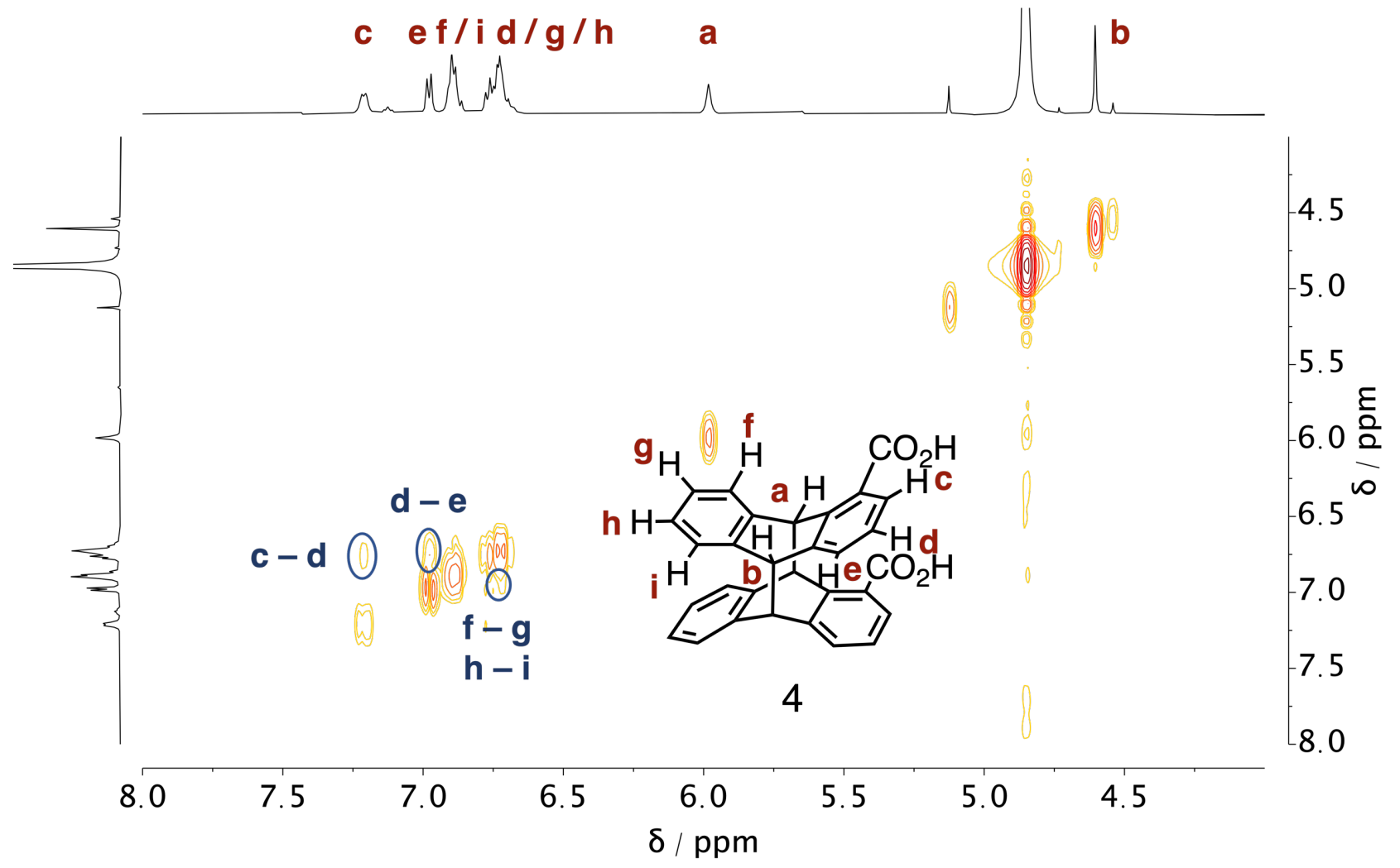

Figure S17. ${ }^{1} \mathrm{H}-{ }^{1} \mathrm{H}$ COSY NMR Spectrum (500 MHz, CD $\left.{ }_{3} \mathrm{OD}, 298 \mathrm{~K}\right)$ of 4 (syn-HH)

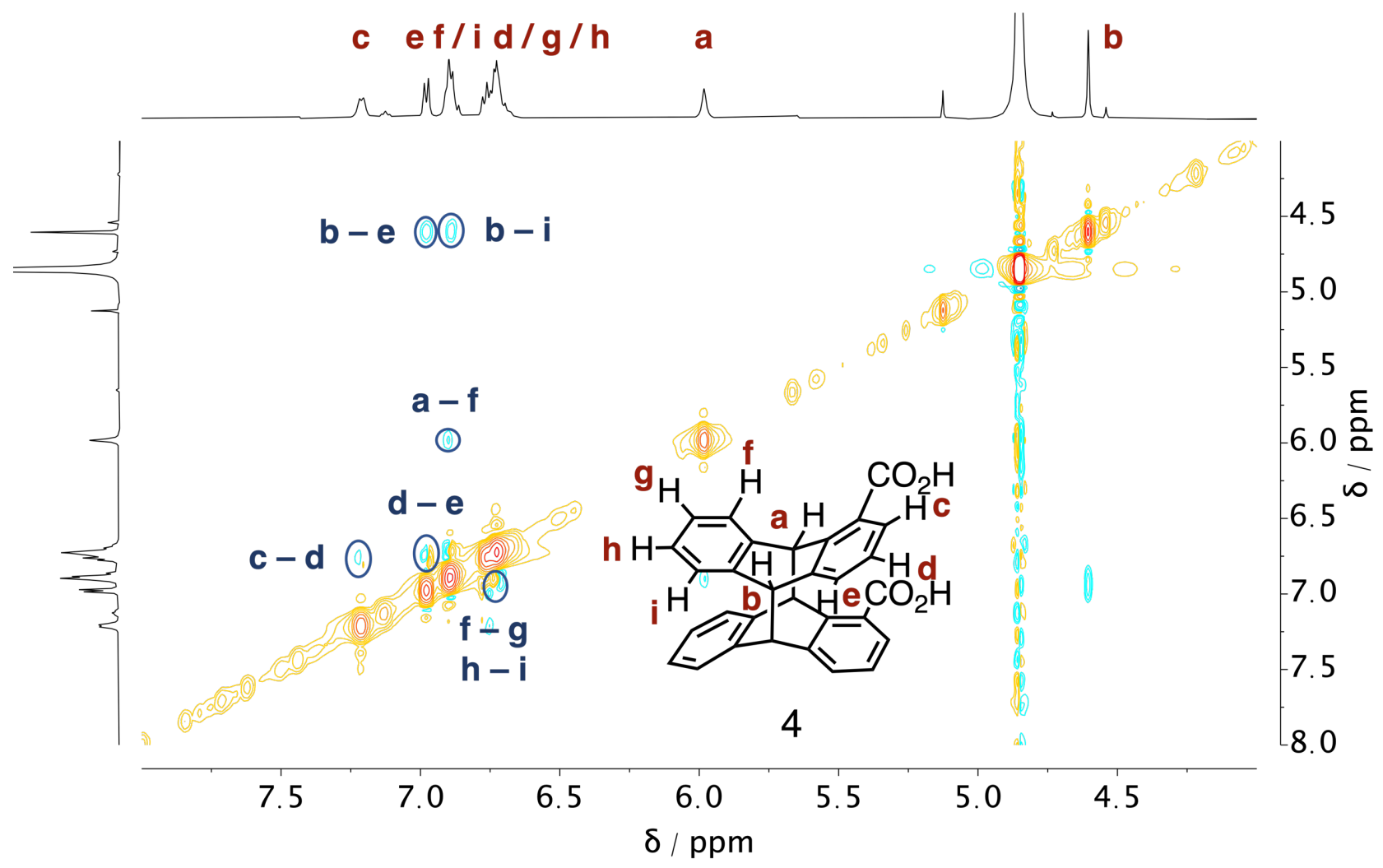

Figure S18. ${ }^{1} \mathrm{H}-{ }^{1} \mathrm{H}$ NOESY NMR Spectrum $\left(500 \mathrm{MHz}, \mathrm{CD}_{3} \mathrm{OD}, 298 \mathrm{~K}\right)$ of $4(s y n-\mathrm{HH})$ 

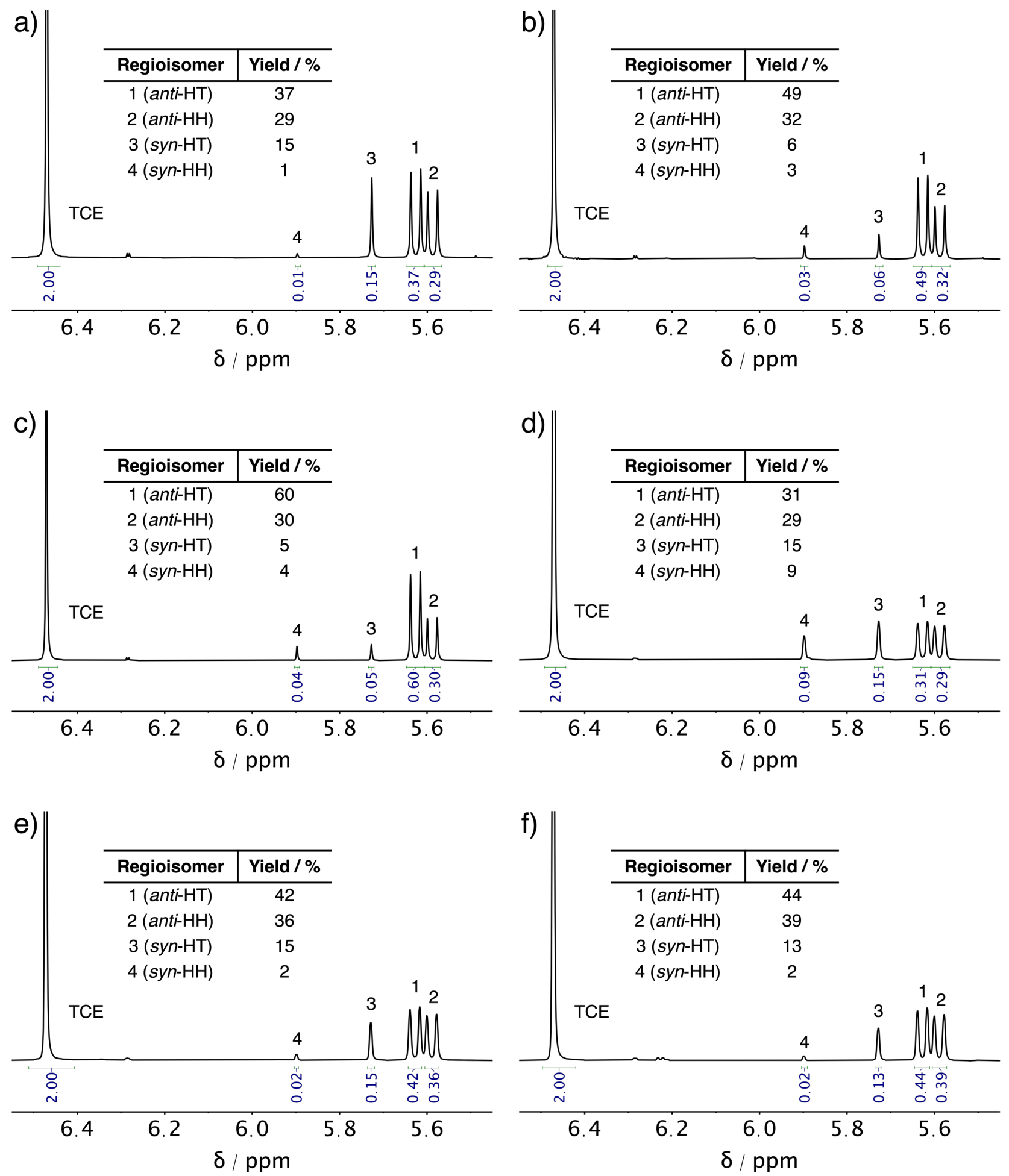

Figure S19. ${ }^{1} \mathrm{H}$ NMR Spectra $\left(500 \mathrm{MHz}, \mathrm{CD}_{3} \mathrm{OD}, 298 \mathrm{~K}\right)$ of the crude products from the photodimerization of $1-\mathrm{AC}^{-}$in solution, revealing the integrated intensity of the signals for protons $\mathbf{a}$ in these regioisomers in relation to the internal standard (1,1,2,2-tetrachloroethane, TCE). Each spectrum is associated with a reaction condition in Table 1 and is assigned as follows: a) entry $1 ; b$ ) entry 2 ; c) entry 3 ; d) entry 4 ; e) entry 5 ; f) entry 6 
a)

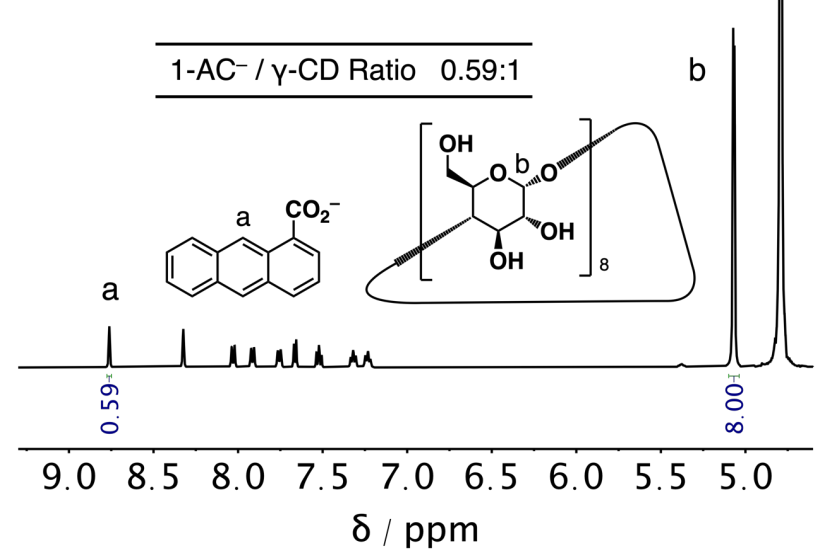

c)

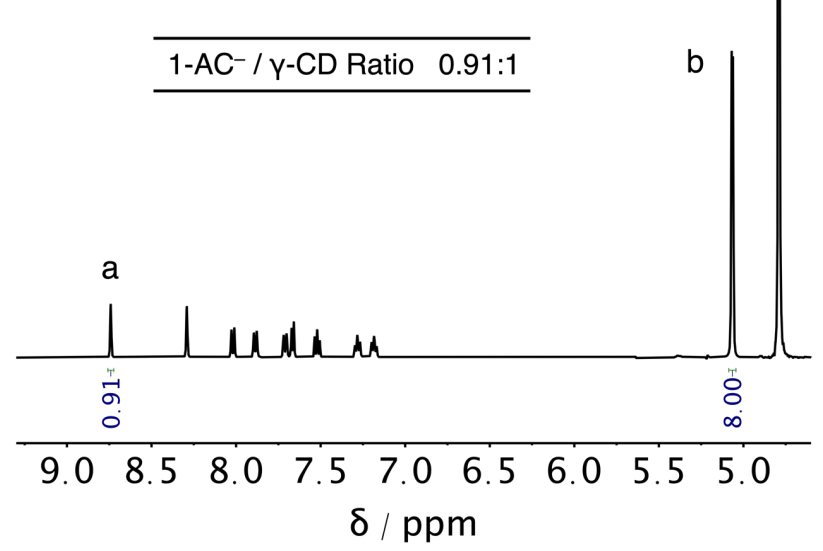

e)

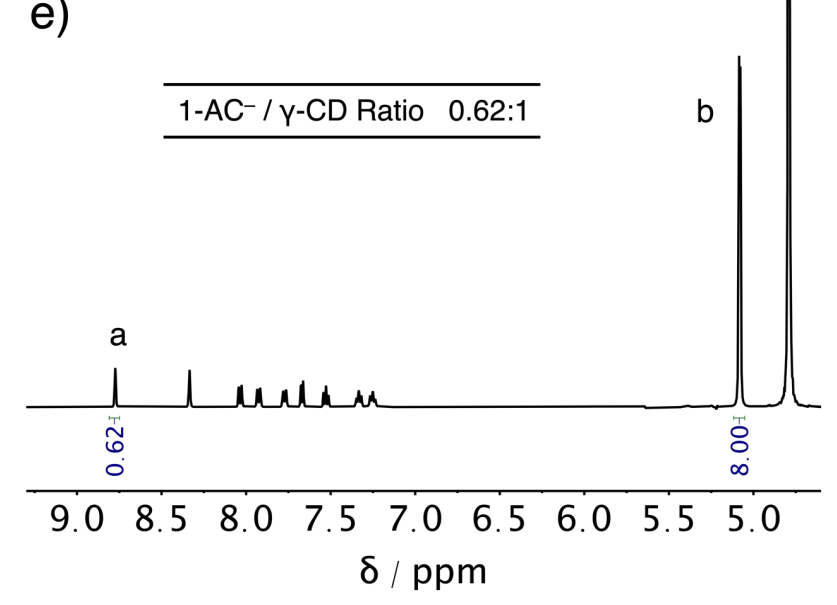

b)

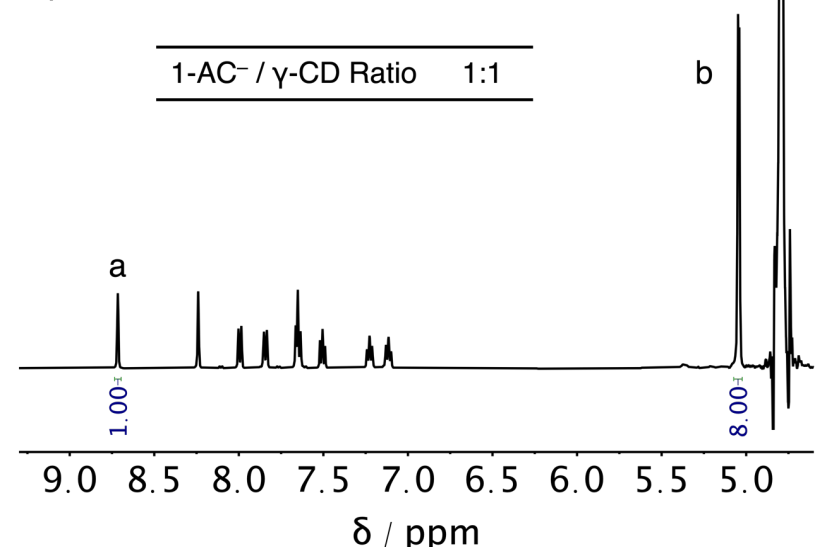

d)

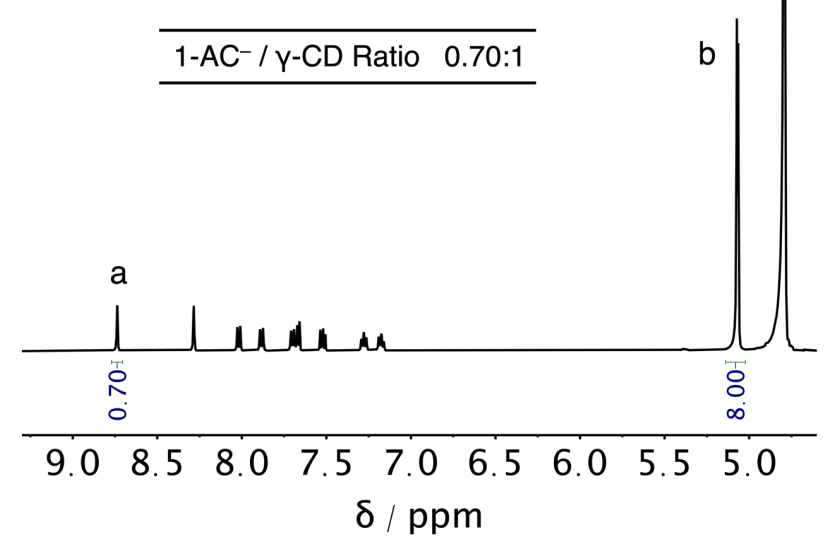

f)

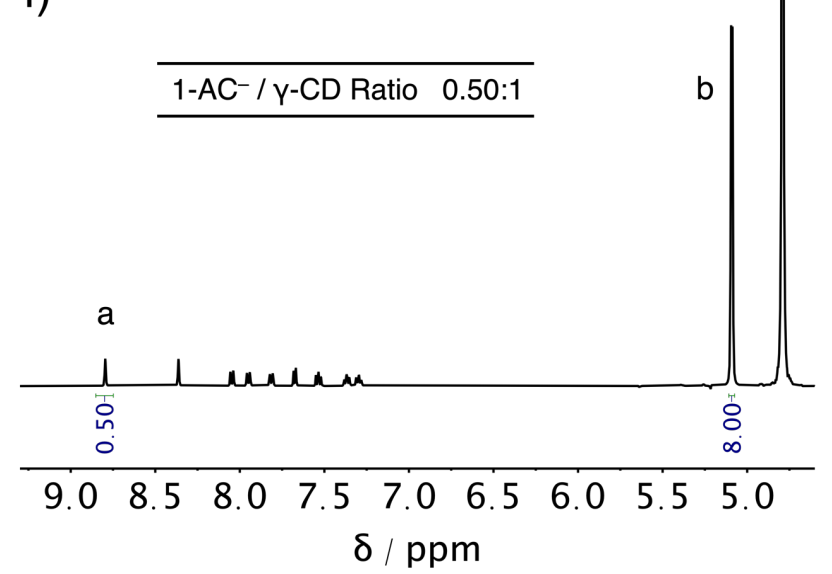

Figure S20. ${ }^{1} \mathrm{H}$ NMR Spectra $\left(500 \mathrm{MHz}, \mathrm{D}_{2} \mathrm{O}, 298 \mathrm{~K}\right)$ of $1-\mathrm{AC}^{-} \subset \mathrm{CD}-\mathrm{MOF}-1$ following their anion exchange, revealing the ratios of $1-\mathrm{AC}^{-} / \gamma-\mathrm{CD}$. Each spectrum is associated with an anion exchange condition in Table 2 and is assigned as follows: a) entry 1, b) entry 2, c) entry 3, d) entry 4 , e) entry $5, \mathrm{f})$ entry 6. 
a)

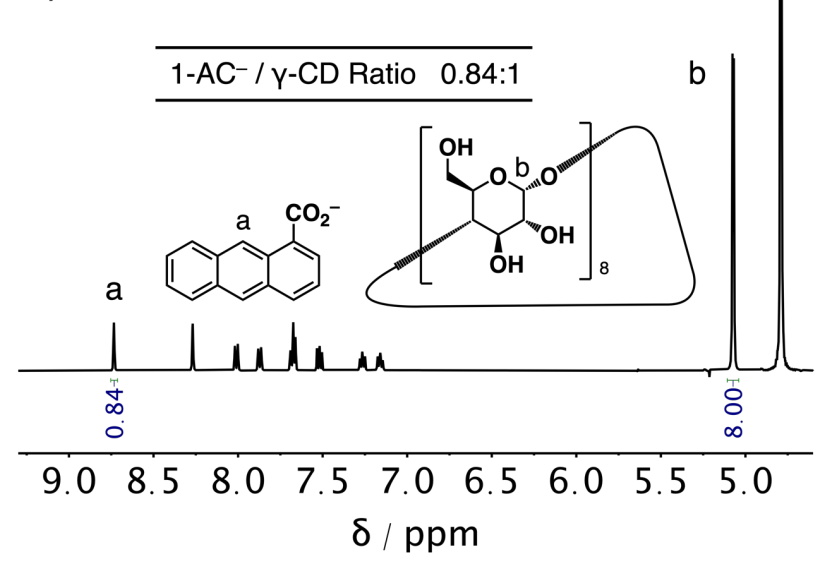

c)

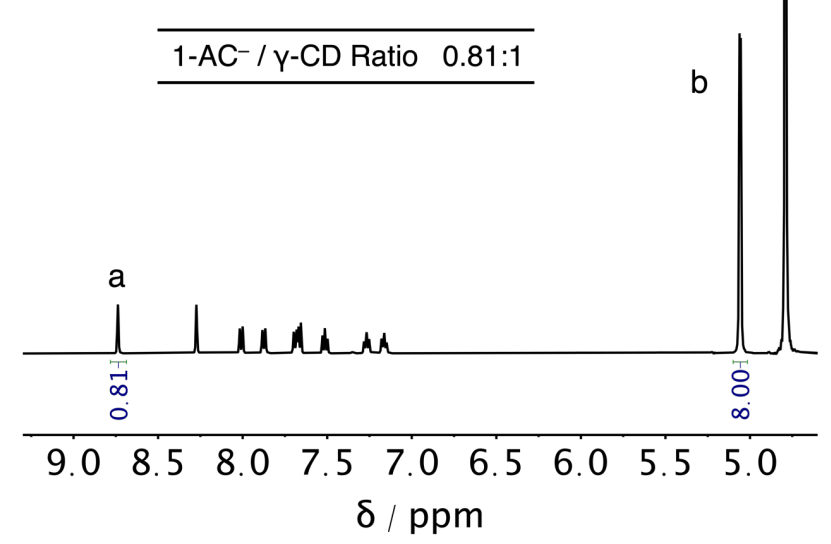

e)

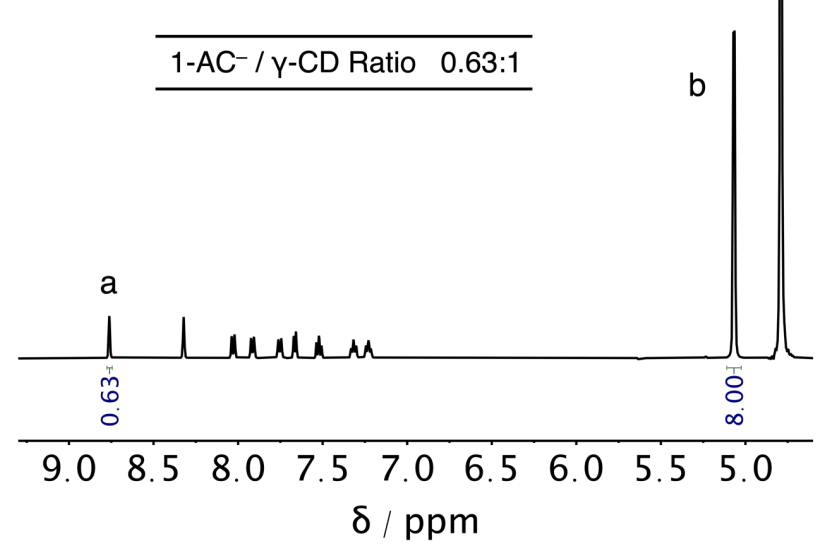

b)

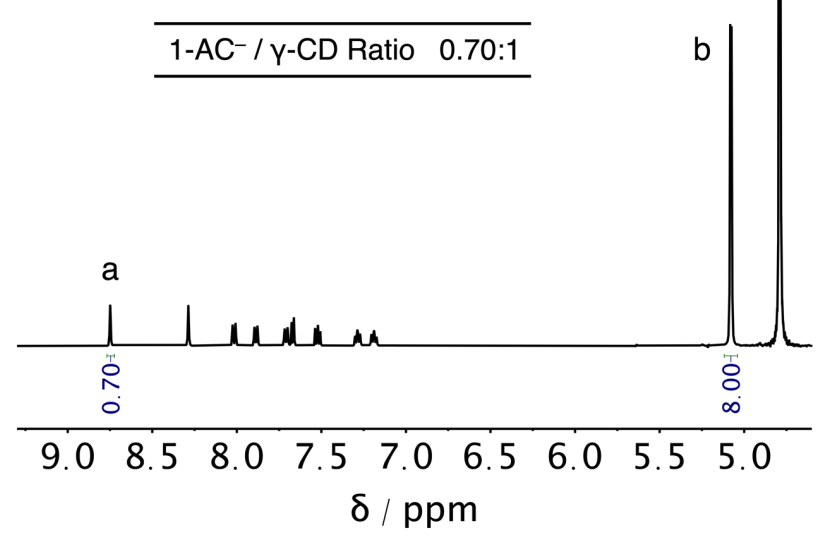

d)

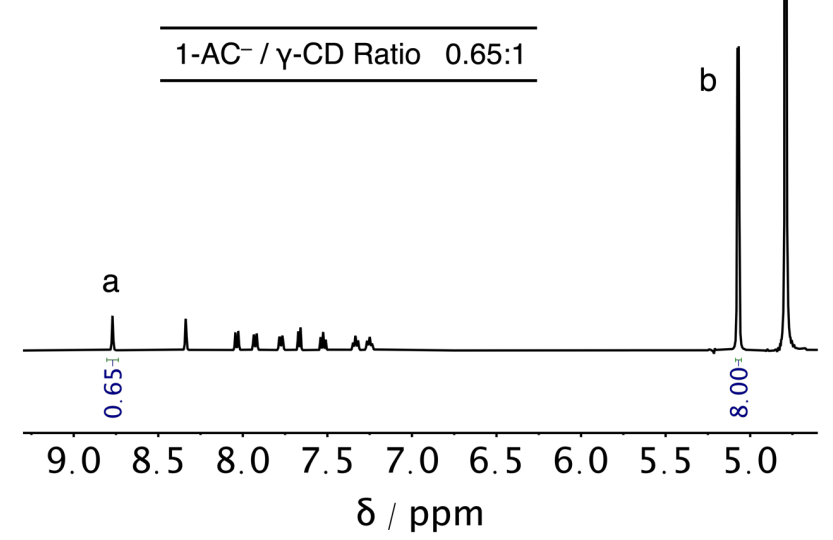

f)

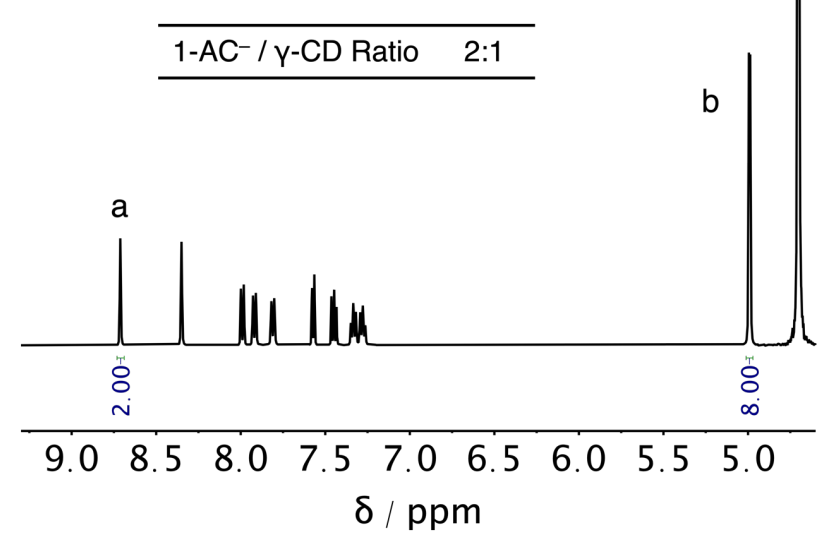

Figure S21. (a-e) ${ }^{1} \mathrm{H}$ NMR Spectra $\left(500 \mathrm{MHz}, \mathrm{D}_{2} \mathrm{O}, 298 \mathrm{~K}\right)$ of $1-\mathrm{AC}^{-} \subset \mathrm{CD}-\mathrm{MOF}$ following their anion exchange, revealing the ratios of $1-\mathrm{AC}^{-} / \gamma-\mathrm{CD}$. Each spectrum is associated with an anion exchange condition in Table S1 or S2 and is assigned as follows: a) Table S1, entry 1, b) Table S1, entry 2, c) Table S2, entry 1, d) Table S2, entry 2, e) Table S2, entry 3. (f) ${ }^{1} \mathrm{H}$ NMR Spectra (500 $\mathrm{MHz}, \mathrm{D}_{2} \mathrm{O}, 298 \mathrm{~K}$ ) of $1-\mathrm{AC}^{-} \subset \mathrm{CD}-\mathrm{HF}$, revealing the ratios of $1-\mathrm{AC}^{-} / \gamma-\mathrm{CD}$. 


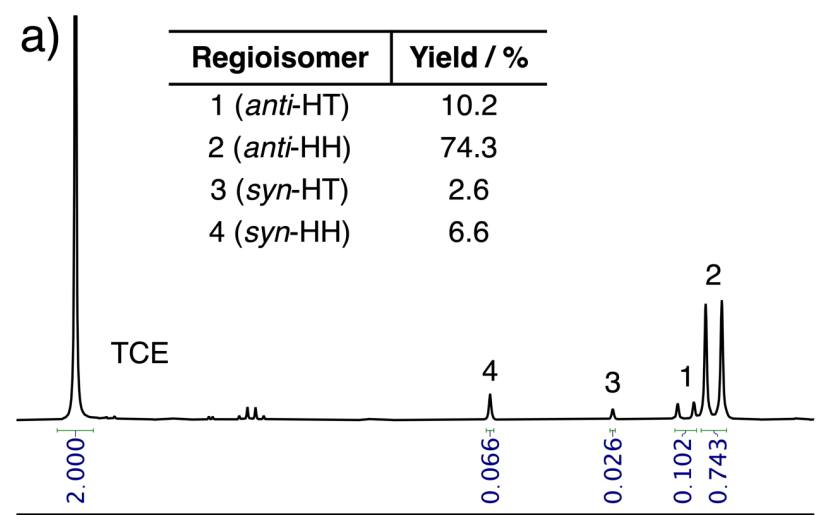

6.56 .46 .36 .26 .16 .05 .95 .85 .75 .65 .5 $\delta / \mathrm{ppm}$
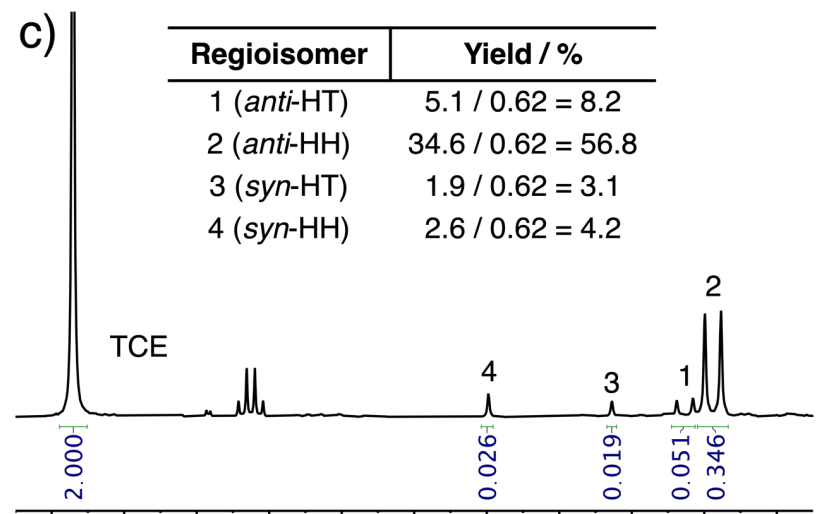

6.56 .46 .36 .26 .16 .05 .95 .85 .75 .65 .5 $\delta / \mathrm{ppm}$
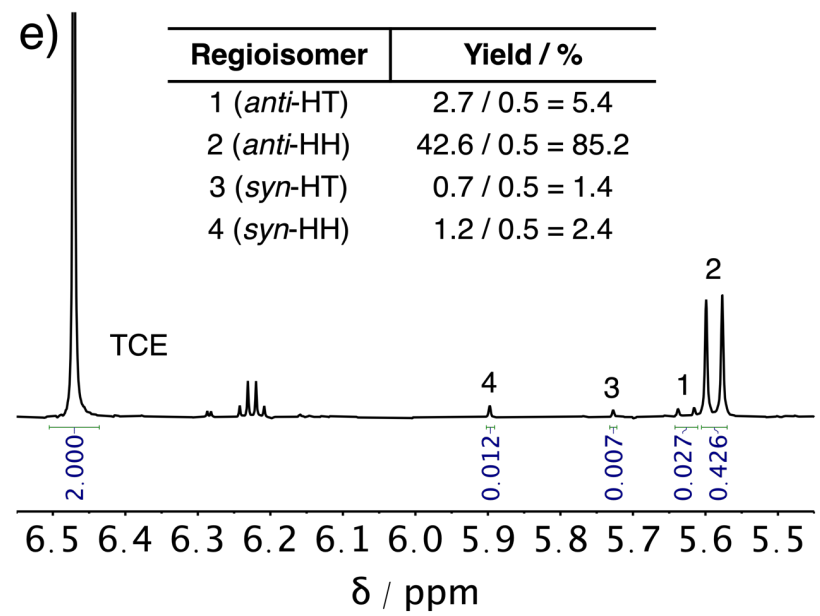
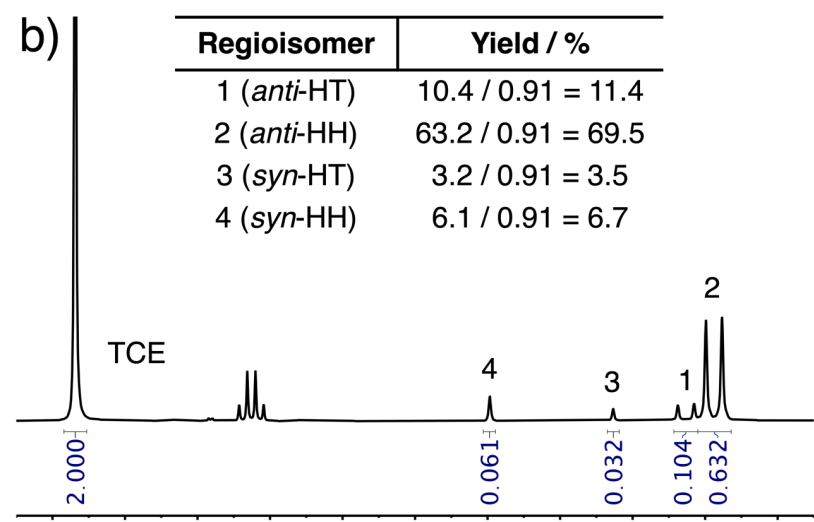

6.56 .46 .36 .26 .16 .05 .95 .85 .75 .65 .5 $\delta / \mathrm{ppm}$

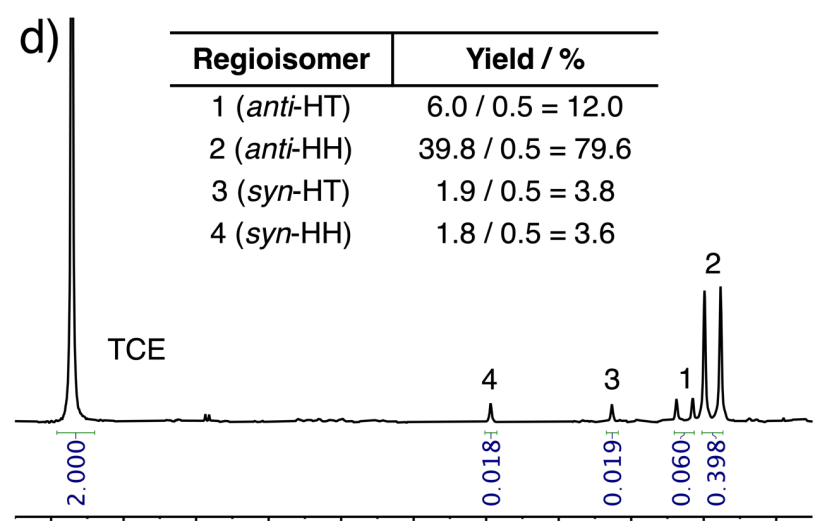

6.56 .46 .36 .26 .16 .05 .95 .85 .75 .65 .5

$\delta / \mathrm{ppm}$

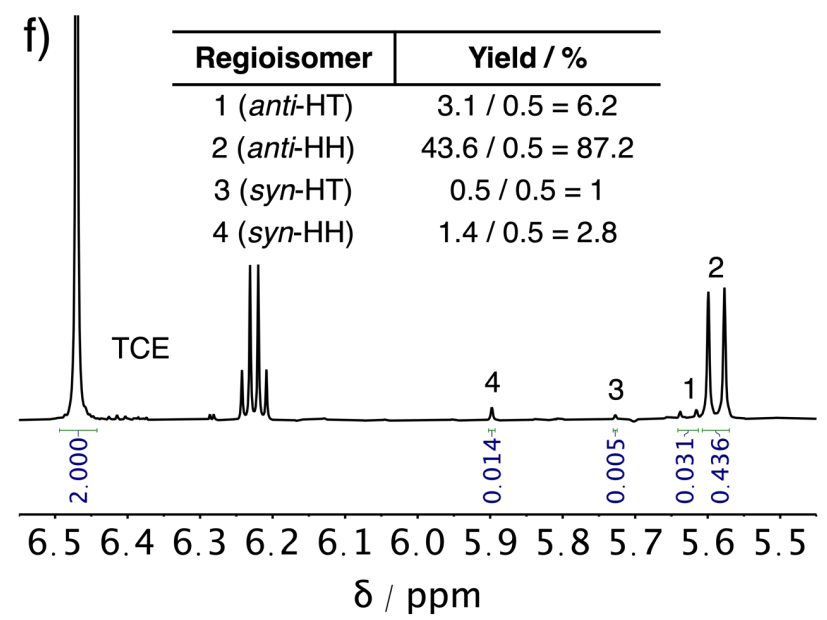

Figure S22. ${ }^{1} \mathrm{H}$ NMR Spectra $\left(500 \mathrm{MHz}, \mathrm{CD}_{3} \mathrm{OD}, 298 \mathrm{~K}\right)$ of the crude products from the photodimerization of $1-\mathrm{AC}^{-} \subset \mathrm{CD}-\mathrm{MOF}-1$, revealing the integrated intensity of the signals for protons $\mathbf{a}$ in these regioisomers in relation to the internal standard (1,1,2,2-tetrachloroethane, TCE). Each spectrum is associated with a reaction condition in Table 3 and is assigned as follows: a) entry $1, \mathrm{~b}$ ) entry 2, c) entry 3,d) entry 4, e) entry 5, f) entry 6. 


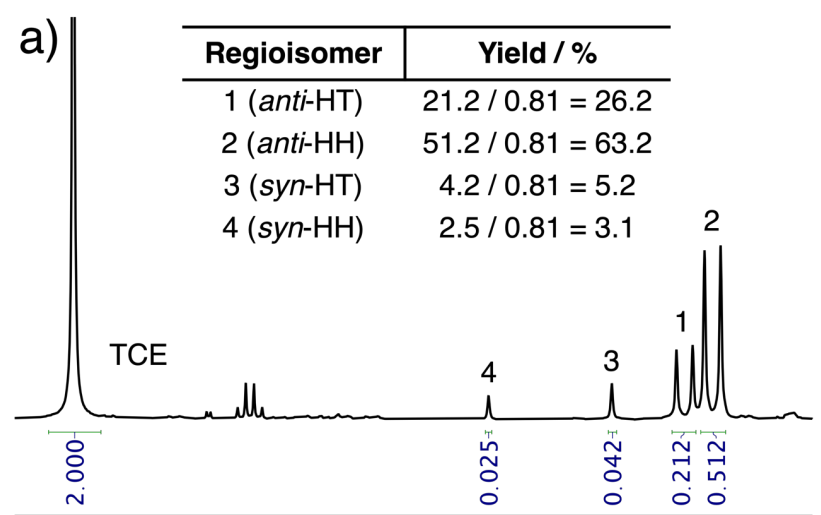

6.56 .46 .36 .26 .16 .05 .95 .85 .75 .65 .5

$\delta / \mathrm{ppm}$

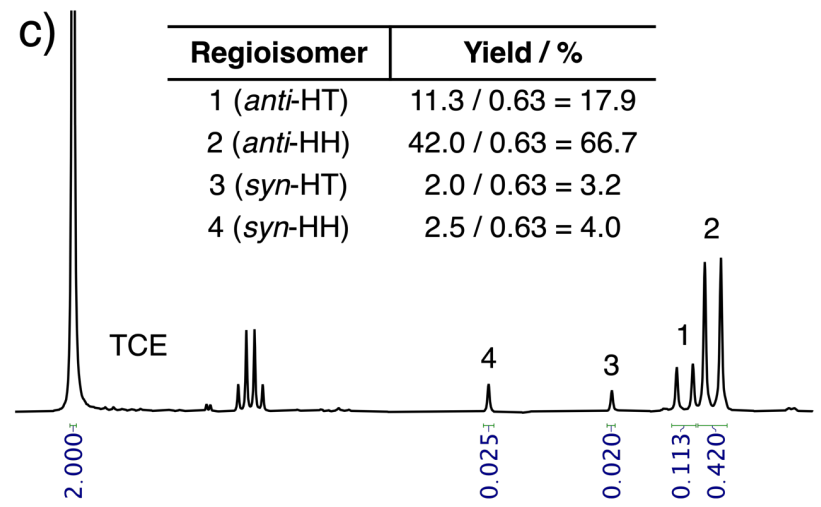

6.56 .46 .36 .26 .16 .05 .95 .85 .75 .65 .5

$\delta / \mathrm{ppm}$

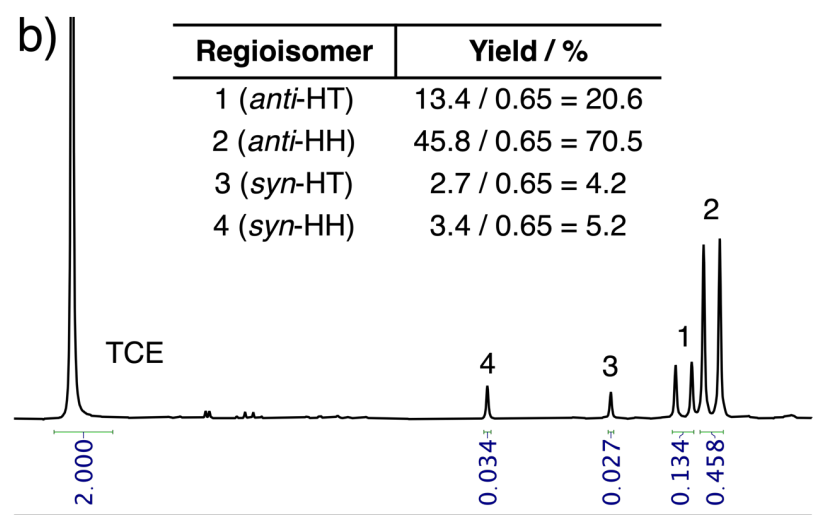

6.56 .46 .36 .26 .16 .05 .95 .85 .75 .65 .5

$\delta / \mathrm{ppm}$

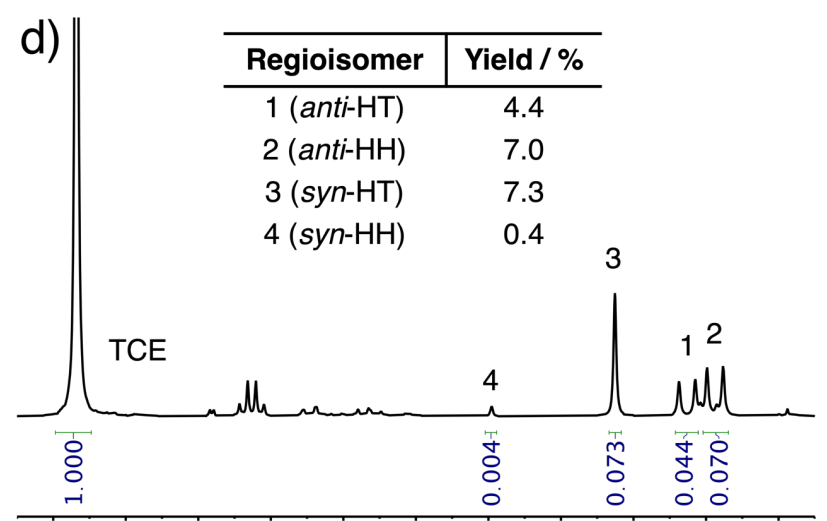

6.56 .46 .36 .26 .16 .05 .95 .85 .75 .65 .5

$\delta / \mathrm{ppm}$

Figure S23. (a-c) ${ }^{1} \mathrm{H}$ NMR Spectra $\left(500 \mathrm{MHz}, \mathrm{CD}_{3} \mathrm{OD}, 298 \mathrm{~K}\right)$ of the crude products from the photodimerization of $1-\mathrm{AC}^{-} \subset \mathrm{CD}-\mathrm{MOF}-2$, revealing the integrated intensity of the signals for protons $\mathbf{a}$ in these regioisomers in relation to the internal standard (1,1,2,2-tetrachloroethane, TCE). Each spectrum is associated with a reaction condition in Table $\mathbf{S 3}$ and is assigned as follows: a) entry 1, b) entry 2, c) entry 3. (d) ${ }^{1} \mathrm{H}$ NMR Spectra $\left(500 \mathrm{MHz}, \mathrm{CD}_{3} \mathrm{OD}, 298 \mathrm{~K}\right)$ of the crude products from the photodimerization of $1-\mathrm{AC}^{-} \subset \mathrm{CD}-\mathrm{HF}$, revealing the integrated intensity of the signals for protons $\mathbf{a}$ in these regioisomers in relation to the internal standard (1,1,2,2-tetrachloroethane, TCE). 


\section{Binding Studies by NMR Titration}

A solution of 1-ACK in $\mathrm{D}_{2} \mathrm{O}(0.5 \mathrm{M})$ was titrated into a solution of $\gamma-\mathrm{CD}$ in $\mathrm{D}_{2} \mathrm{O}(0.01 \mathrm{M}, 0.5 \mathrm{~mL})$. The ${ }^{1} \mathrm{H}$ chemical shifts of $\gamma$-CD were recorded by ${ }^{1} \mathrm{H}$ NMR spectroscopy at room temperature.

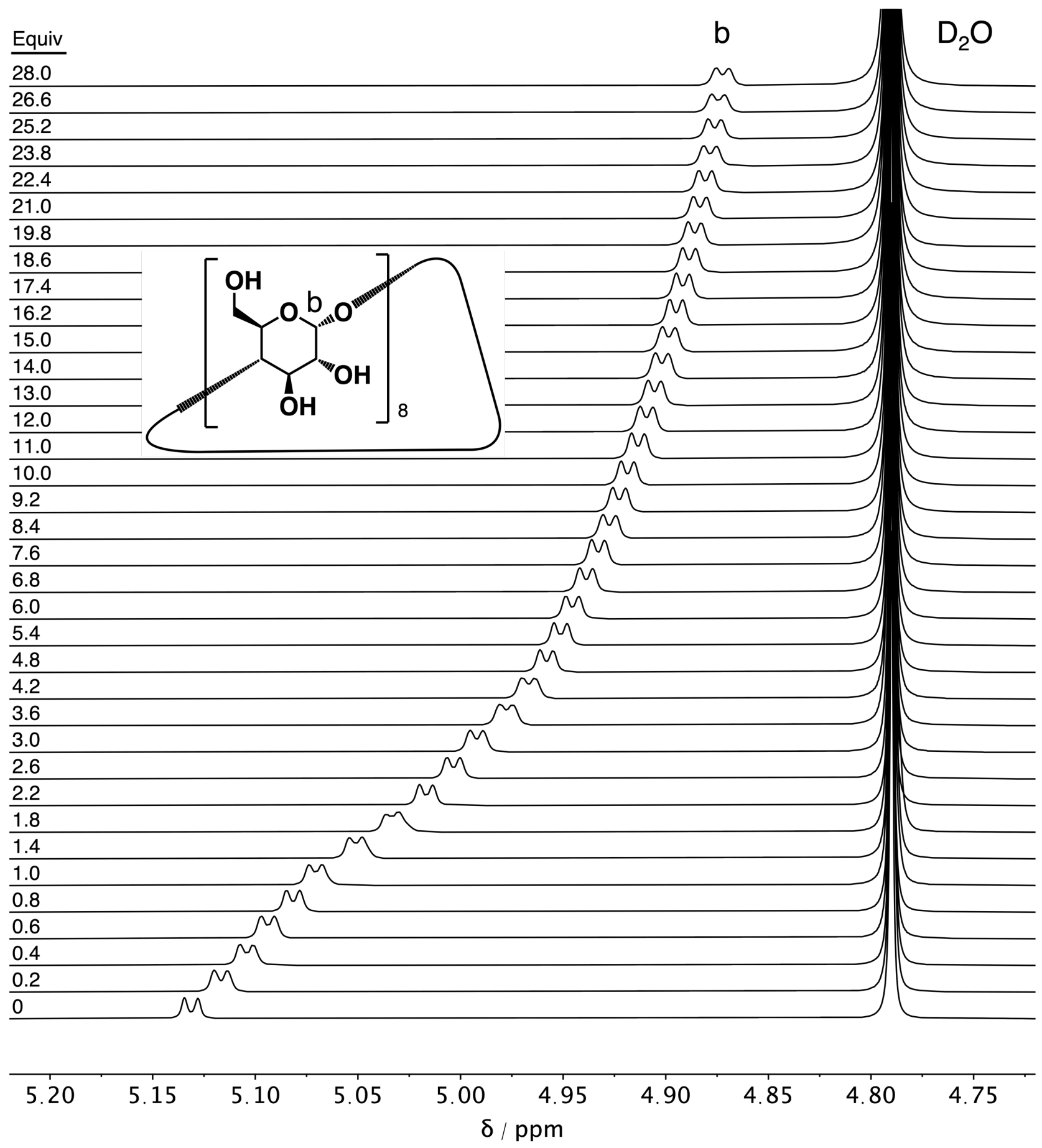

Figure S24. ${ }^{1} \mathrm{H}$ NMR Titration $\left(500 \mathrm{MHz}, \mathrm{D}_{2} \mathrm{O}, 298 \mathrm{~K}\right)$ of $\gamma$-CD upon addition of different equivalents of $1-\mathrm{ACK}([\gamma-\mathrm{CD}]=0.01 \mathrm{M},[1-\mathrm{ACK}] /[\gamma-\mathrm{CD}]=0-28)$. 
a)

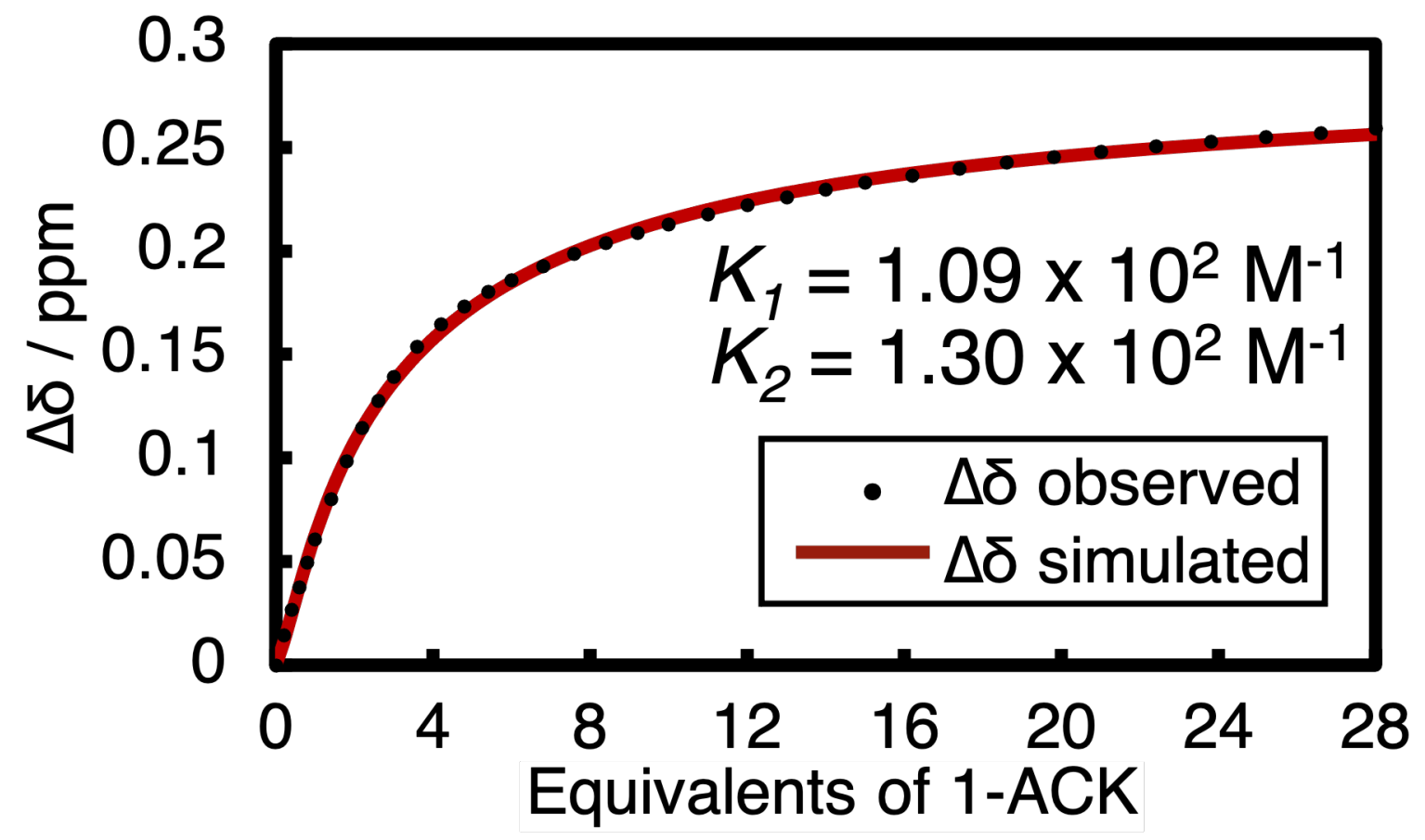

b)

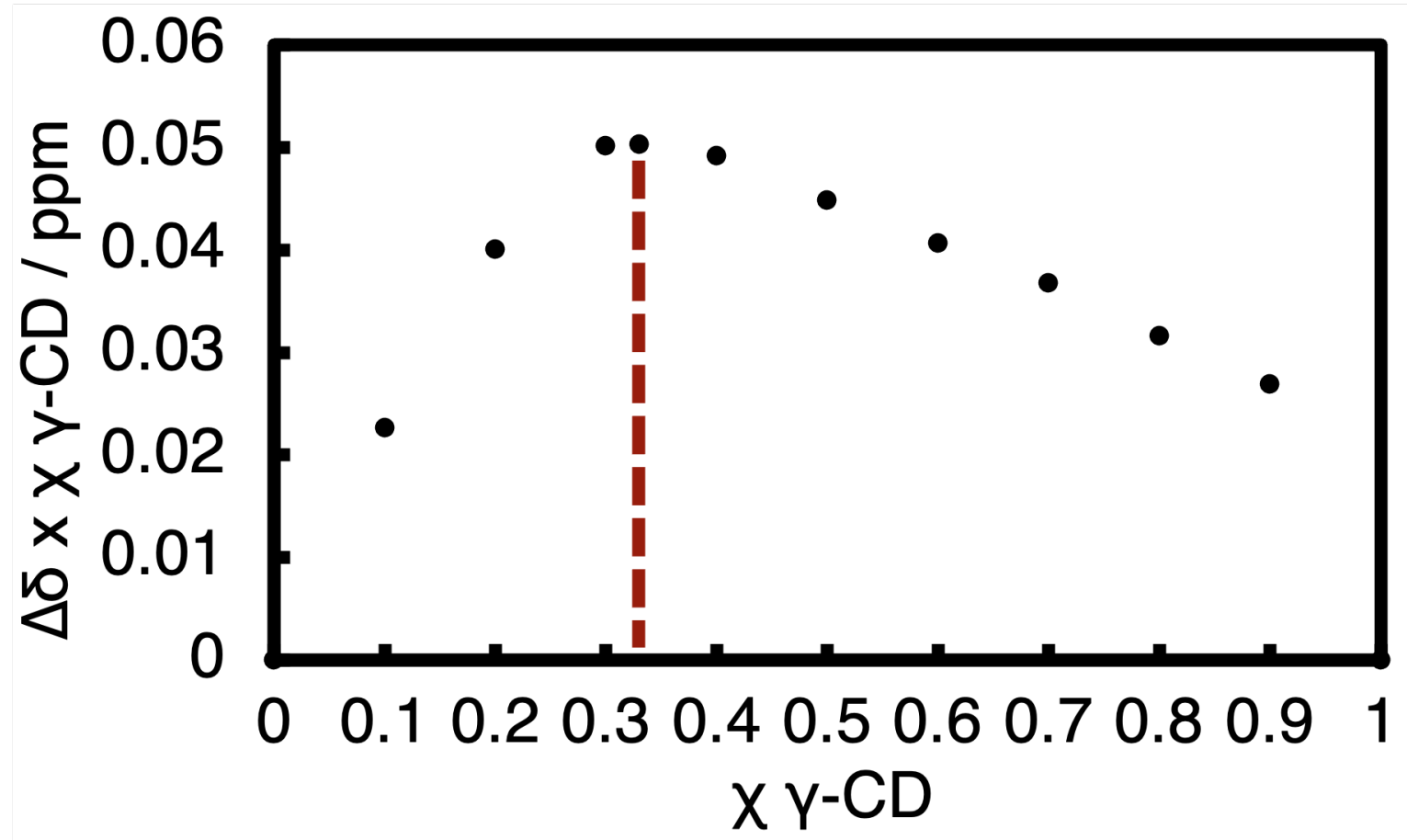

Figure S25. (a) Observed and calculated binding curves for ${ }^{1} \mathrm{H}$ NMR spectra signal of the acetal proton in $\gamma$-CD; (b) Job-plot analysis of the binding ratio between $\gamma$-CD and 1-ACK. 


\section{High-Performance Liquid Chromatography}
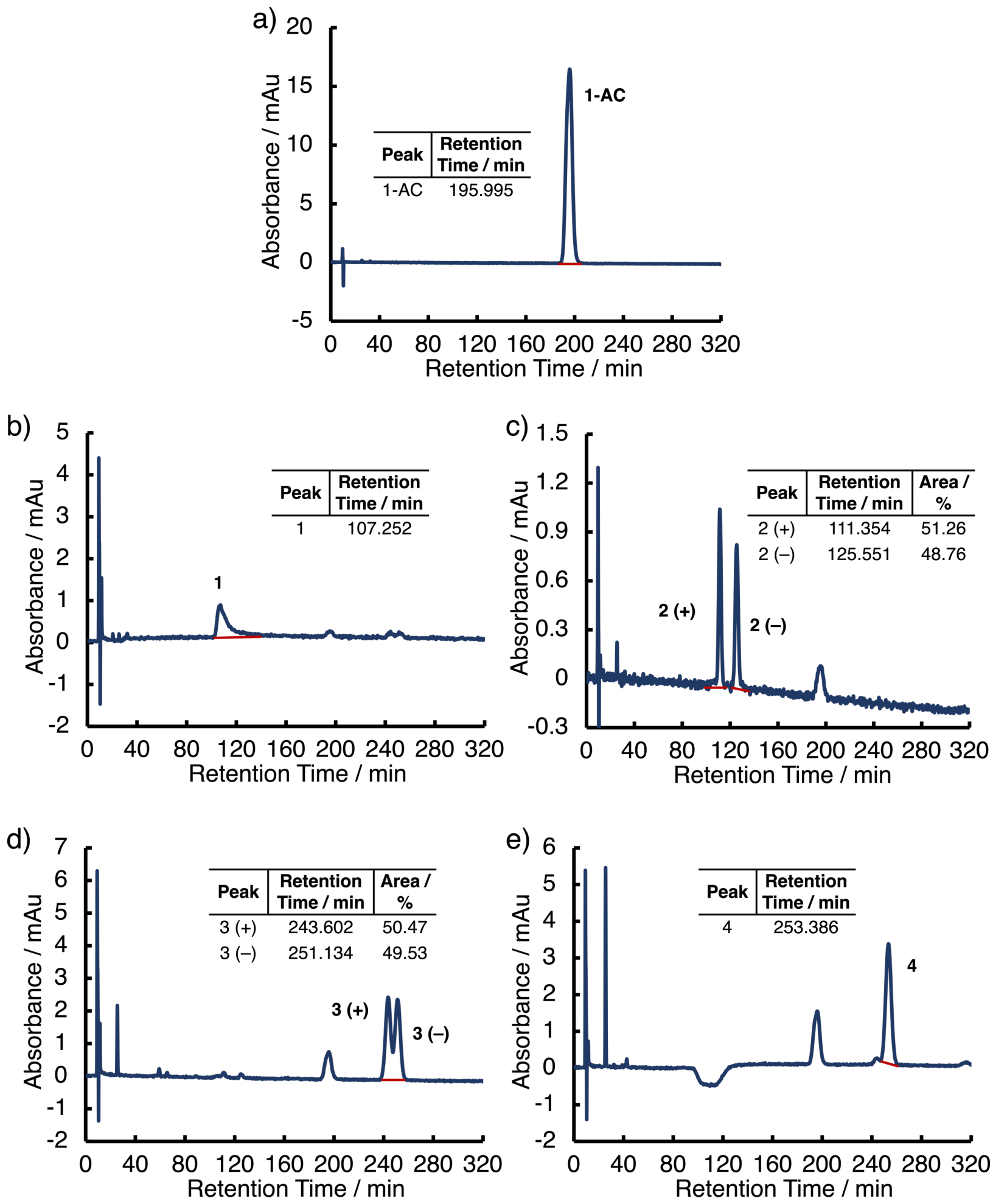

Figure S26. Tandem chiral HPLC chromatograms of the reference compounds (a) 1-AC, (b) anti-HT / 1, (c) anti-HH / ( \pm )-2, (d) syn-HT / ( \pm )-3 and (e) syn-HH / 4, revealing their individual retention time. 

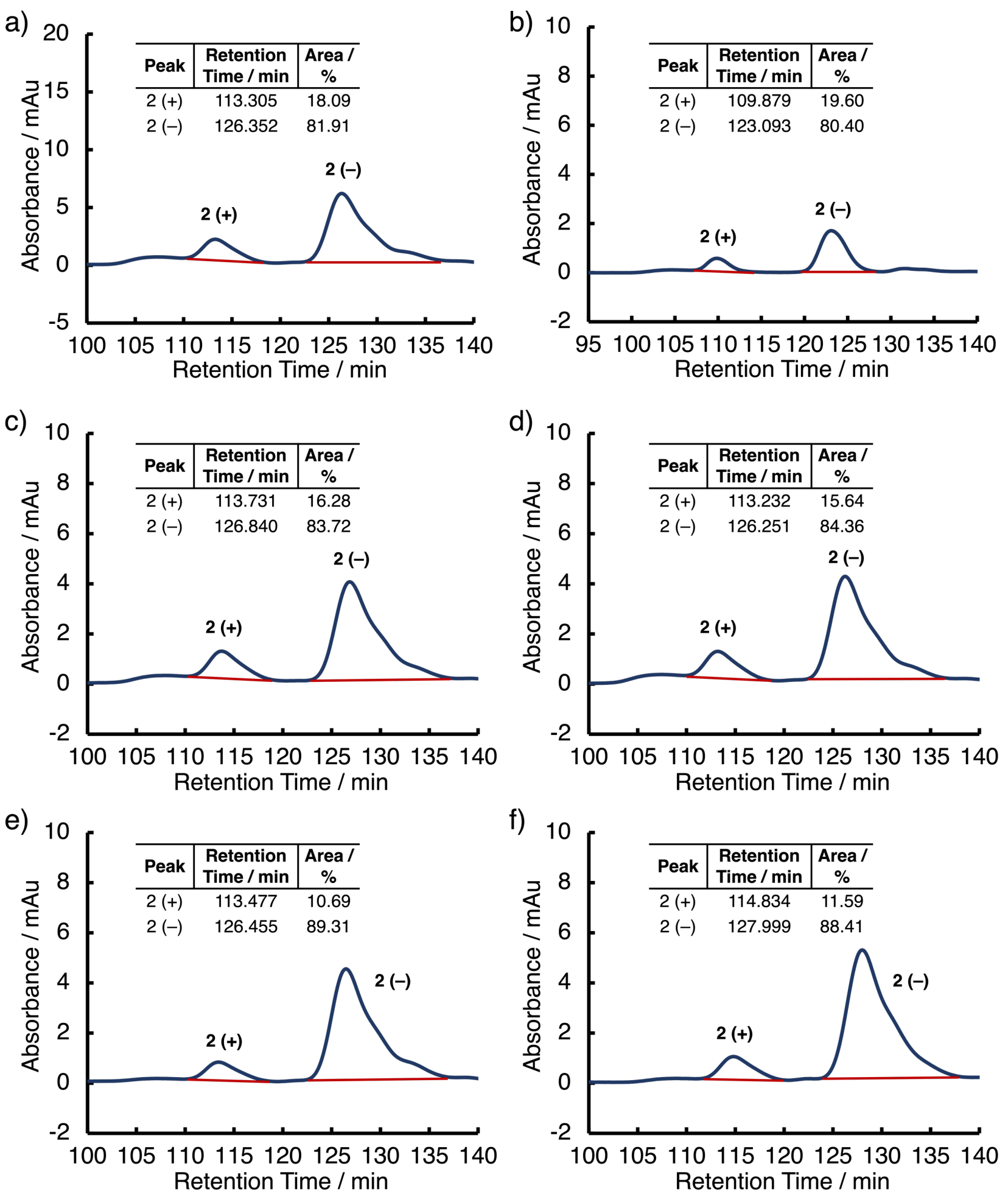

Figure S27. Tandem chiral HPLC chromatograms of anti-HH / ( \pm )-2 from the photodimerization of $1-\mathrm{AC}^{-} \subset \mathrm{CD}-\mathrm{MOF}-1$, revealing the relative abundance of the two enantiomers. Each chromatogram is associated with a reaction condition in Table 3 and is assigned as follows: a) entry 1, b) entry 2, c) entry 3, d) entry 4, e) entry 5 , f) entry 6 . 

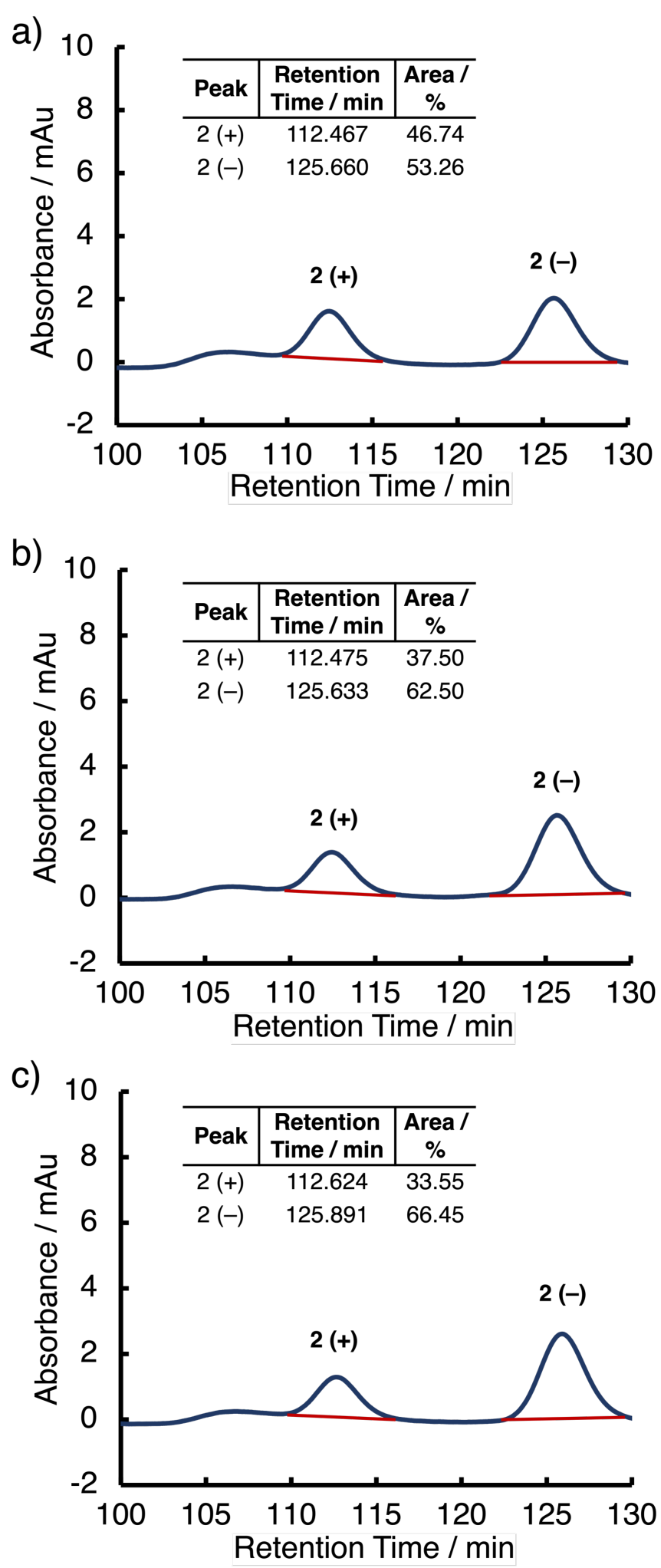

Figure S28. Tandem chiral HPLC chromatograms of anti-HH / $( \pm)-2$ from the photodimerization of 1-AC $\mathrm{C}^{-} \subset \mathrm{CD}-\mathrm{MOF}-2$, revealing the relative abundance of the two enantiomers. Each chromatogram is associated with a reaction condition in Table $\mathbf{S 3}$ and is assigned as follows: a) entry 1, b) entry 2 , c) entry 3 . 


\section{Optical Microscope Images}

a)

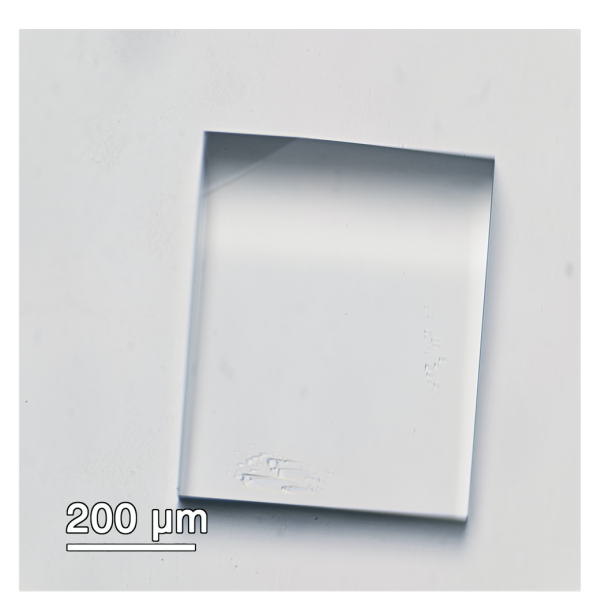

c)

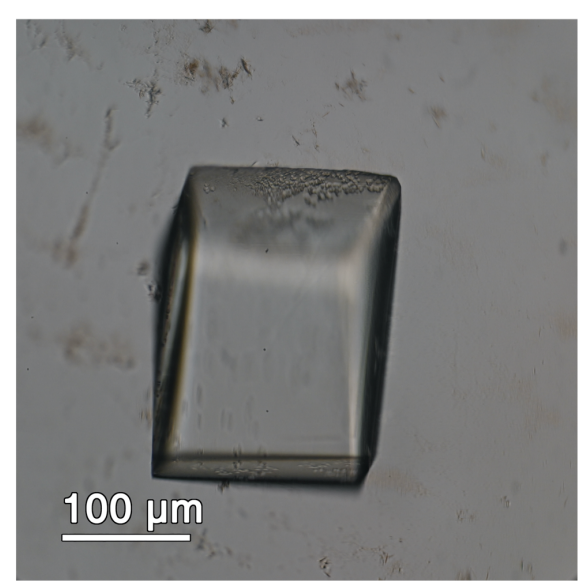

e)

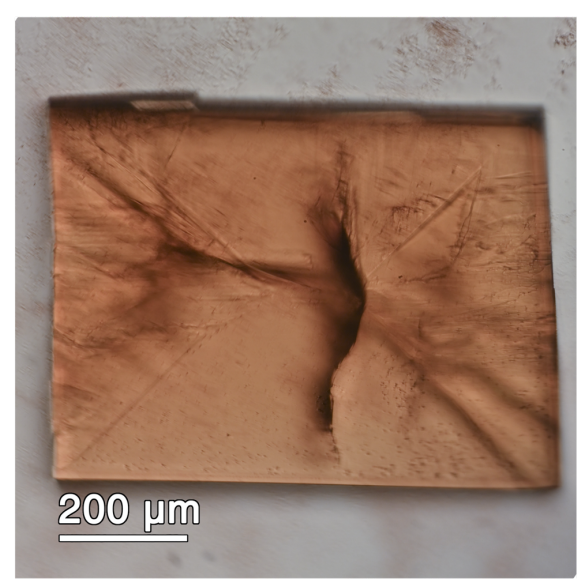

b)

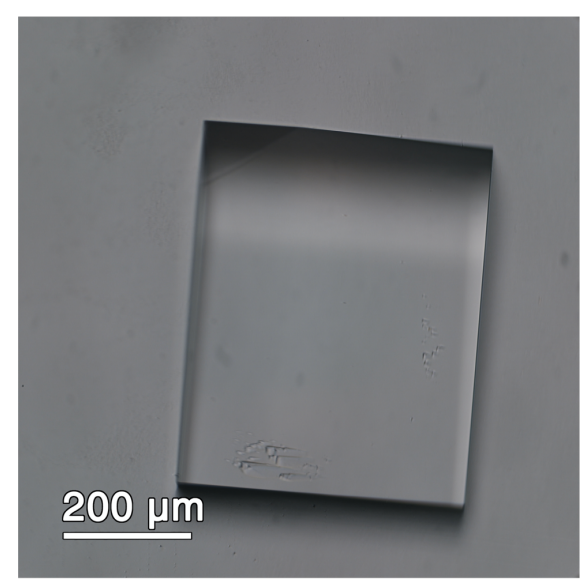

d)

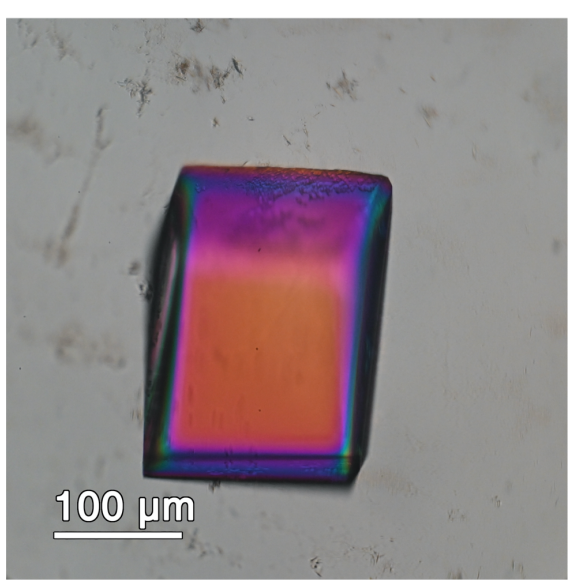

f)

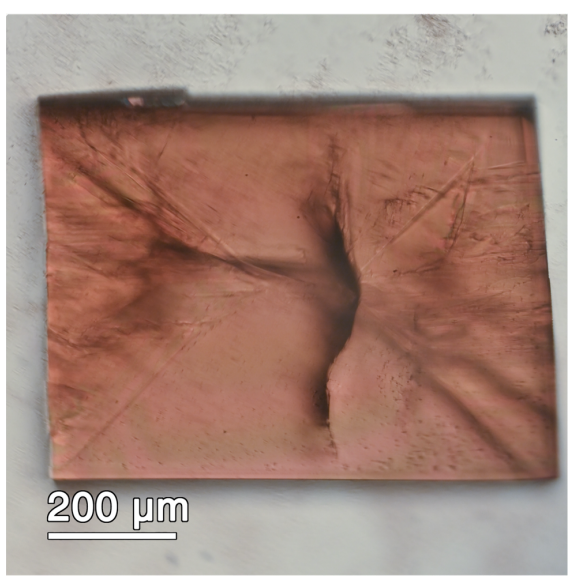

Figure S29. Optical microscope images of (a) CD-MOF-1 without a polarizing filter, (b) CD-MOF1 with a polarizing filter, (c) $1-\mathrm{AC}^{-} \subset \mathrm{CD}-\mathrm{MOF}-1$ without a polarizing filter, (d) $1-\mathrm{AC}^{-} \subset \mathrm{CD}-\mathrm{MOF}-$ 1 with a polarizing filter, (e) $1-\mathrm{AC}^{-} \subset \mathrm{CD}-\mathrm{HF}$ without a polarizing filter and (f) $1-\mathrm{AC}^{-} \subset \mathrm{CD}-\mathrm{HF}$ with a polarizing filter. 


\section{X-ray Crystallography}

\section{1-AC ${ }^{-} \subset$ CD-HF (CCDC 2073804)}

The crystal was mounted on a MITIGEN holder with Paratone oil on a XtaLAB Synergy, Single source at home/near, HyPix diffractometer. The crystal was kept at 100.02(10) K during data collection. Using Olex $2^{2}$, the structure was solved with the ShelXT${ }^{3}$ structure solution program using Intrinsic Phasing and refined with the $\mathrm{XL}^{4}$ refinement package using Least Squares minimization.

\section{Crystal structure determination of $1-\mathrm{AC}^{-} \subset \mathrm{CD}-\mathrm{HF}$}

Crystal Data for $\mathrm{C}_{174} \mathrm{H}_{270} \mathrm{~K}_{5.5} \mathrm{O}_{130}(M=4656.93)$ : tetragonal, space group $P 4_{12}{ }_{12}$ (no. 92), $a=$ 30.69960(10), $c=63.4201(2) \AA, \alpha=90, \beta=90, \gamma=90^{\circ}, V=59771.3(4) \AA^{3}, Z=8, T=100.02(10) \mathrm{K}$, $\mu(\mathrm{CuK \alpha})=1.433 \mathrm{~mm}^{-1}$, Dcalc $=1.035 \mathrm{~g} / \mathrm{mm}^{3}, 387365$ reflections measured $(4.006 \leq 2 \Theta \leq 153.908)$, 61717 unique $\left(R_{\text {int }}=0.0653, R_{\text {sigma }}=0.0323\right)$ which were used in all calculations. The final $R_{1}$ was $0.0566(I>2 \sigma(I))$ and $w R_{2}$ was 0.1598 (all data).

Refinement Details. Distance restraints were imposed on the disordered atoms. The enhanced rigidbond restraint (SHELX keyword RIGU) was applied ${ }^{5}$ as well as restraints on similar amplitudes separated by less than 1.7 Ang. on the disordered atoms.

Solvent Treatment Details. The solvent masking procedure as implemented in Olex2 was used to remove the electronic contribution of solvent molecules from the refinement. As the exact solvent content is not known, only the atoms used in the refinement model are reported in the formula here. Total solvent accessible volume $/$ cell $=23565.3 \AA^{3}[39.4 \%]$ Total electron count $/$ cell $=7230.9$ 
a)

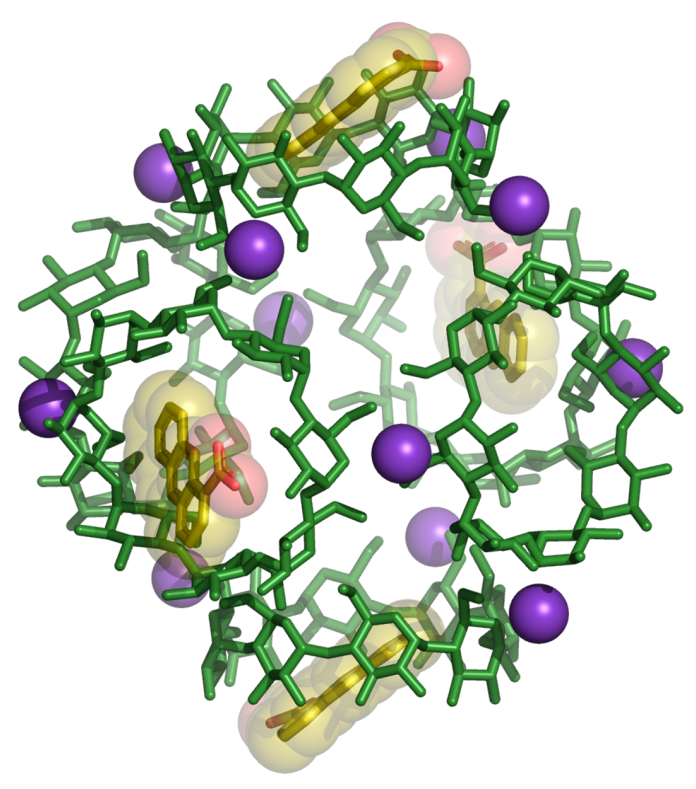

c)

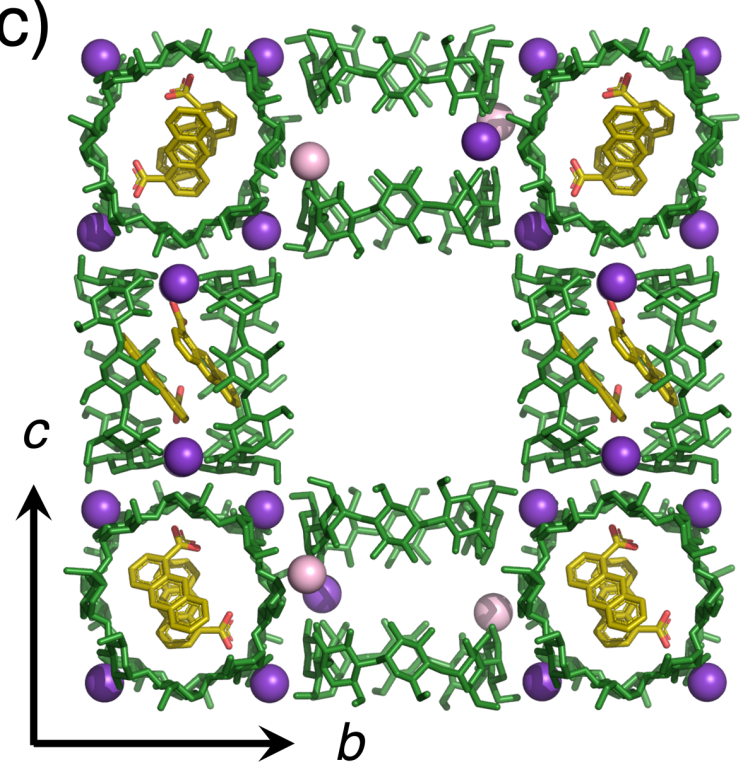

b)
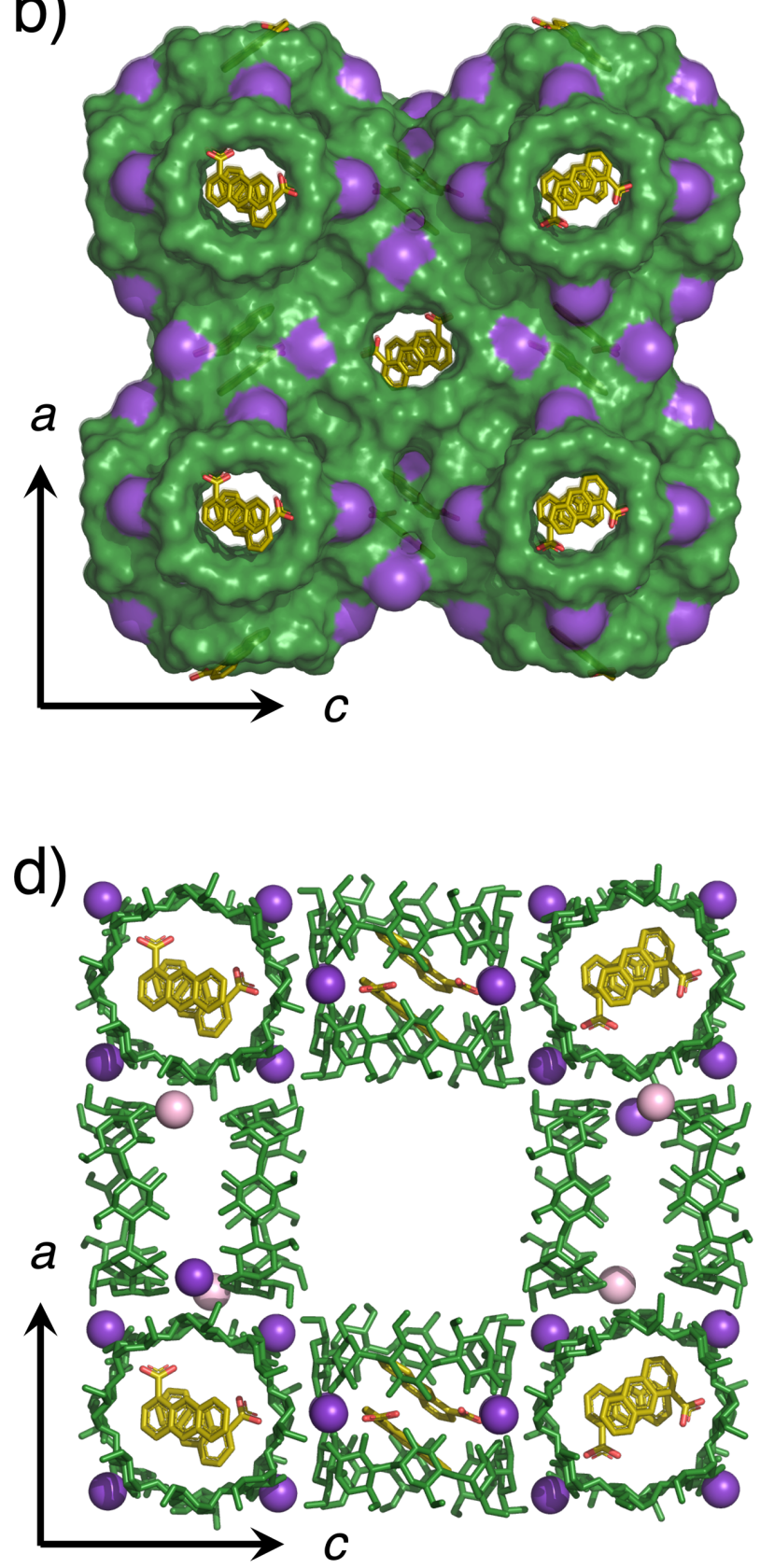

Figure S30. (a) Tubular representation of the solid-state superstructure of the cubic $(\gamma-C D)_{6}$ units of 1-AC ${ }^{-} \subset \mathrm{CD}-H F$. (b) Space-filling representation of the extended body-centered cubic packing of 1$\mathrm{AC}^{-} \subset \mathrm{CD}-\mathrm{HF}$ viewed along the $b$-axis, with $\gamma$-CD, $1-\mathrm{AC}^{-}$and $\mathrm{K}^{+}$ions represented in green, yellow and purple, respectively. (c-d) Tubular representations of the slice through the solid-state superstructure of $1-\mathrm{AC}^{-} \subset \mathrm{CD}$-HF viewed along the (c) $a$ - and (d) $b$-axis, showing a single layer of $(\gamma-\mathrm{CD})_{2}$ tunnels. The $\gamma-\mathrm{CD}$ tori are colored green, the $1-\mathrm{AC}^{-}$anions yellow, and the $\mathrm{K}^{+}$ions purple or light-pink. 


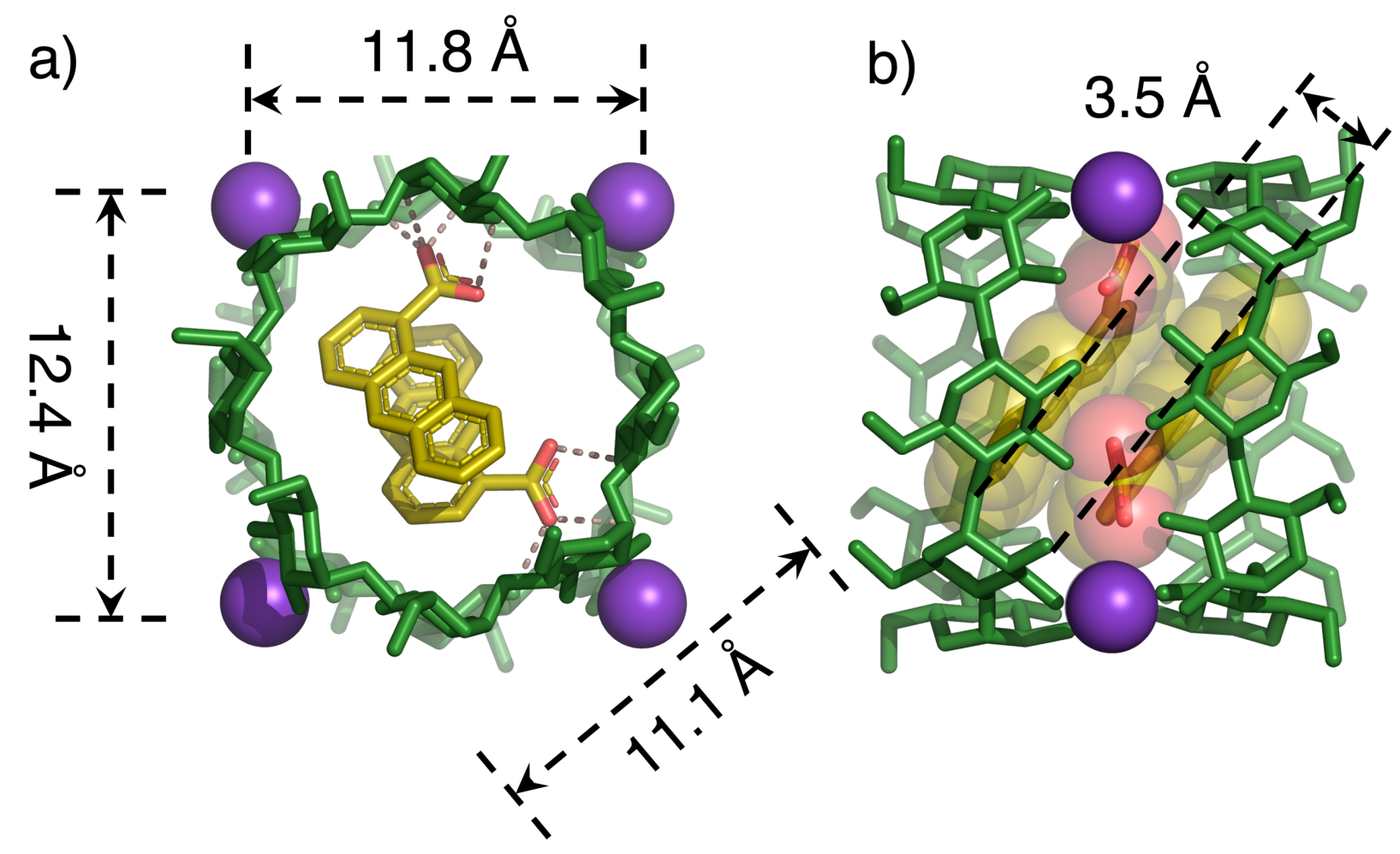

c)

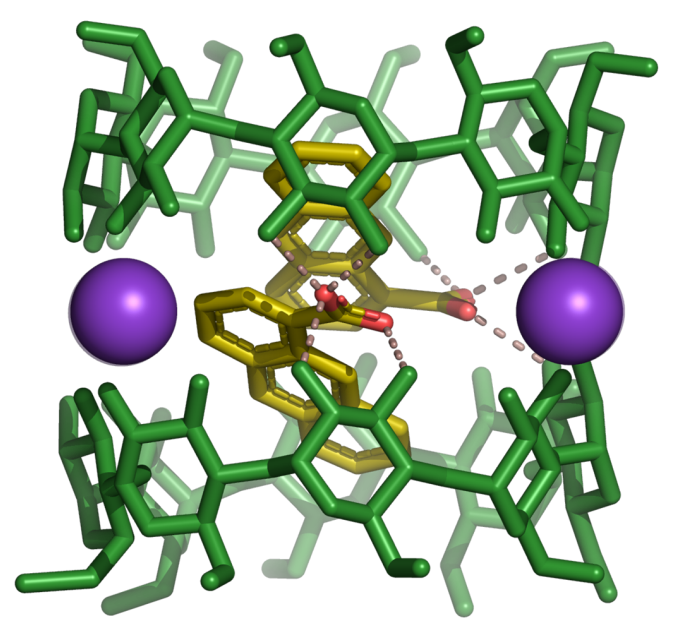

d)

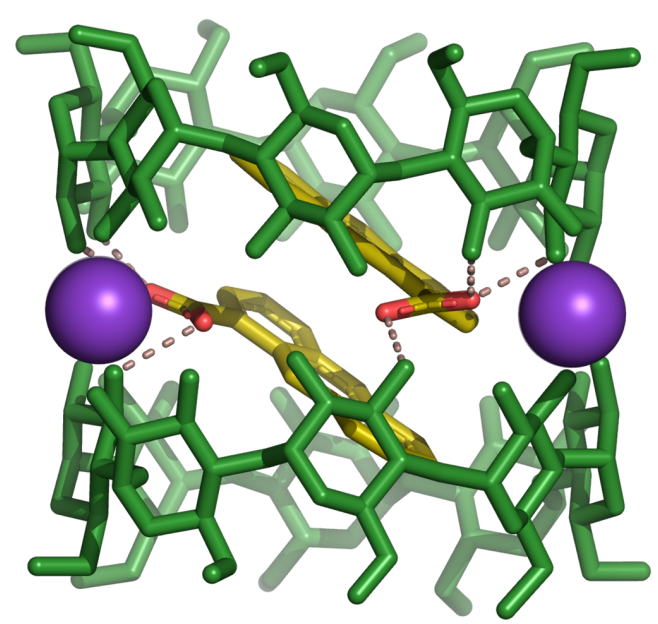

Figure S31. Stick representation of the solid-state superstructure of the $(\gamma-\mathrm{CD})_{2}$ tunnels aligned parallel to the $b$-axis in 1-AC ${ }^{-} \subset \mathrm{CD}-\mathrm{HF}$, (a, c, d) with hydrogen bonds illustrated by light-purple dashes and distortion of the $\gamma$-CD tori illustrated by their unusual diagonal distances, highlighting the contribution of intermolecular forces, and (b) with two $1-\mathrm{AC}^{-}$anions represented in superimposed space-filling mode, showing a pairing distance of $3.5 \AA$ commensurate with $[\pi \cdots \pi]$ stacking. 
1-AC ${ }^{-} \subset$ CD-MOF-1 (CCDC 2073805)

Single crystals, suitable for X-ray crystallography, were obtained by soaking CD-MOF-1 crystals in a $\mathrm{MeOH} / \mathrm{H}_{2} \mathrm{O}(3: 1, v / v)$ solution of $1-\mathrm{ACK}(0.2 \mathrm{M})$ at RT for $14 \mathrm{~d}$. The crystal was mounted on a MITIGEN holder with Paratone oil on a XtaLAB Synergy R, DW system, HyPix diffractometer. The crystal was kept at $100.02(11) \mathrm{K}$ during data collection. Using Olex $2^{2}$, the structure was solved with the $\mathrm{XS}^{6}$ structure solution program using Direct Methods and refined with the $\mathrm{XL}^{4}$ refinement package using Least Squares minimization.

\section{Crystal structure determination of 1-AC ${ }^{-} \subset \mathrm{CD}-\mathrm{MOF}-1$}

Crystal Data for $\mathrm{C}_{96} \mathrm{H}_{160} \mathrm{~K}_{4.25} \mathrm{O}_{81}(M=2776.41)$ : trigonal, space group $R 32$ (no. 155), $a=$ 43.0393(4), $c=56.0212(5) \AA, \alpha=90, \beta=90, \gamma=120^{\circ}, V=89869.5(17) \AA^{3}, Z=18, T=$ 100.02(11) K, $\mu(\mathrm{CuK \alpha})=1.468 \mathrm{~mm}^{-1}$, Dcalc $=0.923 \mathrm{~g} / \mathrm{mm}^{3}, 228266$ reflections measured $(3.946 \leq$ $2 \Theta \leq 141.872), 38059$ unique $\left(R_{\text {int }}=0.0627, R_{\text {sigma }}=0.0363\right)$ which were used in all calculations. The final $R_{1}$ was $0.1175(I>2 \sigma(I))$ and $w R_{2}$ was 0.3138 (all data).

Refinement Details. Distance restraints were imposed on the disordered atoms. Restraints on similar amplitudes separated by less than $1.7 \AA$ on the disordered atoms. The enhanced rigid-bond restraint (SHELX keyword RIGU) was applied ${ }^{5}$ globally.

Solvent Treatment Details. The solvent masking procedure as implemented in Olex2 was used to remove the electronic contribution of solvent molecules from the refinement. As the exact solvent content is not known, only the atoms used in the refinement model are reported in the formula here. Total solvent accessible volume $/$ cell $=42431.8 \AA^{3}[47.2 \%]$ Total electron count $/$ cell $=11108.4$ 

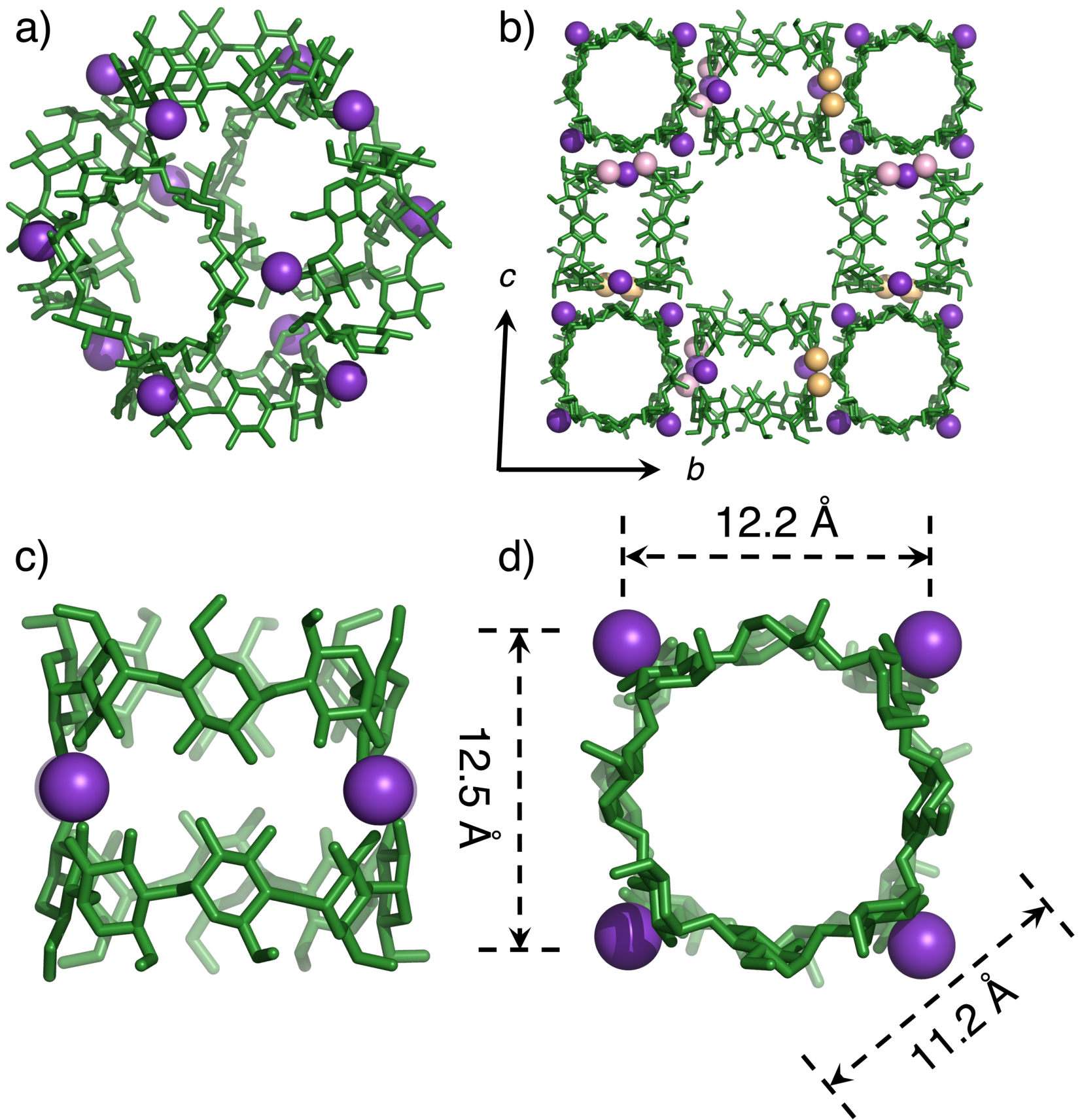

Figure S32. (a) Tubular representation of the solid-state superstructure of the cubic $(\gamma-C D)_{6}$ units of 1-AC ${ }^{-} \subset \mathrm{CD}-\mathrm{MOF}-1$. The $\gamma-\mathrm{CD}$ tori are colored green and the $\mathrm{K}^{+}$ions as purple spheres. (b) Tubular representations of the slice through the solid-state superstructure of $1-\mathrm{AC}^{-} \subset \mathrm{CD}-\mathrm{MOF}-1$, showing a single layer of $(\gamma-\mathrm{CD})_{2}$ tunnels. The $\gamma$-CD tori are colored green and the $\mathrm{K}^{+}$ions as purple, lightpink and light-orange spheres. (c,d) Stick representation of the solid-state superstructure of the $(\gamma$ $\mathrm{CD})_{2}$ tunnels aligned parallel to the $a$-axis in $1-\mathrm{AC}^{-} \subset \mathrm{CD}-\mathrm{MOF}-1$ with distortion of the $\gamma-\mathrm{CD}$ tori illustrated by their unusual diagonal distances, highlighting the contribution of intermolecular forces. 


\section{1-Anthracenecarboxylic Acid (1-AC, CCDC 2073806)}

Single crystals, suitable for X-ray crystallography, were obtained by slow evaporation of a solution of 1-AC in EtOAc at RT. The crystal was mounted on a MITIGEN holder on a XtaLAB Synergy R, DW system, HyPix diffractometer. The crystal was kept at 100.00(10) K during data collection. Using Olex $2^{2}$, the structure was solved with the ShelXT ${ }^{3}$ structure solution program using Intrinsic Phasing and refined with the $\mathrm{XL}^{4}$ refinement package using Least Squares minimization. It is worth noting that an identical structure has been reported ${ }^{7}$ previously.

Crystal Data for $\mathrm{C}_{15} \mathrm{H}_{10} \mathrm{O}_{2}(M=222.23)$ : monoclinic, space group $P 21 / \mathrm{n}$ (no. 14), $a=8.44143(18)$, $b=6.12829(16), c=20.3930(5) \AA, \alpha=90, \beta=91.059(2), \gamma=90^{\circ}, V=1054.78(4) \AA^{3}, Z=4, T=$ $100.00(10) \mathrm{K}, \mu(\mathrm{CuK \alpha})=0.744 \mathrm{~mm}^{-1}$, Dcalc $=1.399 \mathrm{~g} / \mathrm{mm}^{3}, 6454$ reflections measured $(8.674 \leq 2 \Theta$ $\leq 156.634), 2180$ unique $\left(R_{\text {int }}=0.0254, R_{\text {sigma }}=0.0292\right)$ which were used in all calculations. The final $R_{1}$ was $0.0367(I>2 \sigma(I))$ and $w R_{2}$ was 0.1066 (all data).

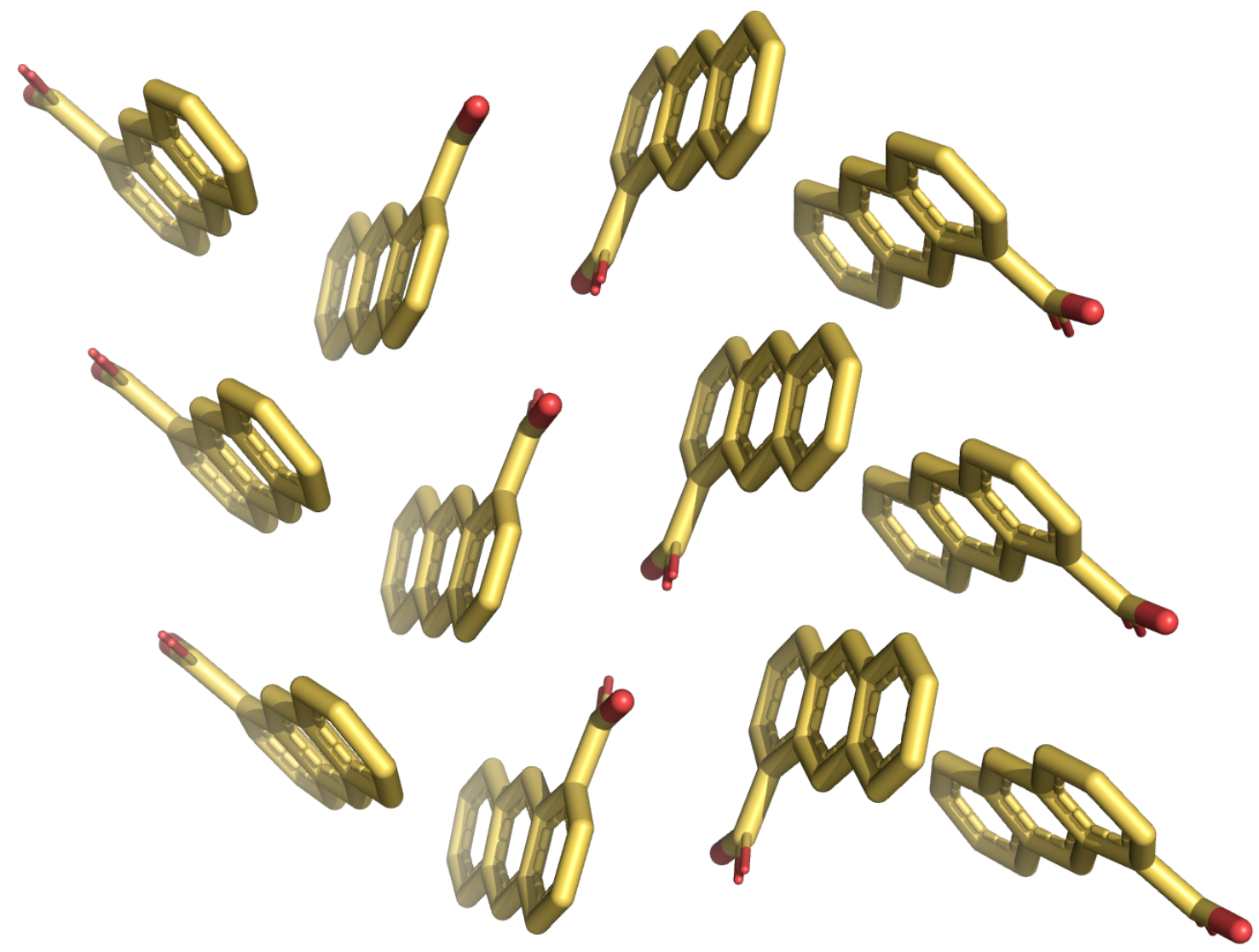

Figure S33. Stick representation of the solid-state superstructure of 1-AC. Hydrogen atoms were omitted for the sake of clarity. 
Powder X-ray Diffraction

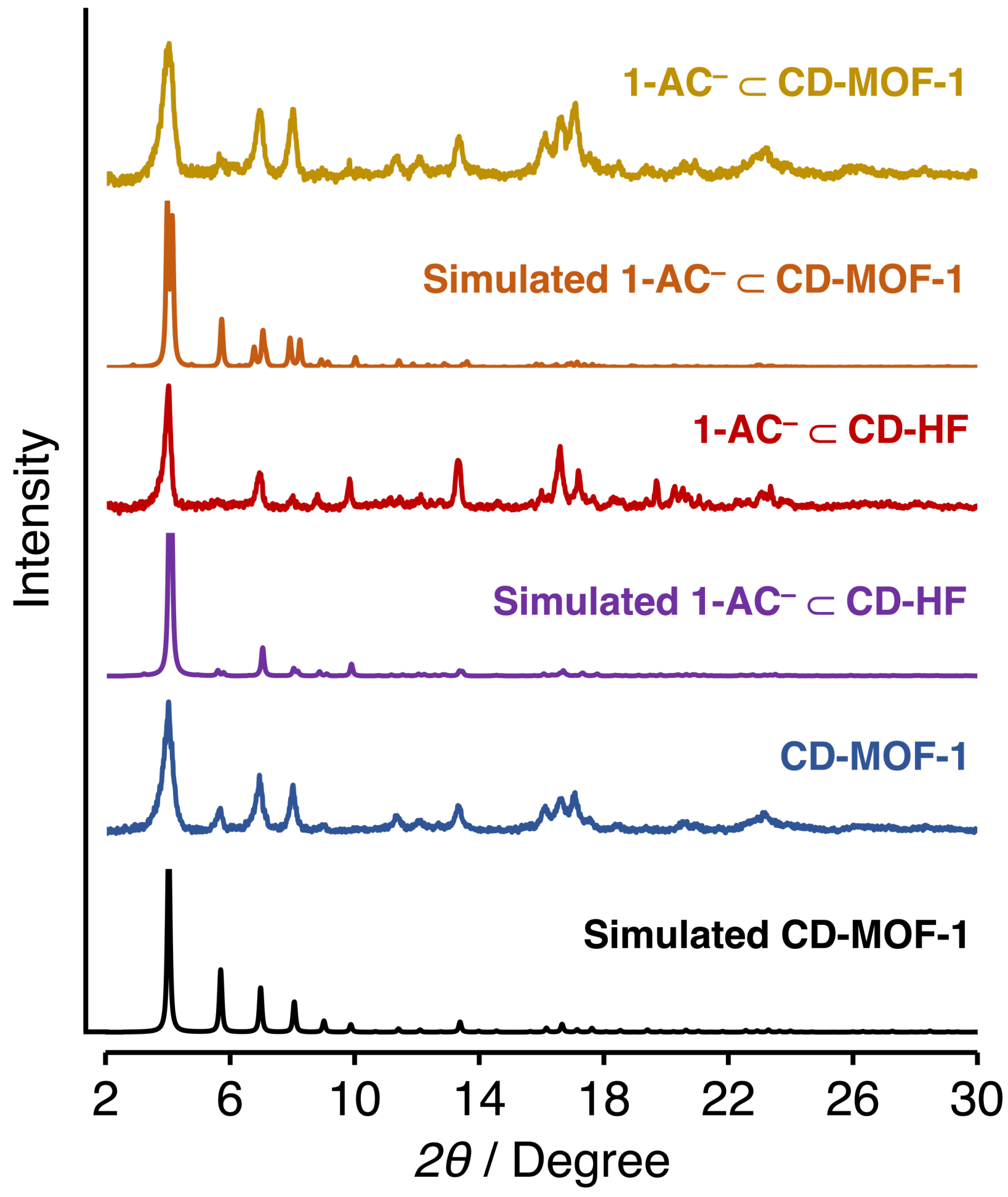

Figure S34. Powder X-ray diffraction of 1-AC ${ }^{-} \subset \mathrm{CD}-\mathrm{MOF}-1,1-\mathrm{AC}^{-} \subset \mathrm{CD}-\mathrm{HF}$ and CD-MOF-1 compared with the predicted diffraction patterns of $1-\mathrm{AC}^{-} \subset \mathrm{CD}-\mathrm{MOF}-1(R 32), 1-\mathrm{AC}^{-} \subset \mathrm{CD}-\mathrm{HF}$ $\left(P 4{ }_{1} 2{ }_{2}\right)$ and CD-MOF-1 (I432). 


\section{DFT and GFN2-xTB Calculations}

\section{DFT Calculations on the Relative Energies of Products}

We performed DFT calculations in Gaussian16 (Rev. A03) ${ }^{8}$ with the M06-2X functional ${ }^{9}$ and the 6$31+\mathrm{G}(\mathrm{d}, \mathrm{p})$ basis set to calculate the relative Gibbs free energies of the four products. The DFT-D3 dispersion correction ${ }^{10}$ with zero damping ${ }^{11}$ was also applied. For each product, geometry optimization was performed followed by vibrational analysis at the optimized geometry to confirm its nature as a stationary point (no imaginary frequencies). Optimized structures and relative energies of the four products are shown in Figure S35. Consistent with experimental findings (Table 1), the DFT calculations predicted that the anti-HT / 1 regioisomer has the lowest energy. The Cartesian coordinates and absolute energies were also provided in a separate supplementary ZIP file.

\section{Monte Carlo Sampling of Product Molecules in CD-MOF}

As a first attempt to explain the observed selectivity, we tried to see how each product interacts with the $\gamma$-CD tori by configurational sampling. For each product, we performed Monte Carlo insertion in the RASPA package ${ }^{12}$ of one product molecule (at the DFT-optimized geometry) into the experimentally resolved CD-MOF unit cell. Both product molecule and CD-MOF were treated as rigid during the simulation and the non-bonded interactions were described using a Lennard-Jones potential with UFF ${ }^{13}$ parameters. 5,000 Monte Carlo cycles were carried out for each product and the position of the product at every step was recorded. Using a geometrical criterion, we found that none of the product molecules entered the $\gamma$-CD tori cavity in any of the steps. We also tried to insert two 1-AC $\mathbf{C}^{-}$molecules into the unit cell, but in 5,000 cycles we did not observe those two molecules occupying the same $\gamma$-CD tori tunnels at the same time. These results suggested that the $\gamma$-CD tori have significant structural flexibility which is essential for the photodimerization. 


\section{GFN2-xTB Modeling of 1-AC ${ }^{-}$Pair in the Cavity}

In order to gain a better understanding of the observed regioselectivity, we modeled the host-guest complex of a 1-AC $\mathbf{C A}^{-}$pair (with four different alignments that correspond to the four products) in the tunnels of the $\gamma$-CD dimers. The starting structure was carved out from the experimental crystal structure that contains a 1-AC $\mathbf{C}^{-}$pair, cleaned up and properly capped. The structure contains 392 atoms which makes $a b$ initio DFT calculations time-consuming, so we chose the GFN2-xTB ${ }^{14}$ semiempirical Hamiltonian in the $\mathrm{xtb}^{15}$ program (6.3.0 preview version) developed by the Grimme group. We performed geometry optimizations for the complex with all four relative orientations of the 1$\mathbf{A C}^{-}$pair. For each alignment, we tested three different setups: (1) no constraints at all, let all the atoms move freely; (2) a weak harmonic constraint (force constant is $0.01 \mathrm{Hartree} / \mathrm{Bohr}^{2}$, or 93.8 $\mathrm{kJ} / \mathrm{mol} / \AA^{2}$ ) on the $\gamma$-CD tori and the $\mathrm{K}^{+}$cations with respect to their crystallographic positions; (3) a strong harmonic constraint (force constant is $1.0 \mathrm{Hartree} / \mathrm{Bohr}^{2}$, or $9382.1 \mathrm{~kJ} / \mathrm{mol} / \AA^{2}$ ) on the $\gamma$-CD tori and the $\mathrm{K}^{+}$cations with respect to their crystallographic positions. By examination of the optimized structures, we found that (2) is the best choice because (1) led to largely distorted structures

due to the lack of constraints and crystallographic confinements while (3) effectively froze the tunnels and suppressed the inherent structural flexibility in the system. The slight conformational change of $\gamma-\mathrm{CD}$ in the optimized structures from (2) was consistent with experimental observations. Using (2), we compared the four optimized structures and found that the relative orientation that leads to the anti-HH / 2 regioisomer has the lowest energy, which agrees with the experimental results. Optimized structures and relative energies are shown in Figures S36. The Cartesian coordinates and absolute energies were also provided in a separate supplementary ZIP file. 
a)

b)

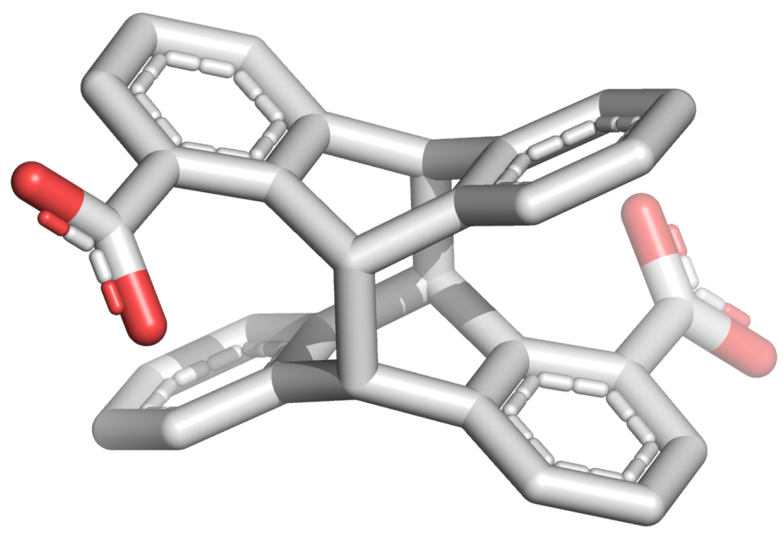

1 (anti-HT) $0 \mathrm{kcal} / \mathrm{mol}$

C)

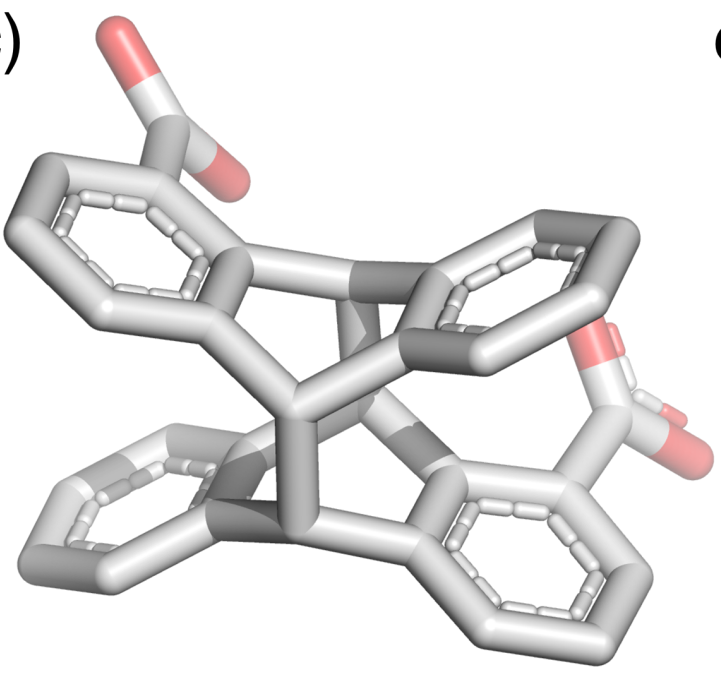

3 (syn-HT) $10.12 \mathrm{kcal} / \mathrm{mol}$ d)
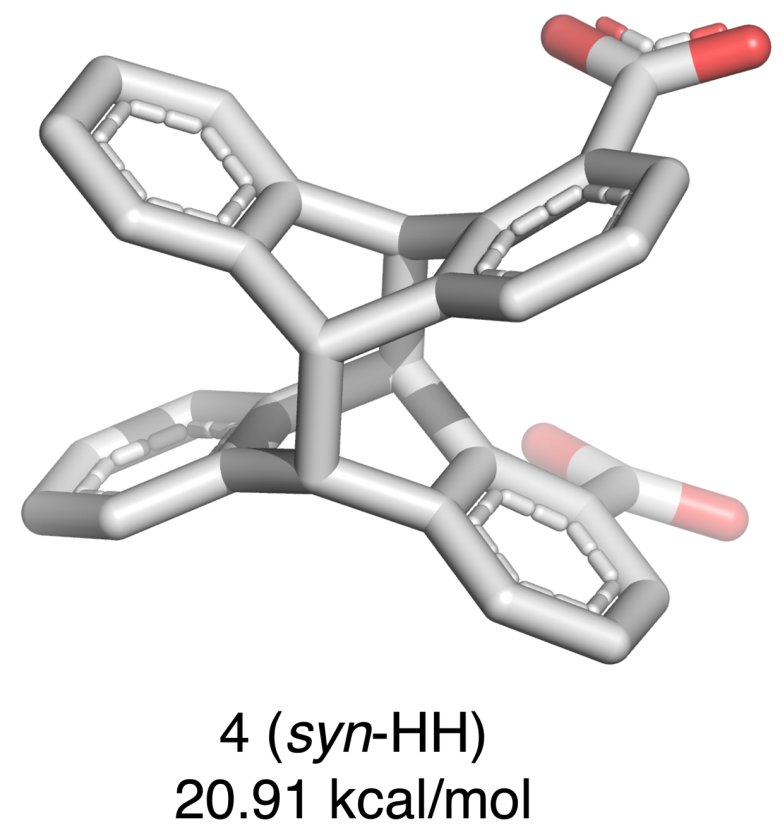

Figure S35. Stick representation of the four regioisomeric products, namely, anti-HT / 1, anti-HH / 2, syn-HT / 3 and syn-HH / 4, predicted by DFT calculations, revealing their relative Gibbs free energies. 
a)

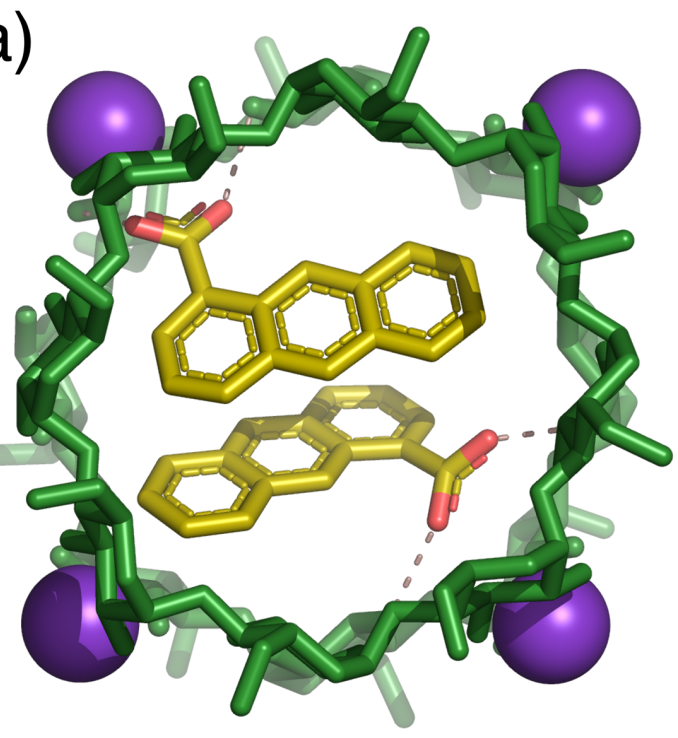

A1 (anti-HT)

$3.97 \mathrm{kcal} / \mathrm{mol}$

c)

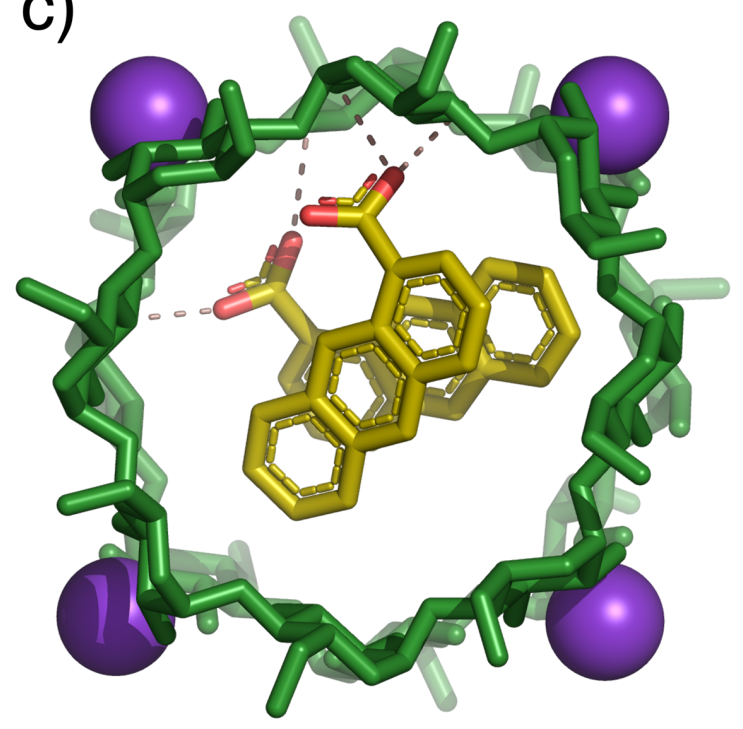

A3 (syn-HT)

$14.46 \mathrm{kcal} / \mathrm{mol}$ b)

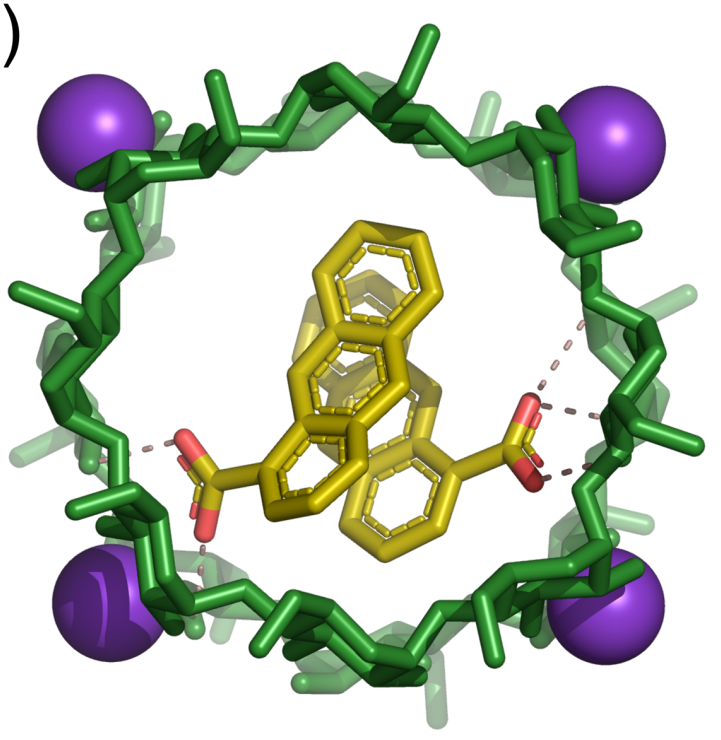

A2 (anti-HH)

$0 \mathrm{kcal} / \mathrm{mol}$

d)

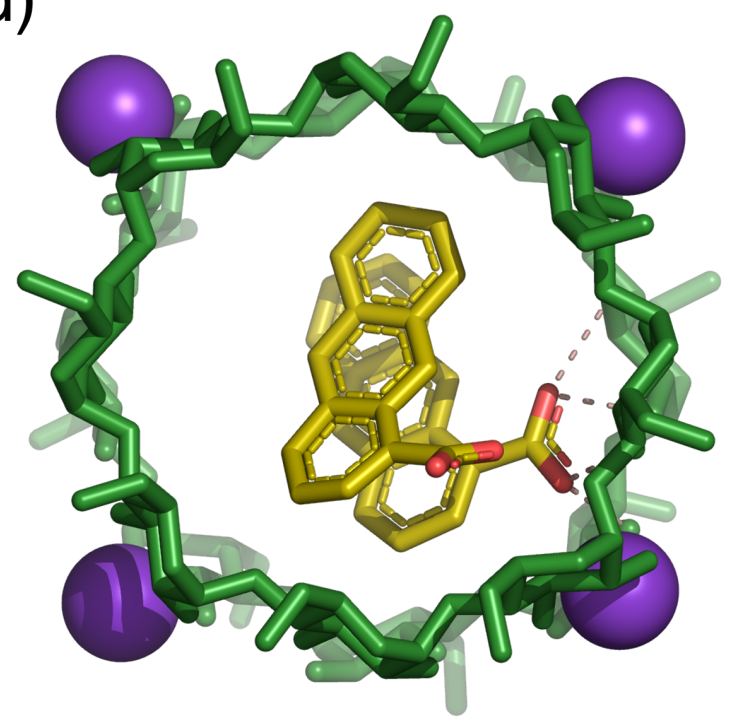

Figure S36. Stick representation of the four possible orientational alignments of the 1-AC $\mathrm{AC}^{-}$pair, namely, A1 (anti-HT), A2 (anti-HH), A3 (syn-HT) and A4 (syn-HH), in the cavity of the $(\gamma-\mathrm{CD})_{2}$ tunnel predicted by GFN2-xTB calculations, revealing their relative energies. 


\section{References}

1. Smaldone, R. A.; Forgan, R. S.; Furukawa, H.; Gassensmith, J. J.; Slawin, A. M. Z.; Yaghi, O. M.; Stoddart, J. F., Metal-Organic Frameworks from Edible Natural Products. Angew. Chem. Int. Ed. 2010, 49, 8630-8634.

2. Dolomanov, O. V.; Bourhis, L. J.; Gildea, R. J.; Howard, J. A. K.; Puschmann, H., OLEX2: A Complete Structure Solution, Refinement and Analysis Program. J. Appl. Crystallogr. 2009, 42, 339341.

3. Sheldrick, G., SHELXT - Integrated Space-Group and Crystal-Structure Determination. Acta Crystallogr. Sect. A 2015, 71, 3-8.

4. Sheldrick, G., Crystal Structure Refinement with SHELXL. Acta Crystallogr. Sect. C 2015, 71, 3-8.

5. Thorn, A.; Dittrich, B.; Sheldrick, G. M., Enhanced Rigid-Bond Restraints. Acta Crystallogr. Sect. A 2012, 68, 448-451.

6. Sheldrick, G., A Short History of SHELX. Acta Crystallogr. Sect. A 2008, 64, 112-122.

7. Fitzgerald, L. J.; Gerkin, R. E., Anthracene-1-carboxylic Acid. Acta Crystallogr. Sect. C 1997, 53, 1080-1082.

8. Frisch, M. J.; Trucks, G. W.; Schlegel, H. B.; Scuseria, G. E.; Robb, M. A.; Cheeseman, J. R.; Scalmani, G.; Barone, V.; Petersson, G. A.; Nakatsuji, H.; Li, X.; Caricato, M.; Marenich, A. V.; Bloino, J.; Janesko, B. G.; Gomperts, R.; Mennucci, B.; Hratchian, H. P.; Ortiz, J. V.; Izmaylov, A. F.; Sonnenberg, J. L.; Williams; Ding, F.; Lipparini, F.; Egidi, F.; Goings, J.; Peng, B.; Petrone, A.; Henderson, T.; Ranasinghe, D.; Zakrzewski, V. G.; Gao, J.; Rega, N.; Zheng, G.; Liang, W.; Hada, M.; Ehara, M.; Toyota, K.; Fukuda, R.; Hasegawa, J.; Ishida, M.; Nakajima, T.; Honda, Y.; Kitao, O.; Nakai, H.; Vreven, T.; Throssell, K.; Montgomery Jr., J. A.; Peralta, J. E.; Ogliaro, F.; Bearpark, M. J.; Heyd, J. J.; Brothers, E. N.; Kudin, K. N.; Staroverov, V. N.; Keith, T. A.; Kobayashi, R.; Normand, J.; Raghavachari, K.; Rendell, A. P.; Burant, J. C.; Iyengar, S. S.; Tomasi, J.; Cossi, M.; 
Millam, J. M.; Klene, M.; Adamo, C.; Cammi, R.; Ochterski, J. W.; Martin, R. L.; Morokuma, K.; Farkas, O.; Foresman, J. B.; Fox, D. J. Gaussian 16 Rev. A.03, Wallingford, CT, 2016.

9. Zhao, Y.; Truhlar, D. G., The M06 Suite of Density Functionals for Main Group Thermochemistry, Thermochemical Kinetics, Noncovalent Interactions, Excited States, and Transition Elements: Two New Functionals and Systematic Testing of Four M06-Class Functionals and 12 Other Functionals. Theor. Chem. Acc. 2008, 120, 215-241.

10. Grimme, S.; Antony, J.; Ehrlich, S.; Krieg, H., A Consistent and Accurate ab initio Parametrization of Density Functional Dispersion Correction (DFT-D) for the 94 Elements H-Pu. $J$. Chem. Phys. 2010, 132, 154104.

11. Grimme, S.; Ehrlich, S.; Goerigk, L., Effect of the Damping Function in Dispersion Corrected Density Functional Theory. J. Comput. Chem. 2011, 32, 1456-1465.

12. Dubbeldam, D.; Calero, S.; Ellis, D. E.; Snurr, R. Q., RASPA: Molecular Simulation Software for Adsorption and Diffusion in Flexible Nanoporous Materials. Mol. Simul. 2016, 42, 81-101.

13. Rappé, A. K.; Casewit, C. J.; Colwell, K. S.; Goddard III, W. A.; Skiff, W. M., UFF, a Full Periodic Table Force Field for Molecular Mechanics and Molecular Dynamics Simulations. J. Am. Chem. Soc. 1992, 114, 10024-10035.

14. Bannwarth, C.; Ehlert, S.; Grimme, S., GFN2-xTB-An Accurate and Broadly Parametrized SelfConsistent Tight-Binding Quantum Chemical Method with Multipole Electrostatics and DensityDependent Dispersion Contributions. J. Chem. Theory Comput. 2019, 15, 1652-1671.

15. Grimme, S.; Bannwarth, C.; Shushkov, P., A Robust and Accurate Tight-Binding Quantum Chemical Method for Structures, Vibrational Frequencies, and Noncovalent Interactions of Large Molecular Systems Parametrized for All spd-Block Elements $(\mathrm{Z}=1-86)$. J. Chem. Theory Comput. 2017, 13, 1989-2009. 